\title{
The battle against obesity : a role for thermogenic and satiating food ingredients
}

Citation for published version (APA):

Diepvens, K. (2007). The battle against obesity : a role for thermogenic and satiating food ingredients. [Doctoral Thesis, Maastricht University]. Universitaire Pers Maastricht.

https://doi.org/10.26481/dis.20071102kd

Document status and date:

Published: 01/01/2007

DOI:

10.26481/dis.20071102kd

Document Version:

Publisher's PDF, also known as Version of record

\section{Please check the document version of this publication:}

- A submitted manuscript is the version of the article upon submission and before peer-review. There can be important differences between the submitted version and the official published version of record.

People interested in the research are advised to contact the author for the final version of the publication, or visit the DOI to the publisher's website.

- The final author version and the galley proof are versions of the publication after peer review.

- The final published version features the final layout of the paper including the volume, issue and page numbers.

Link to publication

\footnotetext{
General rights rights.

- You may freely distribute the URL identifying the publication in the public portal. please follow below link for the End User Agreement:

www.umlib.nl/taverne-license

Take down policy

If you believe that this document breaches copyright please contact us at:

repository@maastrichtuniversity.nl

providing details and we will investigate your claim.
}

Copyright and moral rights for the publications made accessible in the public portal are retained by the authors and/or other copyright owners and it is a condition of accessing publications that users recognise and abide by the legal requirements associated with these

- Users may download and print one copy of any publication from the public portal for the purpose of private study or research.

- You may not further distribute the material or use it for any profit-making activity or commercial gain

If the publication is distributed under the terms of Article $25 \mathrm{fa}$ of the Dutch Copyright Act, indicated by the "Taverne" license above, 


\section{THE BATTLE AGAINST OBESITY}

\section{A ROLE FOR THERMOGENIC AND SATIATING FOOD INGREDIENTS}



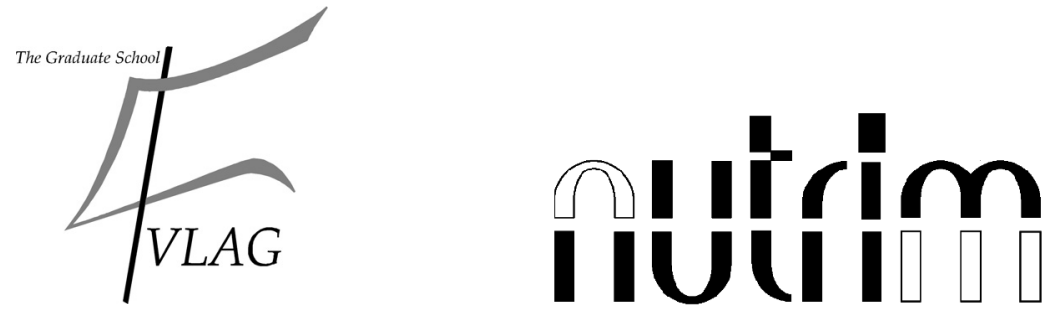

The studies presented in this thesis were performed at the Nutrition and Toxicology Research Institute Maastricht (NUTRIM), which participates in the Graduate School VLAG (Food Technology, Agrobiotechnology, Nutrition and Health Sciences) accredited by the Royal Netherlands Academy of Arts and Sciences.

Cover design: Bart Gielis

Cartoon: Jeroen Vanstiphout (www.kartoen.be)

Layout: Kristel Diepvens

Printed by: Datawyse, Universitaire Pers Maastricht

(C) Kristel Diepvens, 2007

ISBN 978-90-5278-647-6 


\title{
THE BATTLE AGAINST OBESITY
}

\section{A ROLE FOR THERMOGENIC AND SATIATING FOOD INGREDIENTS}

\author{
PROEFSCHRIFT \\ ter verkrijging van de graad van doctor \\ aan de Universiteit Maastricht, \\ op gezag van de Rector Magnificus, \\ Prof. mr. G.P.M.F. Mols \\ volgens het besluit van het College van Decanen, \\ in het openbaar te verdedigen \\ op vrijdag 2 november 2007 om 12:00 uur \\ door
}

Kristel Diepvens

geboren te Diest op 7 augustus 1981

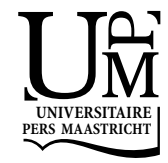




\section{Promotor}

Prof. dr. M.S. Westerterp-Plantenga

\section{Beoordelingscommissie}

Prof. dr. ir. R.P. Mensink (voorzitter)

Prof. dr. R-J.M. Brummer

Dr. C.C. Gerhardt (DSM Food Specialties, Delft)

Prof. dr. A.A. Masclee

Prof. dr. ir. G. Schaafsma (Wageningen Universiteit)

The research described in this thesis was supported by grants from Unilever Food and Health Research Institute, Campina Innovation and DSM Food Specialties.

Financial support by the Netherlands Heart Foundation and the Netherlands Association for the Study of Obesity (NASO) for the publication of this thesis is gratefully acknowledged.

Printing of this thesis was financially supported by DSM Food Specialties, Campina Innovation and Unilever Food and Health Research Institute. 


\section{CONTENTS}

$\begin{array}{lll}1 & \text { General introduction } & 7\end{array}$

2 Effect of green tea on resting energy expenditure and 21 substrate oxidation during weight loss in overweight females

3 Metabolic effects of green tea and of phases of weight loss

$4 \quad$ Obesity and thermogenesis related to the consumption of caffeine, ephedrine, capsaicin, and green tea

5 Long-term effects of consumption of a novel fat emulsion in relation to body-weight management

$6 \quad$ Short-term effects of a novel fat emulsion on appetite and food intake in different weight and age groups

$7 \quad$ Effects of different proteins and biopeptides on satiety and 'satiety' or 'orexigenic' hormones

8 General discussion

Summary

Samenvatting

Dankwoord

Publications

Curriculum Vitae 



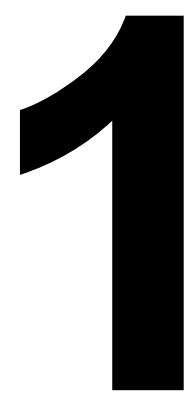

GENERAL INTRODUCTION 


\section{OBESITY}

Obesity is the accumulation of adipose tissue to excess and to an extent that impairs both physical and psychological health and well-being. It is possible to measure body fat directly. Nevertheless, because of the high cost of direct measurement, obesity is defined primarily in terms of weight in relation to height for measurements in populations and in clinical practice. The most widely used and reliable height-weight index in adults is body mass index (BMI), which is defined as weight in kilograms divided by meters squared $(1,2)$. The World Health Organization has made classifications of the BMI in order to define normal weight, overweight and obesity (table 1) (3). Exceptions to the BMl's reliability are in persons with extremes of age, very muscular builds (overestimates obesity) and extreme height (1).

Obesity has reached epidemic proportions globally, with more than 1 billion adults being overweight, of whom at least 300 million are obese (4). The prevalence of overweight and obesity is not only increasing in the US $(1,4-7)$, but also in Western Europe $(1,4,7)$. Co-morbidities of obesity are coronary heart disease, hypertension, type 2 diabetes and certain types of cancer $(6,8)$. In addition, obesity accounts for $2-6 \%$ of total health costs in several developed countries; some estimates put the figure as high as $7 \%(4,9,10)$.

The development of obesity is determined by both genetic and environmental factors $(6,8)$. The ultimate cause of obesity is an imbalance between energy intake (EI) and energy expenditure (EE). Stated simply, obesity is the end results of a long-term positive energy balance, an increased energy intake relative to expenditure.

Table 1 The WHO classification of body mass index (BMI) in adults (3)

\begin{tabular}{lll}
\hline BMI $\left(\mathrm{kg} / \mathrm{m}^{2}\right)$ & Classification & Associated health risks \\
\hline$<18.5$ & Underweight & Low (but risk of other clinical problems increased) \\
$18.5-24.9$ & Normal range & Average \\
$\geq 25.0$ & Overweight & \\
$25.0-29.9$ & Pre-obese & Increased \\
$30.0-34.9$ & Obese class I & Moderately increased \\
$35.0-39.9$ & Obese class II & Severely increased \\
$\geq 40.0$ & Obese class III & Very severely increased \\
\hline
\end{tabular}




\section{THE BATTLE AGAINST OBESITY}

Treatment of overweight and obesity is beneficial in that weight loss reduces the risk for morbidity and mortality. Even modest weight loss, such as $5-10 \%$ of the initial body weight, has beneficial health effects $(11,12)$. An ideal concept to achieve weight loss is to aim a reduced El along with an increased EE. This is, however, not an obtainable approach since a suppression of EE always occurs during energy restriction $(13,14)$. A more realistic concept to achieve successful weight loss and weight maintenance consists of a reduced $\mathrm{El}$ along with a sustained $E E(15,16)$. Also body composition and more particularly fatfree mass (FFM) may play a role in this concept as FFM is the main predictor of basal metabolic rate $(14,17,18)$. A FFM sparing effect has been shown before (19) and is associated to better weight maintenance (20). Another ideal concept for successful weight loss is a reduced $\mathrm{El}$ along with an increased satiety. This is, however, very hard to reach and rarely seen in studies (21). A more realistic approach is to aim a sustained satiety despite an El lower than the energy requirement. Thus two concepts may contribute to successful weight loss, that is, sustained EE related to sparing FFM and sustained satiety during a negative energy balance.

These approaches are being applied in short-term weight reduction. Diets that are severely restricted in carbohydrates (Atkins diet, $3-10 \%$ of total energy) and do not emphasize a reduction of El may be effective in reducing weight in the short term, but there is no evidence that they are sustainable or innocuous in the long term (22-24). In addition, low-carbohydrate diets are not recommended because their fat content is conductive to a high intake of saturated fat, which may be atherogenic $(24,25)$. In low-carbohydrate diets, protein can be consumed to satisfaction and therefore, these diets may be considered as highprotein diets. Protein is more satiating than either fat or carbohydrate. A highprotein diet $(15-30 \%$ of total energy) uses the increased satiating effect of protein with a modest reduction in carbohydrate. Fat is kept low at 30 energy\% (26). There is convincing evidence that a higher protein intake increases thermogenesis and satiety $(27,28)$. Furthermore, a high-protein diet may lead to reduced subsequent $\mathrm{El}$, increased weight loss and improved body composition $(27,28)$. Therefore, a high-protein diet meets the concepts, it may promote both a sustained EE by sparing FFM and a sustained satiety during a negative energy balance. However, it remains to be studied which types of protein or even biopeptides may sustain EE and satiety better than others (see also chapter 7). There is little evidence, however, that high-protein diets pose a risk to kidney function and care should be taken in patients with renal impairment $(26,27)$. Before considering a diet as high protein, the absolute and relative protein content needs to be discriminated, as protein intake is studied under various energy balances. An absolutely normal-protein diet thus becomes a relatively high-protein diet in negative energy balance as well as at weight 
maintenance. Therefore, "high protein negative energy balance diets" aim to keep the grams of proteins ingested at the same level as consumed at energy balance, despite lower El (28) and the kidneys are thus not exposed to a higher amount of protein during a so-called high-protein diet. Low-fat diets contain $<20 \%$ of total energy and have a lower energy density than high-fat diets, which may lead to a lower EI $(26,29)$. Several meta-analyses show that a reduction in dietary fat without restriction of El produces a modest but clinically meaningful $2.5 \mathrm{~kg}$ weight loss in overweight subjects (30). However, other research showed that subjects lowering the fat content of their diet showed a consequent change in fat mass only when El was reduced as well (31). This change in body composition leads to a FFM sparing effect which contributes to the prevention of the decrease in EE seen during weight loss, as stated in the concepts. Fat restriction in a weight-loss regimen appears to be beneficial, but the optimal percentage has yet to be determined (24). In addition, many cannot maintain them long term (26). Special types of fat, such as a fat emulsion formulated from palm oil and oat oil fractions, are hypothesized to have a so-called ileal brake effect (32-35). This ileal brake effect is the inhibition of upper gastrointestinal functions elicited by the presence of unabsorbed nutrients in the ileum (36). The ileal brake appears to be related to the release of one or more peptide hormones from the distal intestine $(37,38)$. Therefore, this novel fat emulsion has been studied with respect to weight maintenance and satiety (see also chapters 5 and 6). An alternative approach to weight loss is to use verylow-energy diets (for example Modifast, Slimfast). These diets (1680-3347 $\mathrm{kJ} /$ day) have enabled many individuals to lose substantial amounts of weight and to maintain these losses long term (39). Very-low-energy diets were already investigated in the 80's by Wechsler et al. and Ditschuneit et al. and they already demonstrated the FFM sparing effect $(40,41)$. They showed that the fat loss as percentage of total weight loss varied from $43 \%$ with $0 \mathrm{~g} /$ day protein, up to $79 \%$ with $50 \mathrm{~g} /$ day protein $(40,41)$. Furthermore, anti-obesity drug therapy can be used for persons who cannot achieve sufficient weight loss with, for example, very-low-energy diets. Most pharmacological treatments are only approved for short-term usage in obesity treatment, but the newer drugs, orlistat and sibutramine, may be used for long-term treatment (42-46). Orlistat is a lipase inhibitor that aids weight loss by reversibly binding to the active center of the enzyme lipase, preventing the digestion and absorption of some dietary fats (43). Sibutramine is a combined norepinephrine and serotonin inhibitor. Its putative effect on weight loss is attributed to appetite suppression and prevention of the decline in EE during weight loss (43), and thus meets the concepts. Sibrutamine and orlistat, however, only provides modest weight loss (often less than $5 \%)(44,47,48)$ and both treatments should be combined with dietary interventions to achieve the optimal results.

Thus weight reduction in the short term can be augmented considerably by use of very-low-energy diets or other approaches described above. With these 
approaches short-term weight loss is satisfactory in many overweight and obese subjects but within one year the majority has regained most of the weight lost $(20,49,50)$. Thus, the major challenge of obesity treatment is to achieve long-term weight loss and maintenance of weight loss after weight reduction. Long-term body weight loss and prevention of body weight (re)gain can be achieved by reducing $\mathrm{El}$ and/or increasing EE. In practice, this is very difficult to realize. Therefore, food ingredients have been identified that promote weight loss and weight maintenance by increasing satiety and increasing EE and thus pursue the concepts, sustained EE and sustained satiety during a negative energy balance. These concepts, that is, sustained satiety and/or sustained EE have been assessed using a selection of ingredients that are hypothesized to contribute to these conditions.

\section{THERMOGENESIS}

As stated in the concepts described above, a target for successful weight loss and weight maintenance is a sustained EE during negative energy balance. Thus the decline in EE which normally occurs during weight loss $(13,14)$, should be prevented.

\section{Components of energy expenditure}

As shown in figure 1, total daily EE (TEE) consists of four components: sleeping metabolic rate (SMR), the energy cost of arousal, diet-induced energy expenditure (DEE) and activity-induced energy expenditure (AEE). SMR and the energy cost of arousal together form the basal metabolic rate (BMR) (51). $B M R$, also referred to as resting energy expenditure (REE), is the main component of average daily metabolic rate. It is defined as the energy expended by the body to maintain and preserve the integrity of vital functions (52). The Harris and Benedict equation has been developed in large groups of subjects and can predict BMR (53). Furthermore, the most frequently used method to measure BMR is the ventilated hood. This indirect calorimetry system measures heat production by measuring oxygen consumption and carbon dioxide production. BMR is measured in the morning after an overnight fast, in a thermo-neutral environment, with subjects being awake who avoided exercise from the day before the test (52). The main determinant of BMR is FFM $(14,17$, 18). During weight loss or weight maintenance, a FFM sparing effect may occur (19). This FFM sparing effect leads to a more beneficial body composition and is associated with better weight maintenance (20).

In addition to BMR, there is an increase in EE in response to food intake. This increase in $E E$ after food consumption is often referred to as diet-induced $E E$ 


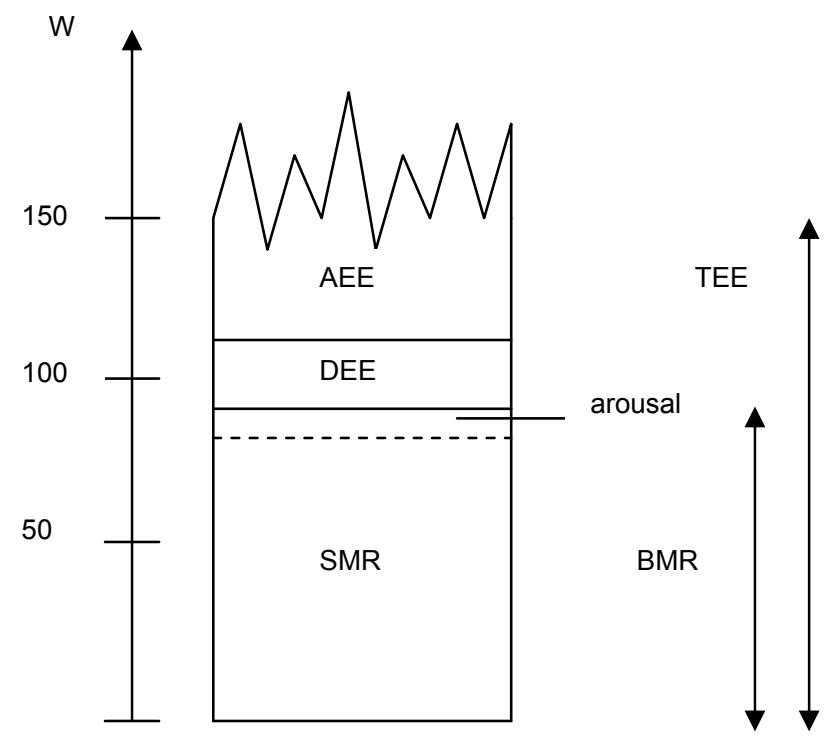

Figure 1 The components of total energy expenditure (TEE): sleeping metabolic rate (SMR), energy cost of arousal, basal metabolic rate (BMR), diet-induced energy expenditure (DEE) and activityinduced energy expenditure (AEE). Values are for an average adult male (70 kg, $15 \%$ body fat) in energy balance (51).

(DEE) and is the energy that is expended in order to digest, metabolize, and store ingested macronutrients (54). The energy cost associated with meal ingestion is primarily influenced by the composition of the food that is consumed (55) and is $10-15 \%$ of TEE in subjects consuming the average mixed diet and being in energy balance (54).

AEE is the most variable component of TEE and includes all forms of physical activity as well as exercise (54).

To increase TEE, it is not necessary to increase all of these components. If one component increases while the others remain stable, this could already have a positive effect on TEE and body weight.

\section{Thermogenesis and obesity}

Thermogenesis is defined as an increase in EE above basal. The sympathetic nervous system (SNS) has been considered as an essential component of the autonomic nervous system, playing an important role in the regulation of EE. An increase in sympathetic activity is reflected by an enhanced outflow of the catecholamines epinephrine from the adrenal medulla and norepinephrine from the peripheral nerve endings of the SNS (56). The effects of epinephrine and norepinephrine include both direct and indirect actions mediated via alpha- and beta-adrenoceptor mechanisms. 
Until now, there is no consensus as to whether obese have reduced SNS activity compared with lean persons. For instance, the viewpoint of Eikelis et al. is that earlier ideas that SNS activity is low in human obesity, contributing to weight gain through absence of sympathetically mediated thermogenesis should be discounted. Application of new techniques, such as sympathetic nerve recording and isotope dilution quantifying neurotransmitter release from sympathetic nerves have shown that peripheral sympathetic outflows to, for example, the kidneys and skeletal muscle vasculature are activated in obese humans (57). In addition, according to Eikelis and Esler et al., the demonstration that the suppressed sympathetic tone characterizing animal models of obesity, largely based on brown fat recordings (58), is not present in humans, weakens the case for the use of adrenergic agonists as thermogenic agents to facilitate weight loss. This is further discussed in chapter 4 .

Nevertheless, the use of thermogenic food ingredients may cause increases in EE in both lean and obese persons, may induce a slight negative energy balance and thereby influence body weight regulation over the long term. Furthermore, thermogenic ingredients added to weight loss products (see chapters 2, 3 and 4), may offset the suppression in BMR which occurs during energy restriction $(13,14)$. This decline in BMR after a period of dieting has been shown to be associated with unsuccessful weight maintenance (59).

\section{SATIETY}

The other concept for successful weight loss and weight maintenance is to aim a sustained satiety despite an El lower than the energy requirement. Satiety refers to the inhibition of hunger and further eating that arises as a consequence of food ingestion, and determines intermeal intervals and meal frequency by determining the next meal initiation. Satiation, on the other hand, refers to the processes that bring a period of eating to an end (60).

Appetite ratings in humans can be measured with the help of subject-specific ratings. Subjects are asked to rate their sensations of hunger, satiety, fullness, thirst, and desire to eat on $100 \mathrm{~mm}$ Visual Analogue Scales (VAS). When used appropriately, these subject-specific ratings have been shown to be a reliable and valid method to predict spontaneous El, free-living total El and body-weight loss (61-63). Furthermore, appetite can be measured by actual food intake. However, measurements of food intake in experimental circumstances suffer from a lack of external validity in relation to eating in the normal context of eating behavior (64). But, because the measurement of food intake in this context has the purpose of reflecting the internal drive to eat, that seems the appropriate way of measuring appetite. The question still remains how large differences in satiety need to be to cause differences in El. A factor that may intervene between appetite and actual food intake is dietary restraint. It was 
observed that restrained eaters consumed less energy, took fewer meals, and showed higher preferences for low-calorie foods than did the complementarily defined unrestrained group $(65,66)$. Therefore, measurement of $\mathrm{El}$ is only useful in unrestrained eaters, as determined by the Three Factor Eating Questionnaire (TFEQ) (67).

Despite the increase in obesity, energy balance is tightly regulated in an individual person. For most people, the amount and composition of food eaten varies considerably from meal to meal and from day to day. Yet over time, El is matched to EE. Thus food intake must also be highly regulated (68). This is shown in figure 2 .

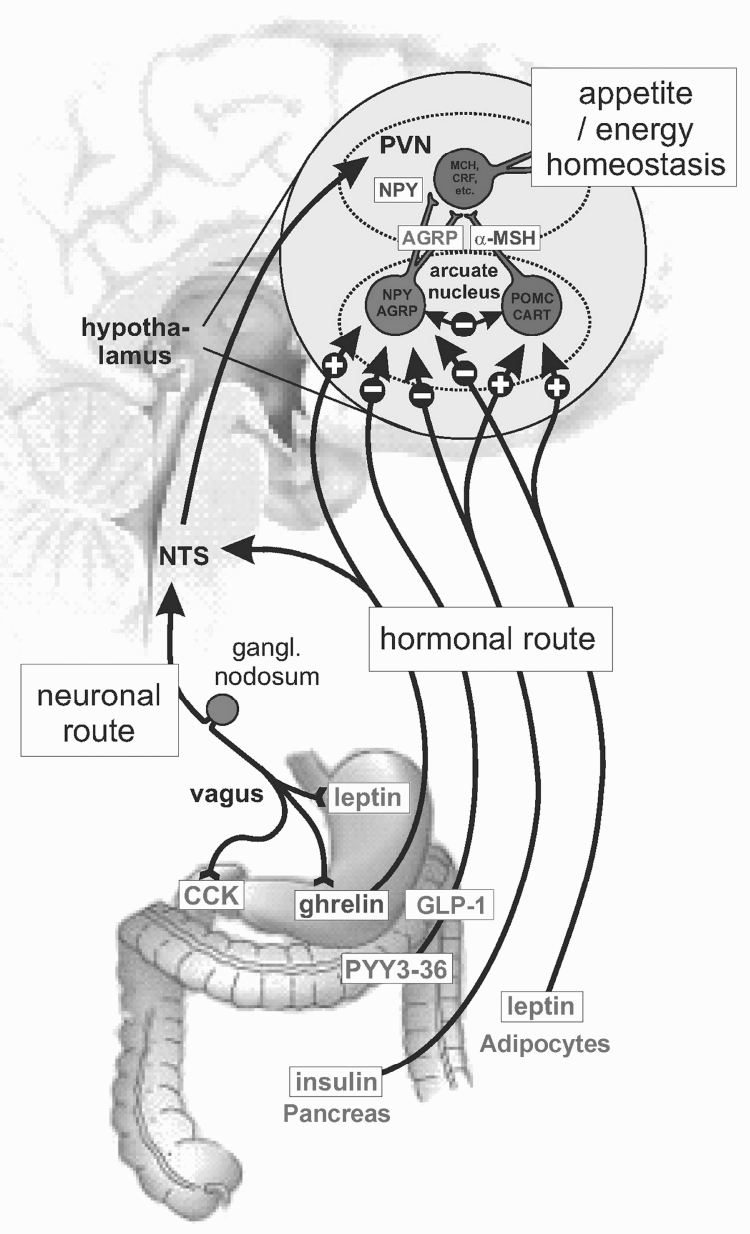

Figure 2 Hormonal and neuronal routes involved in regulation of appetite (adapted from (88)). 
One part of this system involves signals from body energy reserves. These include insulin and leptin. Insulin is produced in the beta cells of the pancreatic islets and is secreted in the blood in response to small increases in blood glucose concentrations (69). Leptin, the product of the ob gene, is suggested to be released into the blood in proportion to the amount of body fat. However, the actual stimulus is related more to the metabolic activity of the fat cell than to fat storage, such that dissociations can occur between stored fat and leptin release, particularly during a fast (70). Nonetheless, under normal conditions, plasma leptin levels are a reliable and rather stable indicator of body fat (70). Both insulin and leptin interact with the brain at the hypothalamic arcuate nucleus (71). Another component of the system is the control of feeding by the gastrointestinal tract. Powerful signals arise from the upper gastrointestinal tract during the course of meals. These signals include a variety of gut peptides (see also chapters 5 and 7$)(69,72,73)$. The initial sites of action of these peptides are peripheral, within the gastrointestinal tract. The peptide-induced satiety messages are then transmitted to the central nervous system by afferent neurons and received in visceral sensory fields of the dorsal hindbrain (72). The small intestine is a crucial source of satiety signals. In humans, infusion of nutrients (lipids, carbohydrates) into the small intestine is associated with suppression of El to a much greater extent than when the same nutrients are given intravenously (72, 74-77). The interaction of nutrients with specific receptors in the small intestine stimulates the release of so-called satiety hormones, such as cholecystokinin (CCK), glucagon-like peptide 1 (GLP-1) and peptide YY (PYY) (72, 78-83). CCK, GLP-1 and PYY are released into the circulation after meals. The net result of increased levels of any of these signals is the sensation of fullness, a contribution to the cessation of eating and thus a reduction in meal size (71). CCK, GLP-1 and PYY are all peptides that have been reported to reduce meal size when administered systematically (71). Another gastrointestinal hormone, ghrelin, is synthesized in the stomach, and is considered as a "hunger" hormone (84) and both the expression and circulating levels are up-regulated by fasting (85). High circulating leptin levels in thin individuals would favor increased $\mathrm{El}$ and positive energy balance (68). Weight loss in obese people results in an elevation in ghrelin levels (86), which may contribute to the difficulty seen in maintaining body weight after weight loss. Food fails to suppress ghrelin levels in obese humans (87), which again could impair postprandial satiety and contribute to overeating (68).

\section{OUTLINE OF THE THESIS}

There is evidence that modest weight loss, $5-10 \%$ of the initial body weight, is sufficient to induce marked clinical improvements $(11,12)$. Sjöström et al., however, showed a reversal effect. They demonstrated that, despite a 
maintained weight reduction of about $5 \%$, risk-factor values were back at baseline after 2 years (89). This finding accords with 2-year observations in the Swedish Obesity Subjects study, showing that during steady-weight conditions, previous weight reductions of about $10 \%$ are required for long-lasting risk factor improvements to be detected (90). Successful weight loss/maintenance and prevention of this reversal effect can be obtained by a sustained EE despite an El lower than the energy requirement. Ingredients have been identified that increase EE and that may counteract the decrease in metabolic rate which is seen during weight loss. One of these ingredients is green tea. The effect of ingestion of green tea along with a low-energy diet on basal metabolic rate and body weight was investigated in overweight females and is described in chapter 2. Chapter 3 presents the effects of green tea on health-related blood parameters. In addition, the relationships among changes in metabolic parameters and phases of weight loss are discussed. Chapter 4 reviews the thermogenic properties of caffeine, ephedrine, capsaicin and green tea in relation to the regulation of body weight, including the role of the sympathetic nervous system. Another concept for successful weight loss and weight maintenance is a sustained satiety despite an El lower than the energy requirement. Based on the results of Burns et al. who showed a significantly increased satiety and subsequently decreased El after yoghurt containing a fat emulsion mixture of fractionated palm oil and fractionated oat oil (32-34), a longterm study was executed to investigate the effects of this yoghurt on body weight, body composition, EE, hunger feelings and satiety hormones. This study is described in chapter 5 . In addition, in chapter 6, Burns' short-term satiety and food intake experiment was repeated in different weight and age groups. Furthermore, the effect of protein on satiety and El was investigated in chapter 7 , with special attention for selected biopeptides that enhance satiety by mimicking action of endogenous peptides which are involved in regulation of food intake. Finally, in chapter 8 , the results of the above described studies are summarized and discussed in a general discussion.

\section{REFERENCES}

1. James PT. Obesity: the worldwide epidemic. Clin Dermatol 2004;22:276-80.

2. Jeffery RW, Drewnowski A, Epstein LH, et al. Long-term maintenance of weight loss: current status. Health Psychol 2000;19:5-16.

3. WHO. Obesity: preventing and managing the global epidemic. Report of a WHO consultation. World Health Organ Tech Rep Ser 2000;894:i-xii, 1-253.

4. WHO. Global strategy on diet, physical activity and health. Resolution WHA 57.17. Geneva, WHO. 2004.

5. Ogden CL, Carroll MD, Curtin LR, McDowell MA, Tabak CJ, Flegal KM. Prevalence of overweight and obesity in the United States, 1999-2004. Jama 2006;295:1549-55.

6. Pi-Sunyer FX. The obesity epidemic: pathophysiology and consequences of obesity. Obes Res 2002;10 Suppl 2:97S-104S. 
7. Prentice AM. The emerging epidemic of obesity in developing countries. Int $\mathrm{J}$ Epidemiol 2006;35:93-9.

8. Stunkard AJ. Current views on obesity. Am J Med 1996;100:230-236.

9. Colditz GA. Economic costs of obesity and inactivity. Med Sci Sports Exerc 1999;31:S663-7.

10. Seidell JC. The impact of obesity on health status: some implications for health care costs. Int J Obes Relat Metab Disord 1995;19 Suppl 6:S13-6.

11. Goldstein DJ. Beneficial health effects of modest weight loss. Int J Obes Relat Metab Disord 1992;16:397-415.

12. Van Gaal LF, Wauters MA, De Leeuw IH. The beneficial effects of modest weight loss on cardiovascular risk factors. Int J Obes Relat Metab Disord 1997;21 Suppl 1:S5-9.

13. Astrup A, Gotzsche PC, van de Werken K, et al. Meta-analysis of resting metabolic rate in formerly obese subjects. Am J Clin Nutr 1999;69:1117-1122.

14. Ravussin E, Lillioja S, Knowler WC, et al. Reduced rate of energy expenditure as a risk factor for body-weight gain. N Engl J Med 1988;318:467-72.

15. Diepvens K, Kovacs EM, Nijs IM, Vogels N, Westerterp-Plantenga MS. Effect of green tea on resting energy expenditure and substrate oxidation during weight loss in overweight females. Br J Nutr 2005;94:1026-34.

16. Diepvens K, Soenen S, Steijns J, Arnold M, Westerterp-Plantenga M. Long-term effects of consumption of a novel fat emulsion in relation to body-weight management. Int $\mathrm{J}$ Obes (Lond) 2007;31:942-9.

17. Seidell JC, Muller DC, Sorkin JD, Andres R. Fasting respiratory exchange ratio and resting metabolic rate as predictors of weight gain: the Baltimore Longitudinal Study on Aging. Int J Obes Relat Metab Disord 1992;16:667-74.

18. Tataranni PA, Harper IT, Snitker S, et al. Body weight gain in free-living Pima Indians: effect of energy intake vs expenditure. Int J Obes Relat Metab Disord 2003;27:1578-83.

19. Dulloo AG, Jacquet J. The control of partitioning between protein and fat during human starvation: its internal determinants and biological significance. Br J Nutr 1999;82:339-56.

20. Vogels N, Westerterp-Plantenga MS. Categorical strategies based on subject characteristics of dietary restraint and physical activity, for weight maintenance. Int $\mathrm{J}$ Obes (Lond) 2005;29:849-57.

21. Weigle DS, Breen PA, Matthys CC, et al. A high-protein diet induces sustained reductions in appetite, ad libitum caloric intake, and body weight despite compensatory changes in diurnal plasma leptin and ghrelin concentrations. Am J Clin Nutr 2005;82:41-8.

22. Astrup A, Meinert Larsen T, Harper A. Atkins and other low-carbohydrate diets: hoax or an effective tool for weight loss? Lancet 2004;364:897-9.

23. Bray GA. Low-carbohydrate diets and realities of weight loss. Jama 2003;289:1853-5.

24. Strychar I. Diet in the management of weight loss. Cmaj 2006;174:56-63.

25. Anderson JW, Konz EC, Jenkins DJ. Health advantages and disadvantages of weightreducing diets: a computer analysis and critical review. J Am Coll Nutr 2000;19:578-90.

26. Clifton P. The science behind weight loss diets--a brief review. Aust Fam Physician 2006;35:580-2.

27. Halton TL, Hu FB. The effects of high protein diets on thermogenesis, satiety and weight loss: a critical review. J Am Coll Nutr 2004;23:373-85.

28. Westerterp-Plantenga MS, Luscombe-Marsh N, Lejeune MP, et al. Dietary protein, metabolism, and body-weight regulation: dose-response effects. Int $\mathrm{J}$ Obes (Lond) 2006;30 Suppl 3:S16-23.

29. Freedman MR, King J, Kennedy E. Popular diets: a scientific review. Obes Res 2001;9 Suppl 1:1S-40S.

30. Astrup A. The role of dietary fat in the prevention and treatment of obesity. Efficacy and safety of low-fat diets. Int J Obes Relat Metab Disord 2001;25 Suppl 1:S46-50. 
31. Westerterp KR, Verboeket-van de Venne WP, Westerterp-Plantenga MS, Velthuis-te Wierik EJ, de Graaf C, Weststrate JA. Dietary fat and body fat: an intervention study. Int J Obes Relat Metab Disord 1996;20:1022-6.

32. Burns AA, Livingstone MB, Welch RW, Dunne A, Reid CA, Rowland IR. The effects of yoghurt containing a novel fat emulsion on energy and macronutrient intakes in nonoverweight, overweight and obese subjects. Int $\mathrm{J}$ Obes Relat Metab Disord 2001;25:1487-96.

33. Burns AA, Livingstone MB, Welch RW, et al. Short-term effects of yoghurt containing a novel fat emulsion on energy and macronutrient intakes in non-obese subjects. Int J Obes Relat Metab Disord 2000;24:1419-25.

34. Burns AA, Livingstone MB, Welch RW, Dunne A, Rowland IR. Dose-response effects of a novel fat emulsion (Olibra) on energy and macronutrient intakes up to $36 \mathrm{~h}$ postconsumption. Eur J Clin Nutr 2002;56:368-77.

35. Logan CM, McCaffrey TA, Wallace JM, et al. Investigation of the medium-term effects of Olibratrade mark fat emulsion on food intake in non-obese subjects. Eur J Clin Nutr 2006;60:1081-91.

36. Spiller RC, Trotman IF, Higgins BE, et al. The ileal brake--inhibition of jejunal motility after ileal fat perfusion in man. Gut 1984;25:365-74.

37. Aponte GW, Fink AS, Meyer JH, Tatemoto K, Taylor IL. Regional distribution and release of peptide YY with fatty acids of different chain length. Am J Physiol 1985;249:G745-50.

38. Jin $\mathrm{H}$, Cai L, Lee $\mathrm{K}$, et al. A physiological role of peptide $Y Y$ on exocrine pancreatic secretion in rats. Gastroenterology 1993;105:208-15.

39. Anderson JW, Konz EC, Frederich RC, Wood CL. Long-term weight-loss maintenance: a meta-analysis of US studies. Am J Clin Nutr 2001;74:579-584.

40. Ditschuneit $\mathrm{H}$. Ergebnisse ambulante adipositastherapie mit verschiedenen protëinereichen diaeten. In: Ditschuneit $\mathrm{H}$, Wechsler JG, eds. Ergebnisse der adipositasfotschung.: perimed Fachbuch-Verlagsgesellschaft mbH: Erlangen, 1984:171178.

41. Wechsler JG, Wenzel H, Swobodnik W, Ditschuneit HH, Ditschuneit H. Nitrogen balance studies during modified fasting. Postgrad Med J 1984;60 Suppl 3:66-73.

42. James WP, Astrup A, Finer N, et al. Effect of sibutramine on weight maintenance after weight loss: a randomised trial. STORM Study Group. Sibutramine Trial of Obesity Reduction and Maintenance. Lancet 2000;356:2119-25.

43. Li Z, Maglione M, Tu W, et al. Meta-analysis: pharmacologic treatment of obesity. Ann Intern Med 2005;142:532-46.

44. Torgerson JS, Hauptman J, Boldrin MN, Sjostrom L. XENical in the prevention of diabetes in obese subjects (XENDOS) study: a randomized study of orlistat as an adjunct to lifestyle changes for the prevention of type 2 diabetes in obese patients. Diabetes Care 2004;27:155-61.

45. Wadden TA, Berkowitz RI, Womble LG, et al. Randomized trial of lifestyle modification and pharmacotherapy for obesity. N Engl J Med 2005;353:2111-20.

46. Wirth A, Krause J. Long-term weight loss with sibutramine: a randomized controlled trial. Jama 2001;286:1331-9.

47. Padwal R, Li SK, Lau DC. Long-term pharmacotherapy for overweight and obesity: a systematic review and meta-analysis of randomized controlled trials. Int J Obes Relat Metab Disord 2003;27:1437-46.

48. Padwal RS, Majumdar SR. Drug treatments for obesity: orlistat, sibutramine, and rimonabant. Lancet 2007;369:71-7.

49. Wing RR, Phelan S. Long-term weight loss maintenance. Am J Clin Nutr 2005;82:222S$225 S$.

50. Lejeune MP, Van Aggel-Leijssen DP, Van Baak MA, Westerterp-Plantenga MS. Effects of dietary restraint vs exercise during weight maintenance in obese men. Eur $\mathrm{J}$ Clin Nutr 2003;57:1338-44. 
51. Westerterp KR. Energy expenditure. In: Westerterp-Plantenga MS, Fredrix EWHM, Steffens AB, eds. Food intake and energy expenditure: CRC Press, 1994:235-257.

52. Adriaens MP, Schoffelen PF, Westerterp KR. Intra-individual variation of basal metabolic rate and the influence of daily habitual physical activity before testing. $\mathrm{Br} \mathrm{J}$ Nutr 2003;90:419-23.

53. Harris JA, Benedict FG. A biometric study of basal metabolism in man. Washington: Carnegia Institution 1919.

54. Westerterp KR, Elbers JMH. Gender differences, energy balance, and effects of sex steroid hormones on circulating leptin levels In: Westerterp-Plantenga MS, Steffens AB, Tremblay A, eds. Regulation of food intake and energy expenditure: EDRA, 1999:305324.

55. Westerterp KR, Wilson SA, Rolland V. Diet induced thermogenesis measured over 24h in a respiration chamber: effect of diet composition. Int $\mathrm{J}$ Obes Relat Metab Disord 1999;23:287-92.

56. Macdonald IA. Advances in our understanding of the role of the sympathetic nervous system in obesity. Int J Obes Relat Metab Disord 1995;19 Suppl 7:S2-S7.

57. Eikelis N, Esler M. The neurobiology of human obesity. Exp Physiol 2005;90:673-82.

58. Bray GA. Autonomic and endocrine factors in the regulation of energy balance. Fed Proc 1986;45:1404-10.

59. Pasman WJ, Saris WHM, Westerterp-Plantenga MS. Predictors of weight maintenance. Obes Res 1999;7:43-50.

60. Westerterp-Plantenga MS. Behavioural and metabolic targets for the prevention and control of obesity. In: Mela DJ, ed. Food, diet and obesity: CRC, 2005:467-492.

61. Drapeau V, King N, Hetherington M, Doucet E, Blundell J, Tremblay A. Appetite sensations and satiety quotient: Predictors of energy intake and weight loss. Appetite 2007;48:159-66.

62. Flint A, Raben A, Blundell JE, Astrup A. Reproducibility, power and validity of visual analogue scales in assessment of appetite sensations in single test meal studies. Int $\mathrm{J}$ Obes Relat Metab Disord 2000;24:38-48.

63. Stubbs RJ, Hughes DA, Johnstone AM, et al. The use of visual analogue scales to assess motivation to eat in human subjects: a review of their reliability and validity with an evaluation of new hand-held computerized systems for temporal tracking of appetite ratings. $\mathrm{Br} \mathrm{J}$ Nutr 2000;84:405-15.

64. Blundell JE, Gillett A. Control of food intake in the obese. Obes Res 2001;9 Suppl 4:263S-270S.

65. Laessle RG, Tuschl RJ, Kotthaus BC, Pirke KM. A comparison of the validity of three scales for the assessment of dietary restraint. J Abnorm Psychol 1989;98:504-7.

66. Tuschl RJ, Platte P, Laessle RG, Stichler W, Pirke KM. Energy expenditure and everyday eating behavior in healthy young women. Am J Clin Nutr 1990;52:81-6.

67. Stunkard AJ, Messick S. The three-factor eating questionnaire to measure dietary restraint, disinhibition and hunger. J Psychosom Res 1985;29:71-83.

68. Druce MR, Small CJ, Bloom SR. Minireview: Gut peptides regulating satiety. Endocrinology 2004;145:2660-5.

69. Schwartz MW, Woods SC, Porte D, Seeley RJ, Baskin DG. Central nervous system control of food intake. Nature 2000;404:661-671.

70. Benoit SC, Clegg DJ, Seeley RJ, Woods SC. Insulin and leptin as adiposity signals. Recent Prog Horm Res 2004;59:267-85.

71. Woods SC. Gastrointestinal satiety signals I. An overview of gastrointestinal signals that influence food intake. Am J Physiol Gastrointest Liver Physiol 2004;286:G7-13.

72. Beglinger C, Degen L. Gastrointestinal satiety signals in humans--physiologic roles for GLP-1 and PYY? Physiol Behav 2006;89:460-4. 
73. Woods SC, Schwartz MW, Baskin DG, Seeley RJ. Food intake and the regulation of body weight. Annu Rev Psychol 2000;51:255-77.

74. Smith GP, Gibbs J. Cholecystokinin: a putative satiety signal. Pharmacol Biochem Behav 1975;3:135-8.

75. Welch I, Saunders K, Read NW. Effect of ileal and intravenous infusions of fat emulsions on feeding and satiety in human volunteers. Gastroenterology 1985;89:1293-7.

76. Welch IM, Cunningham KM, Read NW. Regulation of gastric emptying by ileal nutrients in humans. Gastroenterology 1988;94:401-4.

77. Welch IM, Sepple CP, Read NW. Comparisons of the effects on satiety and eating behaviour of infusion of lipid into the different regions of the small intestine. Gut 1988;29:306-11.

78. Adam TC, Westerterp-Plantenga MS. Nutrient-stimulated GLP-1 release in normal-weight men and women. Horm Metab Res 2005;37:111-7.

79. Batterham RL, Cohen MA, Ellis SM, et al. Inhibition of food intake in obese subjects by peptide YY3-36. N Engl J Med 2003;349:941-8.

80. Batterham RL, Cowley MA, Small CJ, et al. Gut hormone PYY(3-36) physiologically inhibits food intake. Nature 2002;418:650-4.

81. Degen L, Oesch S, Casanova M, et al. Effect of peptide YY3-36 on food intake in humans. Gastroenterology 2005;129:1430-6.

82. Gutzwiller JP, Goke B, Drewe J, et al. Glucagon-like peptide-1: a potent regulator of food intake in humans. Gut 1999;44:81-6.

83. Muurahainen N, Kissileff HR, Derogatis AJ, Pi-Sunyer FX. Effects of cholecystokininoctapeptide (CCK-8) on food intake and gastric emptying in man. Physiol Behav 1988;44:645-9.

84. Kojima M, Hosoda H, Date Y, Nakazato M, Matsuo H, Kangawa K. Ghrelin is a growthhormone-releasing acylated peptide from stomach. Nature 1999;402:656-60.

85. Asakawa A, Inui A, Kaga $\mathrm{T}$, et al. Ghrelin is an appetite-stimulatory signal from stomach with structural resemblance to motilin. Gastroenterology 2001;120:337-45.

86. Hansen TK, Dall R, Hosoda $\mathrm{H}$, et al. Weight loss increases circulating levels of ghrelin in human obesity. Clin Endocrinol (Oxf) 2002;56:203-6.

87. English PJ, Ghatei MA, Malik IA, Bloom SR, Wilding JP. Food fails to suppress ghrelin levels in obese humans. J Clin Endocrinol Metab 2002;87:2984.

88. Holst B, Schwartz TW. Constitutive ghrelin receptor activity as a signaling set-point in appetite regulation. Trends Pharmacol Sci 2004;25:113-7.

89. Sjostrom L, Rissanen A, Andersen T, et al. Randomised placebo-controlled trial of orlistat for weight loss and prevention of weight regain in obese patients. European Multicentre Orlistat Study Group. Lancet 1998;352:167-72.

90. Sjostrom CD, Lissner L, Sjostrom L. Relationships between changes in body composition and changes in cardiovascular risk factors: the SOS Intervention Study. Swedish Obese Subjects. Obes Res 1997;5:519-30. 


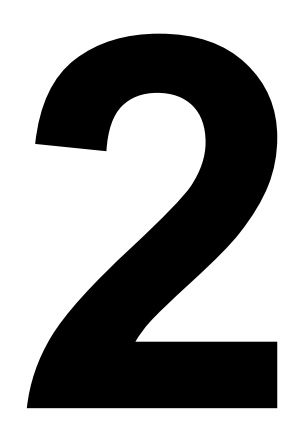

Effect of green tea on resting energy expenditure and substrate oxidation during weight loss in overweight females

Kristel Diepvens, Eva MR Kovacs, Ilse MT Nijs, Neeltje Vogels, Margriet S Westerterp-Plantenga

Br J Nutr 2005; 94: 1026-1034 


\begin{abstract}
We assessed the effect of ingestion of green tea (GT) extract along with a lowenergy diet (LED) on resting energy expenditure (REE), substrate oxidation and body weight as GT has been shown to increase energy expenditure and fat oxidation in the short term in both animals and people. Forty-six overweight women (BMI $27.6 \pm 1.8 \mathrm{~kg} / \mathrm{m}^{2}$ ) were fed in energy balance from day 1 to day 3 , followed by a LED with GT (1125 mg tea catechins + $225 \mathrm{mg}$ caffeine/d) or placebo (PLAC) from day 4 to day 87. Caffeine intake was standardized to 300 $\mathrm{mg} / \mathrm{d}$. Energy expenditure was measured on days 4 and 32 . Reductions in weight $(4.19 \pm 2.0 \mathrm{~kg}$ PLAC, $4.21 \pm 2.7 \mathrm{~kg} \mathrm{GT})$, BMI, waist:hip ratio, fat mass and fat-free mass were not statistically different between treatments. REE as a function of fat-free mass and fat mass was significantly reduced over $32 \mathrm{~d}$ in the PLAC group $(p<0.05)$, but not in the GT group. Dietary restraint increased over time $(p<0.001)$ in both groups, whereas disinhibition and general hunger decreased $(p<0.05)$. The GT group became more hungry over time and less thirsty, and showed increased prospective food consumption compared with PLAC $(p<0.05)$. Taken together, the ingestion of GT along with a LED had no additional benefit for any measures of body weight or body composition. Although the decrease in REE as a function of fat-free mass and fat mass was not significant with GT treatment, whereas it was with PLAC treatment, no significant effect of treatment over time was seen, suggesting that a robust limitation of REE reduction during a LED was not achieved by GT.
\end{abstract}

Keywords: green tea, weight loss, resting energy expenditure, substrate oxidation 


\section{INTRODUCTION}

Overweight and obesity represent a rapidly growing threat to the health of populations in an increasing number of countries (1). The ultimate cause of obesity is an imbalance between energy intake and energy expenditure (EE) (2). A negative energy balance is needed to produce weight loss and can be achieved by either decreasing intake or increasing expenditure. Classical weight loss programs, such as low-fat diets, behavioral modification and exercise, often fail to achieve long-term maintenance of weight loss (2-4). Because of these low success rates, stimulation of EE (or the prevention of its decline during dieting) by the use of natural herbal nutrients has attracted interest. One of these agents is green tea (GT), which is consumed primarily in China, Japan, and a few countries in North Africa and the Middle East $(5,6)$.

Tea is made from the leaves of Camellia sinensis L. species of the Theaceae family, GT being the non-oxidized, non-fermented product. As a consequence of this, it contains high quantities of several polyphenolic components such as epicatechin, epicatechin gallate, epigallocatechin and, the most abundant and probably the most pharmacologically active, epigallocatechin gallate (7).

GT extracts, containing caffeine and catechin-polyphenols, have been reported to have effects on body weight $(7,8)$ and $\operatorname{EE}(9,10)$. It has been reported that in vitro caffeine has thermogenic effects and can stimulate fat oxidation, in part via sympathetic activation of the central nervous system (11). In humans, caffeine has been shown to stimulate thermogenesis and fat oxidation (12-14). The fact that GT stimulates thermogenesis cannot be completely attributed to its caffeine content because the thermogenic effect of GT is greater than that of an equivalent amount of caffeine (9). Dulloo et al. found that catechin-polyphenols increased the respiration rate of brown adipose tissue in vitro, thus stimulating thermogenesis (10). The catechins in GT may stimulate thermogenesis and fat oxidation through inhibition of catechol O-methyl-transferase, an enzyme that degrades noradrenaline (15). Studies in man have shown that GT stimulates thermogenesis and fat oxidation in the short term (9). GT might thus act at different steps of the noradrenaline modulatory pathways and in this way exert a thermogenic and possibly an anti-obesity effect $(7,9,10)$.

There are few data about the effects of GT on thermogenesis and substrate oxidation (9), especially when supplemented for a longer period of time. There are also no data available on the effects of GT supplementation combined with a low-energy diet (LED). This is of interest as it is well established that energy restriction and weight loss may cause a sustained suppression of the resting energy expenditure (REE), which is a risk factor for weight regain (16-19). We hypothesized that GT ingestion during a LED might compensate for the reduction in REE and prevent weight regain and thus weight cycling (the yo-yo effect). Because of possible interactions between GT and habitual caffeine intake level, we investigated the effect of GT in the context of a controlled but 
realistic caffeine level (20). The aim of the present study was therefore to investigate whether GT ingestion, independent of habitual caffeine intake, increased REE and substrate oxidation, whether this effect was present after a 4-week administration of GT along with a LED (meal-replacement diet plan) and whether GT ingestion during the LED offset the expected reduction in REE. Furthermore we investigated the effect of a 12-week GT administration during the LED on body weight and fat loss. We hypothesized that GT might increase REE and fat oxidation compared with PLAC, and that this effect might be present after a 4-week ingestion of GT along with a LED (meal-replacement diet plan). We further hypothesized that GT might offset the reduction in REE that is expected to occur during the LED and that GT might stimulate the loss of body weight and fat.

\section{SUBJECTS AND METHODS}

\section{$\underline{\text { Subjects }}$}

Forty-six overweight women, aged between 19 and 57 years and with a BMI of between 25 and $31 \mathrm{~kg} / \mathrm{m}^{2}$, participated in this study. The subjects were recruited by advertisements in local newspapers. All volunteers $(n=57)$ participated in an initial screening that involved the measurement of body weight, height, waist:hip circumference ratio and blood pressure, the completion of questionnaires related to health, use of medication, smoking behavior, alcohol consumption and physical activity, and a food history questionnaire, specific for caffeine and catechin-containing products. All subjects $(n=46)$ were moderate caffeine-users (200-400 mg caffeine/d) (20-23), in good health, non-smokers, normotensive, not using medication and, at most, moderate alcohol users. The subjects were matched for age, BMI, weight, height, systolic and diastolic blood pressure, heart rate and caffeine intake in two groups. The two groups were randomly assigned to the two treatments: the GT treatment $(n=23)$ and the PLAC treatment $(n=23)$. The baseline characteristics of the subjects are presented in table 1.

The subjects gave their written informed consent and the Medical Ethical Committee of Maastricht University approved the study.

\section{Experimental design}

Before the start of the study, a pilot experiment was conducted in order to determine the dosage of GT. Four female overweight subjects (age $37.5 \pm 13.1$ years, BMI $25.8 \pm 1.6 \mathrm{~kg} / \mathrm{m}^{2}$ ) participated in this experiment, which consisted of three indirect calorimetry tests. The day before the test, the subjects' food and caffeine intake were standardized by the investigators. On the day of the test, 
REE and substrate oxidation were measured by means of an open-circuit, ventilated-hood system with subjects, in the fasted state, lying supine for 30 min. The subjects then received a dose of one of three treatments: PLAC; lowdosage GT (50 mg caffeine and $250 \mathrm{mg}$ catechins) or high-dosage GT (75 mg caffeine and $375 \mathrm{mg}$ catechins), together with a meal-replacement drink (Slim·Fast ${ }^{\circledR}$ ready-to-drink shake, French vanilla, $903 \mathrm{~kJ}$; Unilever Bestfoods Nederland BV, Rotterdam, The Netherlands). EE and substrate oxidation were measured for 180 min after ingestion of the treatment. We concluded that there was a significant increase in diet-induced thermogenesis with the combined intake of the meal-replacement drink and high-dosage GT capsules, compared with low-dosage GT. It was therefore proposed that further long-term research on the thermogenic effects of GT should focus on the high dosage of tea catechins and caffeine.

Table 1 Subject characteristics at baseline

\begin{tabular}{lcc}
\hline & PLAC $(\mathrm{n}=23)$ & GT $(\mathrm{n}=23)$ \\
\hline Age $(\mathrm{y})$ & $41.6 \pm 10.0$ & $41.7 \pm 8.6$ \\
Height $(\mathrm{m})$ & $1.66 \pm 0.05$ & $1.66 \pm 0.05$ \\
Weight $(\mathrm{kg})$ & $76.3 \pm 6.6$ & $76.4 \pm 6.3$ \\
BMI $\left(\mathrm{kg} / \mathrm{m}^{2}\right)$ & $27.7 \pm 1.8$ & $27.7 \pm 1.8$ \\
FFM $(\mathrm{kg})$ & $47.3 \pm 4.5$ & $47.2 \pm 3.2$ \\
Body fat $(\%)$ & $38.0 \pm 4.4$ & $38.1 \pm 4.1$ \\
Waist $(\mathrm{cm})$ & $84.0 \pm 6.0$ & $85.6 \pm 6.2$ \\
Hip $(\mathrm{cm})$ & $107.0 \pm 4.9$ & $105.6 \pm 3.8$ \\
W:H ratio & $0.79 \pm 0.06$ & $0.81 \pm 0.05$ \\
SBP $(\mathrm{mmHg})$ & $122.5 \pm 13.2$ & $127.4 \pm 11.8$ \\
DBP $(\mathrm{mmHg})$ & $78.6 \pm 8.9$ & $80.0 \pm 12.0$ \\
HR $($ beats/min) & $66.2 \pm 6.8$ & $65.3 \pm 7.7$ \\
Caffeine $(\mathrm{mg} / \mathrm{d})$ & $311.8 \pm 61.1$ & $300.2 \pm 54.5$ \\
\hline
\end{tabular}

PLAC (placebo), GT (green tea), age (years), height $(\mathrm{m})$, weight $(\mathrm{kg})$, BMI (Body Mass Index, $\mathrm{kg} / \mathrm{m}^{2}$ ), FFM (fat-free mass, $\mathrm{kg}$ ), body fat $(\%)$, waist circumference $(\mathrm{cm})$, hip circumference $(\mathrm{cm})$, $\mathrm{W}: \mathrm{H}$ ratio (waist:hip ratio), SBP (systolic blood pressure, $\mathrm{mmHg}$ ), DBP (diastolic blood pressure, $\mathrm{mmHg}$ ), HR (heart rate, beats $/ \mathrm{min}$ ), caffeine intake $(\mathrm{mg} / \mathrm{d})$

All data are mean \pm SD. Subjects are matched for the characteristics, no differences between groups were statistically significant $(p<0.05)$. 
A double-blind, placebo-controlled, parallel design was adopted. The experimental design consisted of an intervention period lasting $87 \mathrm{~d}$. During days 1-87, all subjects' background caffeine intake was standardized at 300 $\mathrm{mg} / \mathrm{d}$ (the equivalent of about three $150 \mathrm{ml}$ cups of coffee) in order to maintain their habitual caffeine intake (20-23). The subjects consumed a cup of coffee before breakfast $(08.00 \mathrm{~h})$, in the morning $(10.00 \mathrm{~h})$ and in the afternoon $(14.00$ h). The subjects were asked to abstain from other caffeine-rich products such as tea, cola-type soft drinks and energy drinks.

During days 1-3, subjects consumed a standardized energy-balance diet at $100 \%$ of EE estimated by means of the 'body weight' computer simulation program, which includes body weight, an average physical activity level of 1.6 and the estimated basal energy expenditure (24).

During days 4-87, subjects consumed a LED in order to lose weight. The diet was a meal-replacement diet plan (Slim.Fast, Unilever Bestfoods Nederland B.V.), which is in accordance with $60 \%$ of the predicted EE (average \% energy: protein 25 , fat 15 , carbohydrate 60 ). The subjects consumed a Slim.Fast meal replacement (ready-to-drink shake, soup, bar, pasta) at breakfast and lunch and received instructions about the type and the amount of food they could ingest at dinner and as snacks. In addition, the subjects ingested three capsules (hard gelatine, size no.1) of PLAC (Maltodextrin) or GT three times daily, at breakfast $(09.00 \mathrm{~h})$, lunch $(13.00 \mathrm{~h})$ and dinner $(18.00 \mathrm{~h})$. The composition and dose of the treatments is presented in table 2 .

Measurements took place in the fasted state on days 4, 32 and 87 . In addition, in the morning of days 4 and 32, an indirect calorimetry test was performed. Because a variation in EE may occur in premenopausal women across the menstrual cycle, both tests were performed with subjects in the same phase of their cycle.

\section{$\underline{\text { Open-circuit, ventilated-hood test }}$}

On days 4 and 32, REE, fat and carbohydrate oxidation were measured for 30 min and EE, fat and carbohydrate oxidation were measured for $180 \mathrm{~min}$ after ingestion of a breakfast (Slim.Fast ready-to-drink shake, French vanilla, $903 \mathrm{~kJ}$ ) and the treatment ( $3 \mathrm{GT}$ or PLAC capsules). The test was performed by means of an open-circuit, ventilated-hood system with subjects lying supine (25). Gas analysis was performed by a paramagnetic oxygen analyzer (omnical type 1155B, Crowborough Sussex, UK) and an infrared carbon dioxide analyzer (omnical type 1520/1507). EE was calculated using Weir's formula (26). The respiratory quotient (RQ) was calculated as $\mathrm{CO}_{2}$ produced $/ \mathrm{O}_{2}$ consumed. Relative diet-induced EE (DEE rel, \% of El) was determined using the formula: $\{180 \mathrm{~min} *[\mathrm{EE}(\mathrm{kJ} / \mathrm{min})-\mathrm{REE}(\mathrm{kJ} / \mathrm{min})] / 903 \mathrm{~kJ}\} * 100 \%$, where $903 \mathrm{~kJ}$ reflects the energy content of the shake. 
Table 2 Composition and dose of the treatments

\begin{tabular}{|c|c|c|c|}
\hline & Green tea* & & Placebo \\
\hline Caffeine & 26.3 & & \\
\hline Total catechins & 134.1 & & \\
\hline Catechin & 3.5 & & \\
\hline Epicatechin & 14.0 & & \\
\hline Epigallocatechin & 26.7 & & \\
\hline Epicatechin gallate & 23.6 & & \\
\hline Epigallocatechin gallate & 66.2 & & \\
\hline Maltodextrin & 74.9 & & 310.0 \\
\hline Microcrystalline cellulose & 71.7 & & \\
\hline Silicium dioxide & 1.5 & & \\
\hline Magnesium stearate & 1.5 & & \\
\hline Total (mg/capsule) & 310.0 & & 310.0 \\
\hline Treatment & Caffeine & Tea catechins & Maltodextrin \\
\hline PLAC (mg/capsule) & 0 & 0 & 310.0 \\
\hline PLAC (mg/dose of 3 capsules) & 0 & 0 & 930.0 \\
\hline PLAC (total mg/d) & 0 & 0 & 2790.0 \\
\hline GT (mg/capsule) & 26.3 & 134.1 & 74.9 \\
\hline GT (mg/dose of 3 capsules) & 78.9 & 402.3 & 224.7 \\
\hline GT (total mg/d) & 236.7 & 1206.9 & 674.1 \\
\hline
\end{tabular}

PLAC: placebo; GT: green tea.

* green tea: Sunphenon 100S (Taiyo Kagaku Co. Ltd., Mie, Japan) with added caffeine

\section{Measurements}

Anthropometric measurements were taken in the fasted state during screening and on days 4, 32 and 87 . Body weight was measured using a digital balance accurate to $0.02 \mathrm{~kg}$ (Chyo-MW-150K; Chyo, Japan) with subjects in underwear after voiding their bladder. Height was measured to the nearest $0.1 \mathrm{~cm}$ using a wall-mounted stadiometer (only during screening, model 220; Seca, Hamburg, Germany). BMI $\left(\mathrm{kg} / \mathrm{m}^{2}\right)$ was calculated as body weight $(\mathrm{kg})$ divided by height (m) squared. The ratio of waist:hip circumference is an estimate of the distribution of body fat. The waist:hip ratio was calculated by dividing the waist circumference by the hip circumference. The waist circumference was measured at the site of the smallest circumference between the rib cage and 
the ileac crest, and the hip circumference was measured at the site of the largest circumference between the waist and the thighs. Both measurements were performed with subjects in the standing position.

Body composition was measured on days 4,32 and 87 using the deuterium $\left({ }^{2} \mathrm{H}_{2} \mathrm{O}\right)$ dilution technique (27-29). The dilution of the deuterium isotope is a measure of total body water (27). In the evening, the subjects ingested a dose of deuterium-enriched water $\left({ }^{2} \mathrm{H}_{2} \mathrm{O}\right)$ after collecting a background urine sample. After ingestion of the deuterium solution, no further fluid or food consumption was permitted. The following morning, the second urine sample (second voiding) was collected. The deuterium concentration in the urine samples was measured using an isotope ratio mass spectrometer (Micromass Optima, Manchester, UK). Total body water was obtained by dividing the measured deuterium dilution space by 1.04 to correct for exchange of the ${ }^{2} \mathrm{H}$ label with non-aqueous hydrogen in body solids (29). Fat-free mass (FFM) was calculated by dividing the total body water by hydrating factor 0.73 . By subtracting FFM from body weight, fat mass (FM) was obtained. FM expressed as a percentage of body weight gives percentage of body fat.

To determine the possible adverse effects of the treatments, systolic and diastolic blood pressure and heart rate were recorded during screening and on day 87 in the fasted state, on days 4 and 32 in the fasted state and each hour after the treatment using an automatic blood pressure monitor (OSZ 5 easy; Spreidel \& Keller GmBH and Co. KG, Jungingen, Germany).

\section{$\underline{\text { Questionnaires }}$}

Attitude towards eating was analyzed on days 4,32 and 87 in the fasted state $(08.30 \mathrm{~h})$ using a validated Dutch translation of the Three Factor Eating Questionnaire (TFEQ) (30). Cognitive restrained and unrestrained eating behavior (factor 1), emotional eating and disinhibition (factor 2) and the subjective feeling of hunger (factor 3 ) were scored 0 or 1 and summed. Higher scores denote higher levels of restrained eating, disinhibited eating and predisposition to hunger, respectively. In addition, appetite ratings ( $\mathrm{mm}$; hunger, fullness, appetite, satiety, thirst, prospective food consumption, desire to eat) were scored on anchored $100 \mathrm{~mm}$ visual analogue scales (VAS) on days 4,32 and 87 in the fasted state $(08.30 \mathrm{~h})$ and on day 4 and $32180 \mathrm{~min}$ after ingestion of the capsules. Changes in mood and tolerance of the treatment were determined on day 87 in the fasted state $(08.30 \mathrm{~h})$, on days 4 and 32 in the fasted state and $180 \mathrm{~min}$ after the ingestion of the treatment. Mood (relaxed, gloomy, pleasant, angry, afraid, sad) was assessed with $100 \mathrm{~mm}$ VAS, and tolerance was determined using a questionnaire on the occurrence of complaints (headache, fatigue, nausea, stomach ache, constipation, diarrhea, etc.) and scored. Frequency classification was: 0, never; 1, seldom; 2, sometimes; 3 , relatively often; 4 , often (5-point scale). 


\section{Statistical analysis}

Data are presented as mean and standard deviations (SD). Data were analyzed using Statview SE + Graphics (Abacus Concepts, Berkeley, CA, 1988). Differences over time and between the treatments (PLAC or GT) over time were determined using one- and two-factor ANOVA with repeated measures. When appropriate, differences between groups were analyzed using factorial ANOVA. Univariate and multivariate linear regression was used to determine the relationship between selected variables. The level for establishing significant differences was taken as $p<0.05$.

\section{RESULTS}

Factorial ANOVA showed that none of the baseline (day 4) differences between the groups were statistically significant (table 3, 4, 5 and 6), indicating that the groups were well matched.

There was a significant reduction in body weight during the period of the LED $(\mathrm{p}<0.001)$. The PLAC group lost $2.45 \pm 1.4$ and $4.19 \pm 1.3 \mathrm{~kg}$, and the GT group $2.41 \pm 1.3$ and $4.21 \pm 2.7 \mathrm{~kg}$ on days 32 and 87 respectively (figure 1 ). This decrease in body weight was not statistically different between treatments.

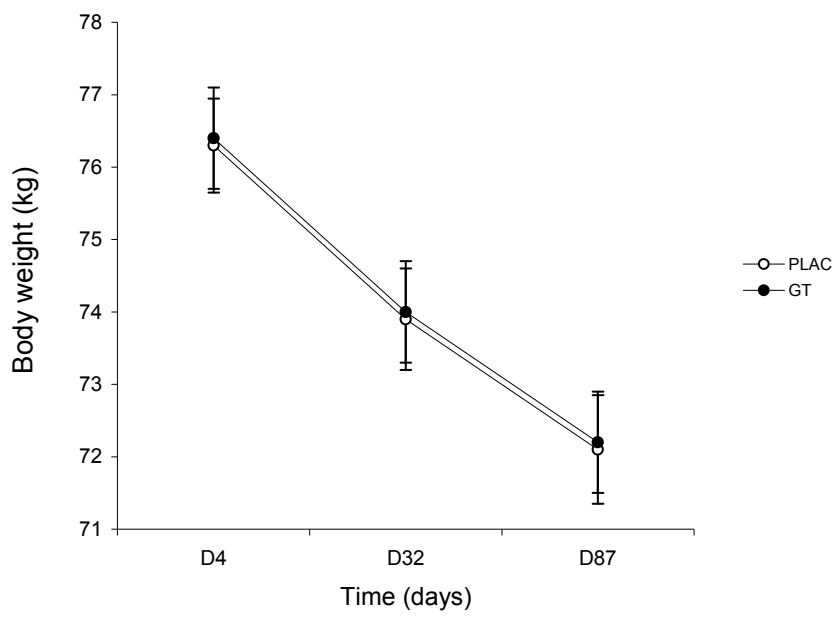

Figure 1 Change in body weight over time in the placebo and green tea groups. Values are means with their standard errors shown by vertical bars. No significant differences were seen between the two groups at any time. 


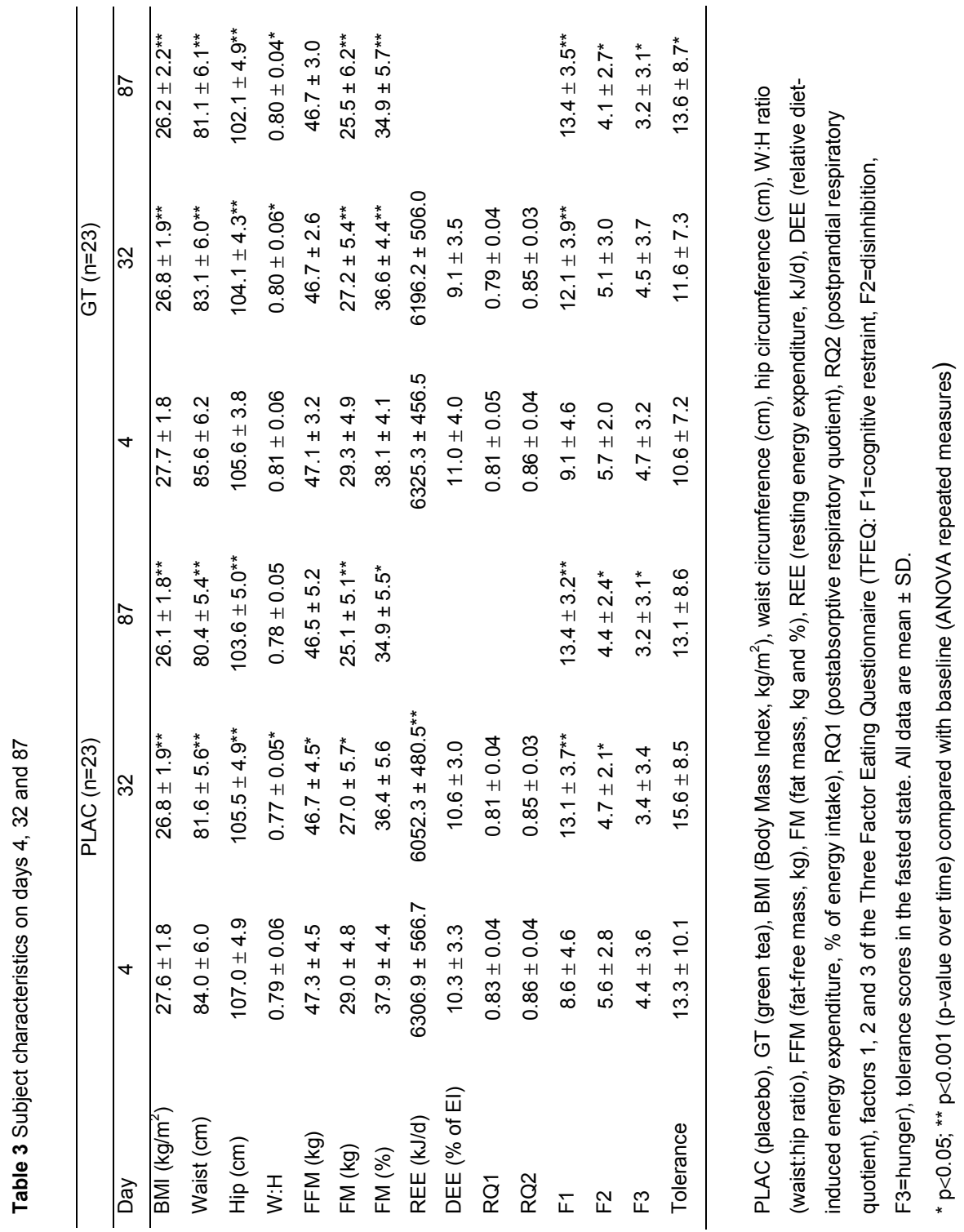




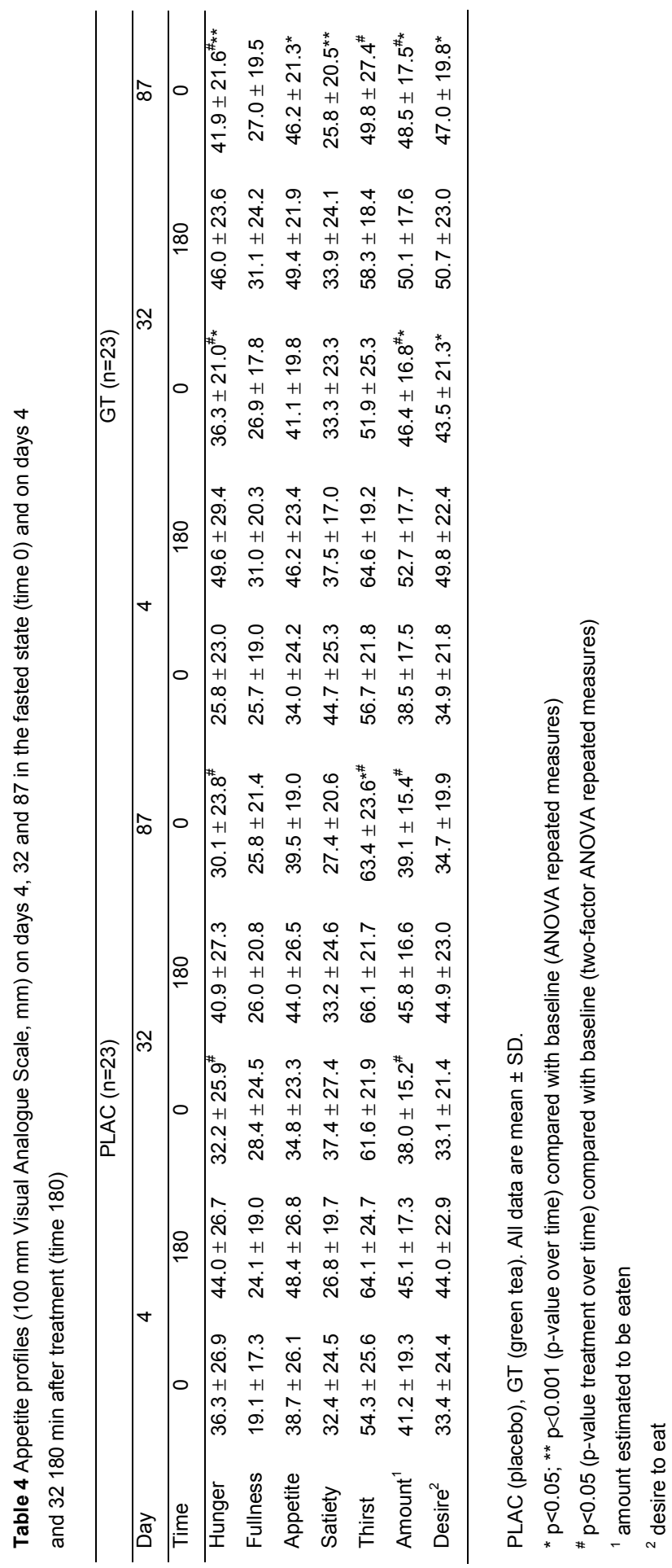




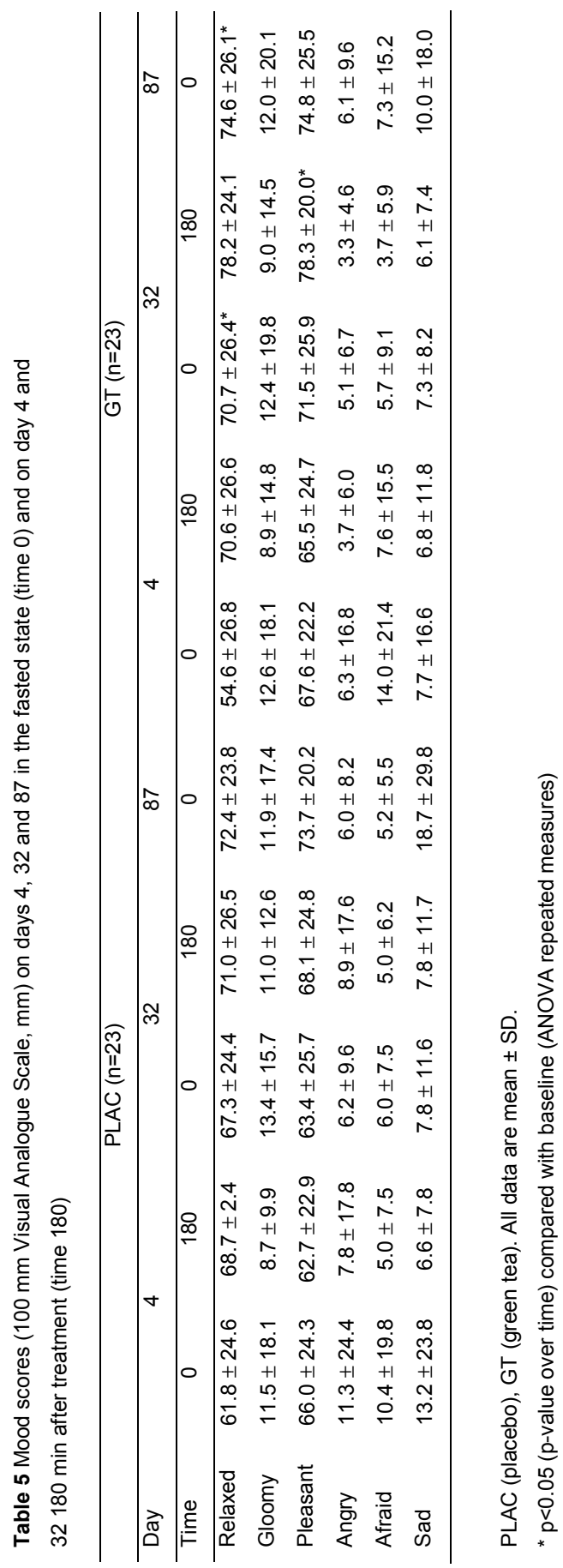




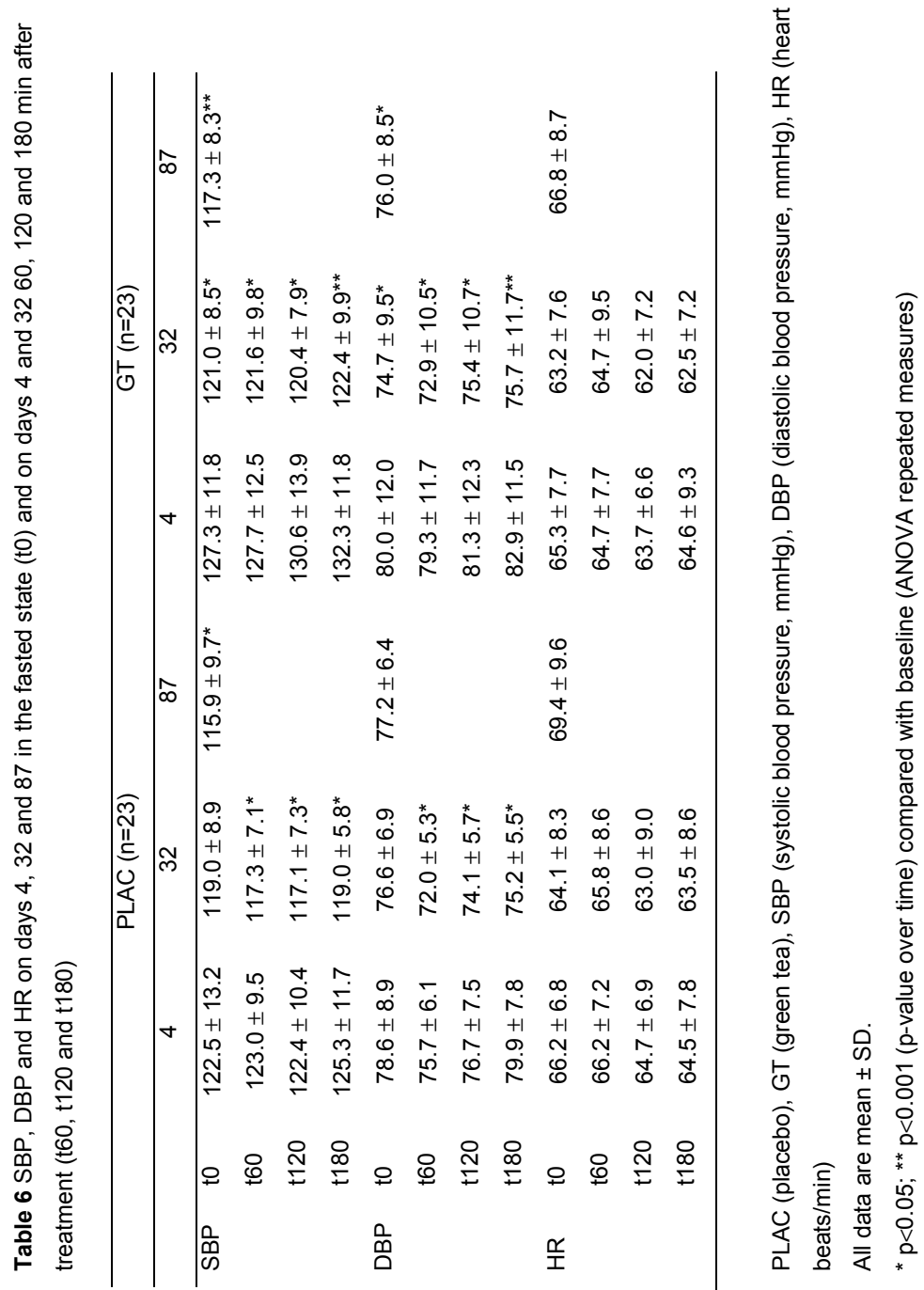


As well as decreased body weight, there were reductions in BMI $(p<0.001)$, waist circumference $(p<0.001)$, hip circumference $(p<0.001)$ and waist:hip ratio $(p<0.05$ on day 32 in both groups and on day 87 in the GT group) (table 3 ). Furthermore, FM (\%) was significantly decreased in the PLAC group on day 87 $(p<0.05)$ and in the GT group on days 32 and $87(p<0.001)$. FFM $(\mathrm{kg})$ was significantly decreased on day 32 in the PLAC group $(p<0.05)$ (table 3 ). However, reductions in BMI, waist and hip circumference, waist:hip ratio, FM and FFM were not statistically different between treatments (table 3 ).

There was a significant linear relation between REE $(\mathrm{kJ} / \mathrm{d})$ and FFM $(\mathrm{kg})$ on days 4 and 32 in both groups $(p<0.001)$. As shown in figures 2 and 3 , where REE is plotted as a function of FFM, the regression line on day 32 was lower than that on day 4 in the PLAC group but, remarkably, not in the GT group. To determine the changes in REE as a function of FFM and FM (regression of REE vs. FFM and FM), this was calculated in each group by filling in the FFM (kg) and $\mathrm{FM}(\mathrm{kg})$ values from day 32 in the slope equation of day 4 . Factorial ANOVA showed that the calculated REE on day 32 was significantly higher than the measured REE on day 32 in the PLAC group $(p<0.05)$ but not in the GT group. A comparison of the differences between the calculated and the measured REE on day 32 between the PLAC and GT group did not show a significant difference (PLAC: $151.3 \pm 261.6 \mathrm{~kJ} / \mathrm{d}, \mathrm{GT}$ : $54.4 \pm 389.4 \mathrm{~kJ} / \mathrm{d}, \mathrm{p}=0.35$, one-factor ANOVA). Thus, the reduction in REE over time was not significantly different between the two treatments.

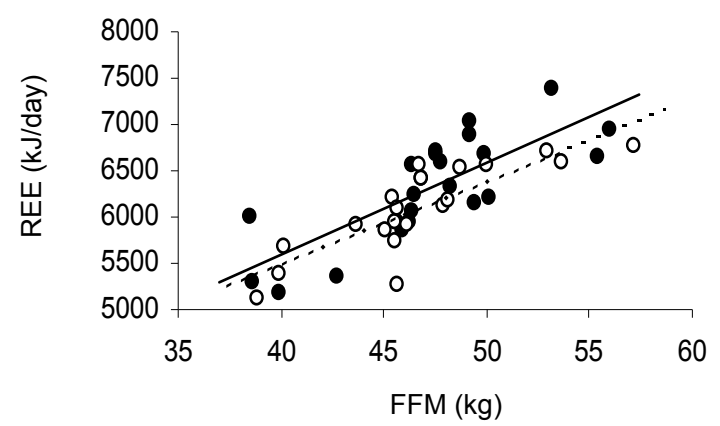

Figure 2 REE as a function of FFM plotted for day 4 (open circles, trendline - ) and day 32 (filled circles, trendline ----) in the PLAC group.

REE (resting energy expenditure, kJ/d), FFM (fat-free mass, kg), PLAC (placebo)

The regression equation for day 4: $R E E=99.43 F F M+1605.6\left(R^{2}=0.62\right)$;

for day 32: REE = 89.5FFM+1896.9 $\left(R^{2}=0.7\right)$. 


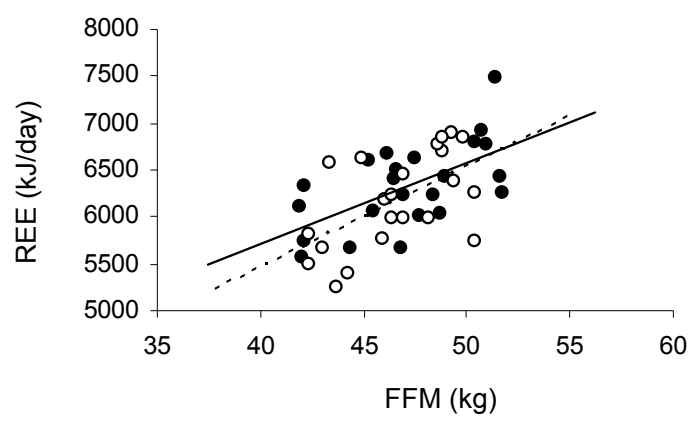

Figure 3 REE as a function of FFM plotted for day 4 (open circles, trendline - ) and day 32 (filled circles, trendline ----) in the GT group.

REE (resting energy expenditure, $\mathrm{kJ} / \mathrm{d}$ ), FFM (fat-free mass, $\mathrm{kg}$ ), GT (green tea)

The regression equation for day 4 : $R E E=86.62 F F M+2240.7\left(R^{2}=0.37\right)$;

for day 32: REE = 108.02FFM+1132.9 $\left(R^{2}=0.32\right)$.

No time or treatment effect was observed on DEE and postabsorptive (RQ1) and postprandial (RQ2) RQ during the 4 weeks of weight loss (table 3 ).

No treatment, yet a time, effect was observed with respect to dietary restraint in that the F1 score of the TFEQ increased significantly over time $(p<0.001)$ on days 32 and 87 in both groups. The F2 (disinhibition) and F3 (hunger) scores were significantly decreased in both groups on day 87 (over time effect, $p<0.05$ ) (table 3).

The appetite ratings are presented in table 4 . The following time $x$ treatment effects were shown $(p<0.05)$. A significant increase in hunger and prospective food consumption was observed in the GT group relative to the PLAC group on days 32 and 87 in the fasted state $(p<0.05)$. Thirst increased significantly in the PLAC group on day $87(p<0.05)$ and decreased in the GT group $(p<0.05)$.

Only an effect over time, but not treatment over time, was seen in the GT group on satiety, which decreased significantly $(p<0.001)$ on day 87 whereas appetite and desire to eat increased significantly $(p<0.05)$ in this group (table 4$)$.

As shown in table 5 , the subjects in the GT group felt significantly more relaxed on day 32 and 87 in the fasted state compared with baseline $(p<0.05$, over time effect). No other changes in mood were found.

Systolic and diastolic blood pressure both decreased during the weight-loss period (table 6), with no difference in treatments over time. There was no change in heart rate during weight loss and no differences between treatments (table 6). The occurrence of complaints was significantly increased on day 87 in the GT group ( $p<0.05$, over time effect), but remained low (table 3 ). 


\section{DISCUSSION}

This study has shown that GT extract had no added benefits for any measures of body weight or body composition when used as a part of a LED (mealreplacement diet plan).

In contrast, Japanese studies show that the long-term (12-week) administration of tea catechins in a dose of 400 to $600 \mathrm{mg} / \mathrm{d}$ in human subjects would reduce body fat and body-fat parameters and might be useful in the prevention and reduction of obesity (31-33). The Japanese participants were, however, studied during a weight-maintenance period, with limited caffeine intake, whereas our subjects were studied in a weight-loss period. Furthermore, a recent Japanese article found that the daily consumption of $340 \mathrm{ml}$ tea containing $690 \mathrm{mg}$ catechins (green tea extract) for 12 weeks reduced body weight, BMI, waist circumference and body fat compared with the control group, who had a daily consumption of $340 \mathrm{ml}$ tea with $22 \mathrm{mg}$ catechins (34). In addition, unlike the Japanese studies, it was found by Kovacs et al., who investigated the effects of GT in 104 subjects (BMI 25-35 $\mathrm{kg} / \mathrm{m}^{2}$ ) participating in a very-low-energy diet intervention of 4 weeks followed by a weight-maintenance period of 13 weeks, that weight maintenance after $7.5 \%$ weight loss was not affected by GT treatment (20).

In the present study, the first data assessing the effect of GT on REE along with a LED, that is, during a negative energy balance, are reported. We hypothesized that the ingestion of GT $(225 \mathrm{mg}$ caffeine and $1125 \mathrm{mg}$ catechins/d) could offset the reduction in REE that occurs during a LED. However, the difference between groups over time was not statistically significant. The present study shows that REE as a function of both FFM and FM did not decrease significantly over time when GT, independent of habitual caffeine intake, was ingested together with a LED (60\% of predicted EE), whereas the decrease in REE was significant in the PLAC group, yet no treatment over time effect was observed. Attenuating a reduction in REE during weight loss has been shown before (16-18). In the present study, however, a robust limitation of REE reduction during a LED was not achieved by GT, and further research is required.

Our study design was based on the observations by Dulloo et al. who have recently demonstrated in vitro and in vivo that GT causes a stimulation of thermogenesis that cannot be explained per se by its caffeine content $(9,10)$. The 24h EE with GT extract was significantly greater than that with both the placebo and caffeine (9). The study by Dulloo et al. was performed with young men (age $25 \pm 1 \mathrm{y}$, BMl $25.1 \pm 1.2 \mathrm{~kg} / \mathrm{m}^{2}$ ), whereas our subjects were women. The difference in gender possibly plays a role as women have higher circulating leptin concentrations than men (35). Furthermore, the subjects in the study by Dulloo et al. were relatively low consumers of caffeine $(100-200 \mathrm{mg} / \mathrm{d})$, and they had to abstain from caffeine-containing foods and beverages the day before 
and during the experiment. The ingestion of GT capsules provided daily a total of $150 \mathrm{mg}$ caffeine (9). In contrast, our subjects had a habitual intake of 300 $\mathrm{mg} / \mathrm{d}$ before and during the study, and the ingestion of GT capsules provided $236.7 \mathrm{mg}$ caffeine/d. It is possible that prior habitual caffeine use led to tolerance to the anticipated effects of caffeine, rendering the GT supplement ineffective.

No difference in body weight loss was seen between the experimental and control groups. This cannot be explained by the attitude towards eating. The TFEQ scores showed a normal profile (more dietary restraint, less disinhibition and hunger after the LED) and did not differ statistically between the groups $(36,37)$. One possible explanation is the significant differences between the groups with respect to the appetite parameters, in that the GT group became more hungry and less thirsty, and had an increased prospective food intake, compared with PLAC. Furthermore, the GT group was less satiated and had an increased appetite and desire to eat in comparison to baseline. The downregulation of the leptin release through stimulation of the sympathetic nervous system by GT may play a role since leptin reduces appetite $(38,39)$. To offset the increase in hunger with GT, it may be of value to look at the effect of GT given together with a satiating agent such as guar gum $(40,41)$.

It is possible that the thermogenic efficacy of GT is weak in this study as food restriction (LED) is a state of reduced sympathetic activity (reduced noradrenaline release). Owing to this reduced noradrenaline release, the pharmacologically active ingredients (tea catechins and caffeine) have not many "negative modulators" to inhibit. Dulloo et al. showed in vitro that, in the absence of increased noradrenaline release from sympathetic nerves, catechins, caffeine or catechins + caffeine had only mild effects on the respiration rate of brown adipose tissue (10).

In contrast to Dulloo et al., no stimulation of GT on fat oxidation was found (9). Dulloo et al. measured $24 \mathrm{~h} \mathrm{RQ}$, whereas in the present study, we measured 30 min postabsorptive $R Q$ and $180 \mathrm{~min}$ postprandial $R Q$. Since breakfast stimulates carbohydrate oxidation and not fat oxidation, no effect of GT on fat oxidation was seen. Another explanation is that the $R Q$ is already low during weight loss induced by a LED.

Systolic and diastolic blood pressure and heart rate were not affected by GT. This is in accordance with a study of Hodgson et al., who found that regular consumption of GT (five $200 \mathrm{ml}$ cups/d, $50 \mathrm{mg}$ caffeine/cup and tea bags containing $2 \mathrm{~g}$ tea leaves) over $7 \mathrm{~d}$ had no significant effect on ambulatory blood pressure (42). The reduction in blood pressure is probably caused by weight loss or by the fact that the subjects felt more relaxed on days 32 and 87.

Taken together, 12-week GT administration during a LED, independent of habitual caffeine intake, had no effect on measures of body weight or body composition at 4 weeks or 3 months. This may be due to increased hunger with 
GT treatment and the lack of a robust effect on the prevention of decrease in REE. With respect to the safety of the treatment, no adverse events occurred. For future research, we recommend testing the combination of GT with another thermogenic ingredient, for example capsaicin, assessing a possible synergism, and adding a satiating agent such as guar gum (40, 41, 43, 44). Another possibility is the administration of GT in conjunction with approaches that counteract the fall in sympathetic activity during a LED regimen.

\section{ACKNOWLEDGEMENTS}

We thank Tanja Adam, Arnold Kester, Paul Schoffelen, Joan Senden and Loek Wouters for their contribution to the study. This study was supported by Unilever Food and Health Research Institute, Unilever R\&D Vlaardingen, Vlaardingen, The Netherlands. The Slim.Fast products were donated by Unilever Bestfoods Nederland BV.

\section{REFERENCES}

1. WHO. Obesity: preventing and managing the global epidemic. Report of a WHO consultation. World Health Organ Tech Rep Ser 2000;894:i-xii, 1-253.

2. Stunkard AJ. Current views on obesity. Am J Med 1996;100:230-236.

3. Wadden TA, Stunkard AJ, Liebschutz J. Three-year follow-up of the treatment of obesity by very low calorie diet, behavior therapy, and their combination. J Consult Clin Psychol 1988;56:925-8.

4. Pasman WJ, Saris WH, Muls E, Vansant G, Westerterp-Plantenga MS. Effect of exercise training on long-term weight maintenance in weight-reduced men. Metabolism 1999;48:15-21.

5. Weisburger JH. Tea and health: a historical perspective. Cancer letters 1997;114:315317.

6. Graham HN. Green tea composition, consumption, and polyphenol chemistry. Prev Med 1992;21:334-350.

7. Kao Y-H, Hiipakka RA, Liao S. Modulation of endocrine systems and food intake by green tea epigallocatechin gallate. Endocrinology 2000;141:980-987.

8. Chantre P, Lairon D. Recent findings of green tea extract AR25 (Exolise) and its activity for the treatment of obesity. Phytomedicine 2002;9:3-8.

9. Dulloo AG, Duret C, Rohrer D, et al. Efficacy of a green tea extract rich in catechinpolyphenols and caffeine in increasing 24-h energy expenditure and fat oxidation in humans. Am J Clin Nutr 1999;70:1040-1045.

10. Dulloo AG, Seydoux J, Girardier L, Chantre P, Vandermander J. Green tea and thermogenesis: interactions between catechin-polyphenols, caffeine and sympathetic activity. Int J Obes 2000;24:252-258.

11. Dulloo AG, Seydoux J, Girardier L. Potentiation of the thermogenic antiobesity effects of ephedrine by dietary methylxanthines: adenosine antagonism or phosphodiesterase inhibition. Metabolism 1992;41:1233-1241. 
12. Dulloo AG, Geissler CA, Horton T, Collins A, Miller DS. Normal caffeine consumption: influence on thermogenesis and daily energy expenditure in lean and postobese human volunteers. Am J Clin Nutr 1989;49:44-50.

13. Astrup A, Toubro S, Cannon S, Hein P, Breum L, Madsen J. Caffeine: a double-blind, placebo-controlled study of its thermogenic, metabolic, and cardiovascular effects in healthy volunteers. Am J Clin Nutr 1990;51:759-767.

14. Bracco D, Ferrarra J-M, Arnaud MJ, Jequier E, Schutz Y. Effects of caffeine on energy metabolism, heart rate, and methylxanthine metabolism in lean and obese women. Am J Physiol 1995;269:E671-E678.

15. Borchardt RT, Huber JA. Catechol O-methyltransferase. Structure-activity relationships for inhibition by flavonoids. J Med Chem 1975;18:120-122.

16. Astrup A, Gotzsche PC, van de Werken K, et al. Meta-analysis of resting metabolic rate in formerly obese subjects. Am J Clin Nutr 1999;69:1117-1122.

17. Menozzi R, Bondi M, Baldini A, Venneri MG, Velardo A, Del Rio G. Resting metabolic rate, fat-free mass and catecholamine excretion during weight loss in female obese patients. Br J Nutr 2000;84:515-520.

18. Ravussin E, Bogardus C. A brief overview of human energy metabolism and its relationship to essential obesity. Am J Clin Nutr 1992;55:242S-245S.

19. Ravussin E, Lillioja S, Knowler WC, et al. Reduced rate of energy expenditure as a risk factor for body-weight gain. N Engl J Med 1988;318:467-72.

20. Kovacs EM, Lejeune MP, Nijs I, Westerterp-Plantenga MS. Effects of green tea on weight maintenance after body-weight loss. Br J Nutr 2004;91:431-7.

21. Hulshof KF, Brussaard JH, Kruizinga AG, Telman J, Lowik MR. Socio-economic status, dietary intake and 10 y trends: the Dutch National Food Consumption Survey. Eur J Clin Nutr 2003;57:128-37.

22. van Boxtel MP, Schmitt JA, Bosma H, Jolles J. The effects of habitual caffeine use on cognitive change: a longitudinal perspective. Pharmacol Biochem Behav 2003;75:921-7.

23. van Dam RM, Feskens EJ. Coffee consumption and risk of type 2 diabetes mellitus. Lancet 2002;360:1477-8.

24. Westerterp KR, Donkers JHHLM, M. FEWH, Boekhoudt P. Energy intake, physical activity and body weight: a simulation model. Br J Nutr 1995;73:337-347.

25. Schoffelen PFM, Westerterp KR, Saris WHM, Ten Hoor F. A dual-respiration chamber system with automated calibration. J Appl Physiol 1997;83:2064-2072.

26. Weir JBDV. New methods for calculating meatbolic rate with special references to protein metabolism. J Physiol 1949;109:1-9.

27. van Marken Lichtenbelt WD, Westerterp KR, Wouters L. Deuterium dilution as a method for determining total body water: effect of test protocol and sampling time. $\mathrm{Br} \mathrm{J}$ Nutr 1994;72:491-497.

28. Westerterp KR, Wouters L, van Marken Lichtenbelt WD. The maastricht protocol for the measurement of body composition and energy expenditure with labeled water. Obes Res 1995;3 (suppl 1):49-57.

29. Schoeller DA, van Santen E, Peterson DW, Dietz W, Jaspan J, Klein PD. Total body water measurement in humans with 180 and $2 \mathrm{H}$ labeled water. Am J Clin Nutr 1980;33:2686-2693.

30. Stunkard AJ, Messick S. The three-factor eating questionnaire to measure dietary restraint, disinhibition and hunger. J Psychosom Res 1985;29:71-83.

31. Tsuchida $\mathrm{T}$, Itakura $\mathrm{H}$, Nakamura $\mathrm{H}$. Reduction of body fat in humans by long-term ingestion of catechins. Prog Med 2002;22:2189-2203.

32. Nagao T, Meguro S, Soga S, et al. Tea catechins suppress accumulation of body fat in humans. J Oleo Sci 2001;50:717-728.

33. Hase $T$, Komine $\mathrm{Y}$, Meguro $\mathrm{S}$, et al. Anti-obesity effects of tea catechins in humans. $J$ Oleo Sci 2001;50:599-605. 
34. Nagao $\mathrm{T}$, Komine $\mathrm{Y}$, Soga $\mathrm{S}$, et al. Ingestion of a tea rich in catechins leads to a reduction in body fat and malondialdehyde-modified LDL in men. Am J Clin Nutr 2005;81:122-9.

35. Trayhurn P. Biology of leptin - its implications and consequences for the treatment of obesity. int J Obes 2001;25 (suppl 1):S26-S28.

36. Pasman WJ, Saris WHM, Westerterp-Plantenga MS. Predictors of weight maintenance. Obes Res 1999;7:43-50.

37. Westerterp-Plantenga MS, Kempen KPG, Saris WHM. Determinants of weight maintenance in women after diet-induced weight reduction. Int J Obes 1998;22:1-6.

38. Trayhurn P, Hoggard N, Mercer JG, Rayner DV. Leptin: fundamental aspects. Int J Obes 1999;23 (suppl 1):22-28.

39. Rayner DV, Trayhurn P. Regulation of leptin production: sympathetic nervous system interactions. J Mol Med 2001;79:8-20.

40. Kovacs EM, Westerterp-Plantenga MS, Saris WH, Goossens I, Geurten P, Brouns F. The effect of addition of modified guar gum to a low-energy semisolid meal on appetite and body weight loss. Int J Obes Relat Metab Disord 2001;25:307-15.

41. Kovacs EM, Westerterp-Plantenga MS, Saris WH, et al. The effect of guar gum addition to a semisolid meal on appetite related to blood glucose, in dieting men. Eur J Clin Nutr 2002;56:771-8.

42. Hodgson JM, Puddey IB, Burke V, Beilin LJ, Jordan N. Effects on blood pressure of drinking green and black tea. J Hypertens 1999;17:457-463.

43. Lejeune MPGM, Kovacs EMR, Westerterp-Plantenga MS. Effect of capsaicin on substrate oxidation and weight maintenance after modest body-weight loss in human subjects. $\mathrm{Br} \mathrm{J}$ Nutr 2003;90:1-10.

44. Yoshioka M, Doucet E, Drapeau V, Dionne I, Tremblay A. Combined effects of red pepper and caffeine consumption on $24 \mathrm{~h}$ energy balance in subjects given free access to foods. Br J Nutr 2001;85:203-211. 


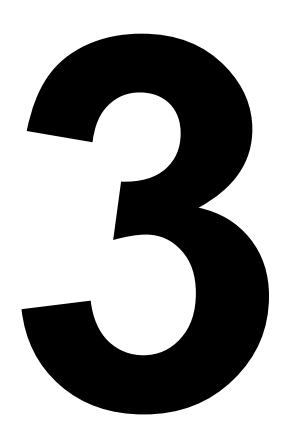

\section{Metabolic effects of green tea and of phases of weight loss}

Kristel Diepvens, Eva MR Kovacs, Neeltje Vogels, Margriet S Westerterp-Plantenga

Physiol Behav 2006; 87: 185-191 


\section{ABSTRACT}

The effect of ingestion of green tea (GT) extract along with a low-energy diet (LED) on health-related blood parameters, and the relationships among changes in metabolic parameters and phases of weight loss were assessed. A double-blind, placebo-controlled, parallel design was used. Forty-six female subjects (BMl $27.7 \pm 1.8 \mathrm{~kg} / \mathrm{m}^{2}$ ) were fed in energy balance from days 1-3, followed by a LED with GT $(n=23)$ or placebo (PLAC, $n=23)$ from days 4-87. The LED period consisted of a phase 1 of 4 weeks (days 4-32), followed by a phase 2 of 8 weeks (days 32-87). Body composition and fasting blood samples were determined on days 4,32 and 87 . No significant differences were observed between the blood parameters of the PLAC and GT group. In phase 1 compared to phase 2 , the rate of weight loss was $0.09 \pm 0.05 \mathrm{~kg} /$ day vs. $0.03 \pm$ $0.03 \mathrm{~kg} /$ day $(\mathrm{p}<0.001)$; Fat-free mass (FFM) was $21 \%$ of weight loss in phase 1 vs. $7 \%$ in phase 2 (ns). Surprisingly, favourable changes in free fatty acids, triacylglycerol, $\beta$-hydroxybutyrate, glucose and total cholesterol in phase 1 were reversed in phase $2(p<0.01)$. Taken together, GT supplementation during a LED had no effect on health-related blood parameters. Initial improvements in several blood measures at day 32 were reversed by day 87 , despite continued weight loss. Modest weight loss improved HDL cholesterol and blood pressure.

Keywords: green tea, blood parameters, phases of weight loss, reversal, fatfree mass 


\section{INTRODUCTION}

The global prevalence of obesity has increased considerably in the last decade (1). Obesity raises the risk for developing diseases such as coronary artery disease and non-insulin-dependent diabetes mellitus (2, 3). Modest weight loss, $5-10 \%$ of the initial body weight, is associated with marked improvements in many risk factors $(4,5)$.

Green tea (GT), containing caffeine and catechin-polyphenols, may have effects on body weight (6-8), possibly through stimulation of energy expenditure and fat oxidation (9-11). We have previously reported on effects of GT on energy metabolism in relation to weight loss and body composition. 12-week GT administration during a low-energy diet (LED) had no effect on measures of body weight or body composition (12). In the present study, we investigated whether GT ingestion during LED, independent of habitual caffeine intake, affects health-related risk factors.

The main objective of this study was to investigate whether GT consumption during LED brings about changes related to the blood parameters. Therefore, we assessed the effect of GT during weight loss on the following blood parameters; triacylglycerol (TG), free fatty acids (FFA), glycerol (Gly), $\beta$ hydroxybutyrate (BHB), glucose (Glu), HDL cholesterol (HDL), LDL cholesterol (LDL), total cholesterol (TotChol), leptin and ghrelin. Based upon earlier research, we hypothesized that GT during a LED might decrease leptin, glucose, triacylglycerol, LDL and total cholesterol more than the LED alone (6, 7, 13-17). We further hypothesized that GT might increase HDL cholesterol more than the LED alone (16). With respect to the other blood parameters (ghrelin, glycerol), these may change with a LED with GT more than without GT if GT indeed would affect body weight.

Although there is a lot of research about the effects of weight reduction on blood parameters, little is known about the changes in different phases of weight loss. Therefore, we were interested in the relationships among changes in metabolic parameters and phases of weight loss, e.g. after the first phase with the usual strong negative energy balance, e.g. 1 month, and during the remaining time of the experiment, where the energy balance usually is less negative (18).

Since Dulloo et al. noticed that the body composition of a given individual continuously changes towards a leaner composition during energy restriction, we investigated the effect of phases of weight loss on body composition (18). 


\section{SUBJECTS AND METHODS}

\section{Subjects}

Forty-six overweight female subjects, aged 19 to 57 years and with a body mass index (BMI) between 25 and $31 \mathrm{~kg} / \mathrm{m}^{2}$, participated in this study. The subjects were recruited by advertisements in local newspapers. All initial volunteers $(n=57)$ participated in an initial screening that involved measurement of body weight, height, waist:hip circumference and blood pressure, completion of questionnaires related to health, use of medication, smoking behavior, alcohol consumption and physical activity, and a food history questionnaire, specific for caffeine and catechin-containing products. Subjects selected $(n=46)$ were moderate caffeine users (200-400 mg caffeine/day), in good health, nonsmokers, normotensive, not using medication and at most moderate alcohol users. The subjects were assigned to one of 2 groups and matched for age, BMI, weight, height, systolic and diastolic blood pressure (SBP, DBP), resting heart rate and caffeine intake. The two groups were randomly assigned to one of two treatments: green tea $(G T)(n=23)$ or placebo (PLAC) $(n=23)$. Baseline characteristics of the subjects are presented in table 1.

Table 1 Subject characteristics at baseline

\begin{tabular}{lcc}
\hline & PLAC $(\mathrm{n}=23)$ & GT $(\mathrm{n}=23)$ \\
\hline Age $($ years $)$ & $41.6 \pm 10.0$ & $41.7 \pm 8.6$ \\
Height $(\mathrm{m})$ & $1.66 \pm 0.05$ & $1.66 \pm 0.05$ \\
Weight $(\mathrm{kg})$ & $76.3 \pm 6.6$ & $76.4 \pm 6.3$ \\
BMI $\left(\mathrm{kg} / \mathrm{m}^{2}\right)$ & $27.7 \pm 1.8$ & $27.7 \pm 1.8$ \\
FFM $(\mathrm{kg})$ & $47.3 \pm 4.5$ & $47.2 \pm 3.2$ \\
Body fat $(\%)$ & $38.0 \pm 4.4$ & $38.1 \pm 4.1$ \\
Waist circumference $(\mathrm{cm})$ & $84.0 \pm 6.0$ & $85.6 \pm 6.2$ \\
Hip circumference $(\mathrm{cm})$ & $107.0 \pm 4.9$ & $105.6 \pm 3.8$ \\
W:H ratio & $0.79 \pm 0.06$ & $0.81 \pm 0.05$ \\
SBP $(\mathrm{mmHg})$ & $122.5 \pm 13.2$ & $127.4 \pm 11.8$ \\
DBP $(\mathrm{mmHg})$ & $78.6 \pm 8.9$ & $80.0 \pm 12.0$ \\
Heart rate $($ beats/min) & $66.2 \pm 6.8$ & $65.3 \pm 7.7$ \\
Caffeine intake $(\mathrm{mg} /$ day) & $311.8 \pm 61.1$ & $300.2 \pm 54.5$ \\
\hline
\end{tabular}

PLAC (placebo), GT (green tea), BMI (Body Mass Index, $\mathrm{kg} / \mathrm{m}^{2}$ ), FFM (fat-free mass, $\mathrm{kg}$ ), W:H ratio (waist:hip ratio), SBP (systolic blood pressure, $\mathrm{mmHg}$ ), DBP (diastolic blood pressure, $\mathrm{mmHg}$ ) All data are mean $\pm S D$. None of the differences between the groups were statistically significant $(p<0.05)$, subjects are matched for the characteristics. 
The subjects gave their written informed consent and the Medical Ethical Committee of Maastricht University approved the study.

\section{Experimental design}

The experiment had a double-blind, placebo-controlled, parallel design. The experimental design consisted of an intervention period lasting 87 days.

During days 1-87, all subjects' caffeine background intake was standardized at approximately $300 \mathrm{mg} /$ day (the equivalent of about three $150 \mathrm{ml}$ cups of coffee) to maintain the habitual caffeine intake (19-22). The subjects consumed a cup of coffee before breakfast $(08.00 \mathrm{~h})$, in the morning $(10.00 \mathrm{~h})$ and in the afternoon (14.00 h). The subjects were asked to abstain from other caffeine-rich products like tea, cola-type soft drinks, and energy drinks.

During days 1-3, subjects consumed a standardized energy balance diet at $100 \%$ of energy expenditure estimated as $1.6 \mathrm{x}$ basal expenditure, estimated by means of the computer simulation program (23).

During days 4-87, subjects consumed a LED in order to lose weight. The weight-loss period was divided in 2 phases for further analyses. The first 4 weeks of the LED (days 4-32) are considered phase 1 and the last 8 weeks (days 32-87) phase 2. The diet was a meal-replacement diet plan (Slim.Fast, Unilever Bestfoods Nederland BV), which provided approximately $60 \%$ of the predicted energy expenditure (average \% energy: protein 25, fat 15 , carbohydrate 60). The subjects consumed a meal replacement (ready-to-drink shake, soup, bar, pasta) at breakfast and lunch and received instructions about the type and the amount of food they could ingest at dinner and as snacks. In addition, the subjects ingested 3 capsules of PLAC (Maltodextrin) or GT extract three times daily, at breakfast, lunch and dinner. To estimate compliance, remaining capsules were counted. The composition and dose of the treatments is presented in table 2 .

\section{Measurements}

Anthropometric measurements took place in the fasted state during screening, on days 4, 32 and 87 , thus measurements were performed with subjects in the same phase of their menstrual cycle. Body weight was measured using a digital balance accurate to $0.02 \mathrm{~kg}$ (Chyo-MW-150K, Japan) with subjects in underwear and after voiding their bladder. Height was measured to the nearest $0.1 \mathrm{~cm}$ using a wall-mounted stadiometer (only during screening). For determination of waist:hip ratio (W:H ratio), waist circumference was measured at the site of the smallest circumference between the rib cage and the ileac crest and hip circumference was measured at the site of the largest circumference between the waist and the thighs. Both measurements were performed with subjects in standing position. 
Table 2 Treatments

\begin{tabular}{|c|c|c|c|}
\hline & \multicolumn{2}{|c|}{ Green tea* } & Placebo \\
\hline Caffeine & \multicolumn{2}{|c|}{26.3} & \\
\hline Total catechins & \multicolumn{2}{|c|}{134.1} & \\
\hline Catechin & \multicolumn{2}{|c|}{3.5} & \\
\hline Epicatechin & \multicolumn{2}{|c|}{14.0} & \\
\hline Epigallocatechin & \multicolumn{2}{|c|}{26.7} & \\
\hline Epicatechin gallate & \multicolumn{2}{|c|}{23.6} & \\
\hline Epigallocatechin gallate & \multicolumn{2}{|c|}{66.2} & \\
\hline Placebo (maltodextrin) & \multicolumn{2}{|c|}{74.9} & 310.0 \\
\hline Microcrystalline cellulose & \multicolumn{2}{|c|}{71.7} & \\
\hline Silicium dioxide & \multicolumn{2}{|c|}{1.5} & \\
\hline Magnesium stearate & \multicolumn{2}{|c|}{1.5} & \\
\hline Total (mg/capsule) & \multicolumn{2}{|c|}{310.0} & 310.0 \\
\hline Treatment & Caffeine & Tea catechins & Maltodextrin \\
\hline PLAC (mg/day) & 0 & 0 & 2790.0 \\
\hline GT (mg/day) & 236.7 & 1206.9 & 0 \\
\hline
\end{tabular}

PLAC: placebo; GT: green tea.

* green tea: Sunphenon 100S (Taiyo Kagaku Co. Ltd., Mie, Japan) with added caffeine

Body composition was measured on days 4,32 and 87 using the deuterium $\left({ }^{2} \mathrm{H}_{2} \mathrm{O}\right)$ dilution technique (24-26). The dilution of the deuterium isotope is a measure for total body water (TBW) (25). In the evening, the subjects ingested a dose of deuterium-enriched water $\left({ }^{2} \mathrm{H}_{2} \mathrm{O}\right)$ after collecting a background urine sample. After ingestion of the deuterium solution no further fluid or food consumption was permitted. The following morning, the second urine sample (second voiding) was collected. Deuterium concentration in the urine samples was measured using an isotope ratio mass spectrometer (Micromass Optima, Manchester, UK). TBW was obtained by dividing the measured deuterium dilution space by 1.04 to correct for exchange of the ${ }^{2} \mathrm{H}$ label with non-aqueous hydrogen of body solids (26). Fat-free mass (FFM) was calculated by dividing the TBW by hydrating factor 0.73 and fat mass (FM) as difference from body weight.

Systolic and diastolic blood pressure (SBP, DBP) were recorded during screening and on days 4,32 and 87 in the fasted state using an automatic blood pressure monitor (OSZ 5 easy, Spreidel \& Keller GmBH and Co. KG, Jungingen, Germany). 


\section{Blood parameters}

On days 4 and 32 , a 15-ml blood sample was taken in the fasted state. On day 87 , a fasting $10 \mathrm{ml}$ blood sample was obtained. The blood samples were mixed with EDTA to prevent clotting. Plasma was obtained by centrifugation $\left(4^{\circ} \mathrm{C}\right.$, $3000 \mathrm{rpm}, 10 \mathrm{~min}$ ), frozen in liquid nitrogen and stored at $-20^{\circ} \mathrm{C}$ until further analysis. Triacylglycerol (TG), free fatty acids (FFA), glycerol (Gly), $\beta$ hydroxybutyrate (BHB), Glucose (Glu), HDL cholesterol (HDL), LDL cholesterol (LDL), total cholesterol (TotChol) and leptin were measured on days 4, 32 and 87. Ghrelin was measured on days 4 and 32 only.

TG was measured using the GPO-trinder kit (Sigma Diagnostics Inc., St.Louis, USA), FFA were determined with the Wako NEFA C-kit (Wako chemicals, Neuss, Germany), Gly with the glycerolkinase method (Boehringer Mannheim $\mathrm{GmBH}$, Mannheim, Germany) and BHB with the $\beta$-hydroxybutyrate dehydrogenase method (Sigma Diagnostics Inc., St.Louis, USA). Leptin concentrations were measured using a human leptin RIA-kit (Linco research Inc., St. Charles, USA) and glucose concentrations were determined using the hexokinase method (Glucose HK 125 kit, ABX diagnostics, Montpellier, France). TotChol was measured with the cholesterol 100 kit (ABX diagnostics, Montpellier, France), HDL with a combination of the cholesterol 100 kit and the HDL-C kit (Roche diagnostics $\mathrm{GmBH}$, Mannheim, Germany) and LDL (mmol/l) was calculated by the following formula: Totchol (mmol/l)-HDL (mmol/l)-[(TG $(\mu \mathrm{mol} / \mathrm{l}) / 2200]$ (27). Ghrelin concentrations were determined with a ghrelin (total) RIA kit (Linco research Inc., St. Charles, USA).

\section{$\underline{\text { Statistical analysis }}$}

Data are presented as mean \pm standard deviation (SD). Data were analyzed using Statview SE + Graphics (Abacus Concepts, Berkeley, CA, 1988). Differences over time and between the treatments (PLAC or GT) over time were determined using one- and two-factor ANOVA with repeated measures. When appropriate, differences between groups were analyzed using a factorial ANOVA. Reversal effects have been analyzed by testing possible differences between changes during phases using one-factor ANOVA with repeated measures. Univariate linear regression was used to determine the relationship between selected variables. The level for establishing significant differences was taken at $p<0.05$. 


\section{RESULTS}

A factorial ANOVA showed that none of the baseline (day 4) differences between the groups were statistically significant (tables 3 and 4), indicating that the groups were well matched.

The changes in subject characteristics over time are given in table 3 (12).

For the dynamics of the fasted blood parameters, see table 4. No significant differences, except for Gly, were observed between the PLAC and GT group. Simple regression analyses showed that there was a significant linear relation between $\Delta$ leptin (days 4-87) and $\Delta$ FM (days 4-87), $\left(p<0.05, r^{2}=0.13\right)$.

Given that the changes in metabolic parameters were similar for the two groups, and were not significantly different (except for Gly), data from the PLAC and GT group have been combined to elucidate the relationships among changes in metabolic parameters and phases of weight loss. Subjects lost respectively 2.4 $\pm 1.4 \mathrm{~kg}$ and $1.8 \pm 1.6 \mathrm{~kg}$ during phase 1 and $2, p<0.05$. The rate of weight loss was also significantly higher in phase 1 compared with phase $2, p<0.001$.

Changes in FFA, TG, BHB, Glu, HDL and Totchol in phase 1 were reversed in phase 2 ( $p<0.01$, table 4). The reversal of TG, FFA, BHB and Glu is shown in figure $1 a, b, c$ and d respectively. No reversal effect was found for LDL, Gly and leptin. Figure 2 shows the reversal of HDL cholesterol $(p<0.001)$. HDL is significantly increased on day 87 compared with day $32(p<0.001)$. This effect is shown in table 4 . The SBP was significantly decreased on day 87 compared with day 4 (table $3, p<0.05$ ).

(a)

Delta TG

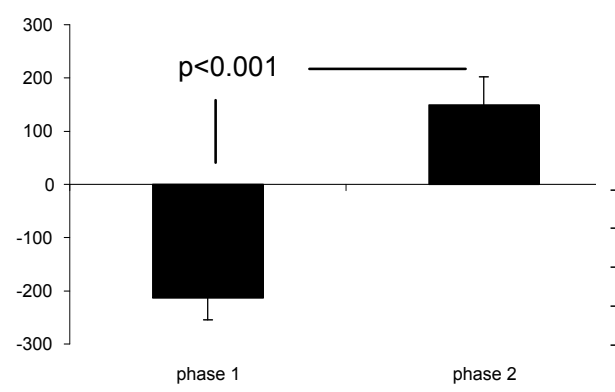

(b)

Delta FFA

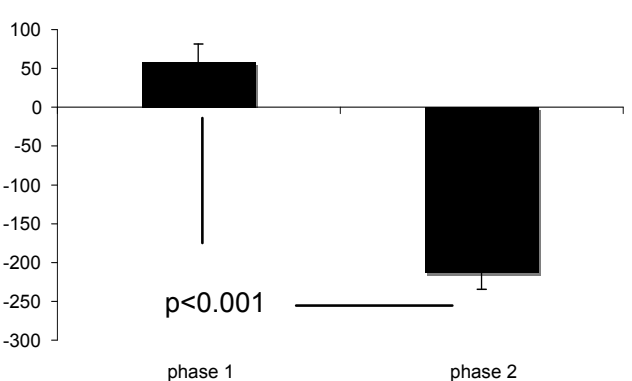


(c)

Delta BHB

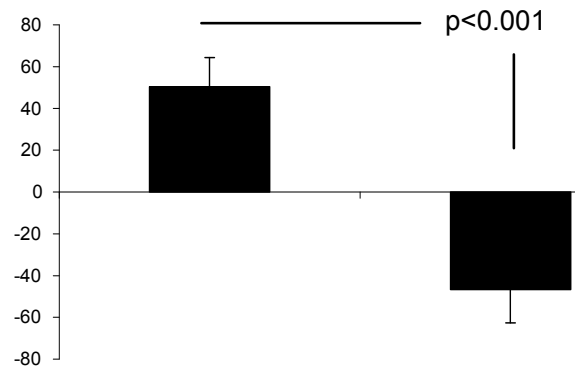

phase 1 (d)

Delta Glu

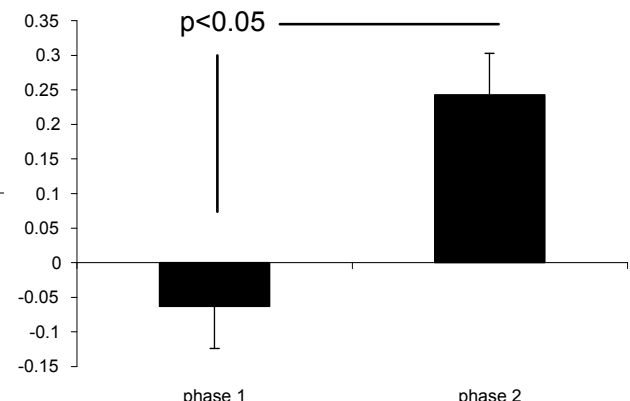

phase 2

Figure 1 Reversal of TG (a), FFA (b), BHB (c) and Glu (d).

TG (triacylglycerol, $\mu \mathrm{mol} / \mathrm{l}), \mathrm{FFA}$ (free fatty acids, $\mu \mathrm{mol} / \mathrm{l}$ ), BHB ( $\beta$-hydroxybutyrate, $\mu \mathrm{mol} / \mathrm{l}$ ), Glu (glucose, mmol/l); one factor ANOVA-repeated measures.

Delta HDL

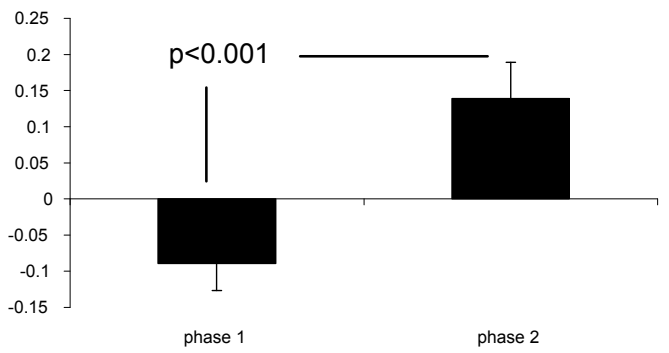

Figure 2 Reversal of HDL.

HDL (HDL cholesterol, mmol/l); one factor ANOVA-repeated measures.

Composition of body weight lost was $2.0 \mathrm{~kg}$ and $1.9 \mathrm{~kg} \mathrm{FM}$ and $0.5 \mathrm{~kg}$ and 0.1 kg FFM during phase 1 and 2 respectively. Yet in phase 1, FFM contributed $21 \%$ to weight loss and in phase 2 the contribution was only $7 \%$. This is also presented in figure 3 which shows the rate of FM loss (3a) and FFM loss (3b) per day. The rate of FM loss was significantly different between phase 1 and 2, $p<0.05$. 
(a)

Rate of FM loss/day

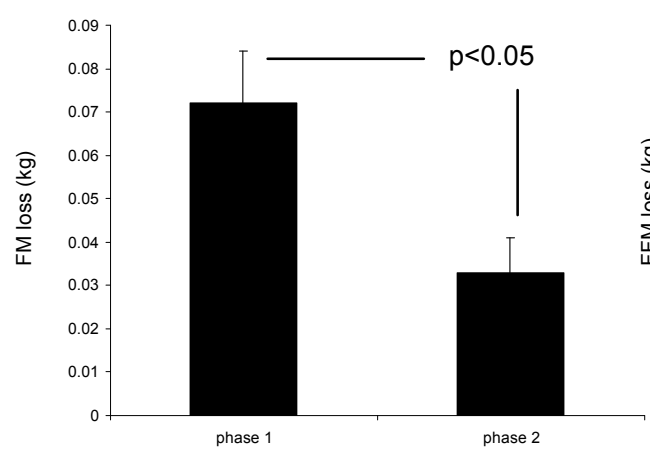

(b)

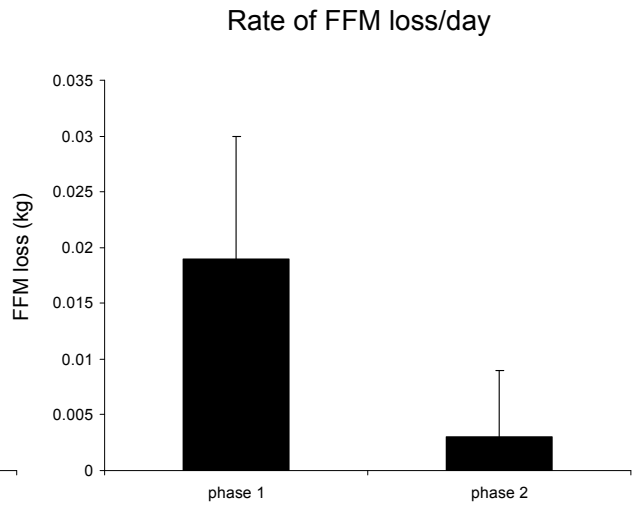

Figure 3 Composition of weight loss.

FM (fat mass, kg), FFM (fat-free mass, kg); one factor ANOVA-repeated measures.

\section{DISCUSSION}

The present study shows that GT supplementation during a LED (mealreplacement diet plan) had no effect on health-related blood parameters. We have already reported that GT had no effect on body weight or body composition during this LED (12).

Animal studies have shown that GT can lower Totchol, LDL, Glu, TG and leptin concentrations and can increase HDL blood concentrations (7, 15-17). Hase et al. found a significant decrease in body weight, Totchol and Glu after 12-week GT administration (tea catechins: $483 \mathrm{mg} /$ day, caffeine: $75 \mathrm{mg} /$ day) in healthy men (6). In contrast, our subjects had a habitual caffeine intake of $300 \mathrm{mg} / \mathrm{day}$ before and during the study and ingestion of GT capsules provided $236.7 \mathrm{mg}$ caffeine/day and $1206.7 \mathrm{mg}$ tea catechins/day. Furthermore, there has been shown that oral consumption of GT or EGCG can lower human serum Totchol and LDL levels $(6,28)$. There also was reported that tea catechins can have anti-obesity effects in humans. However, other research has studied subjects in a weight-maintenance period while our subjects were studied in a weight-loss period $(6,28)$. It is possible that the effect of GT on blood parameters is not additional to the beneficial effects of weight loss on blood levels. Also in contrast to the Japanese studies $(6,28)$, Kovacs et al. found that Glu, BHB, Gly, FFA, TG and leptin during weight maintenance after $7.5 \%$ weight loss were not affected by GT (19). 


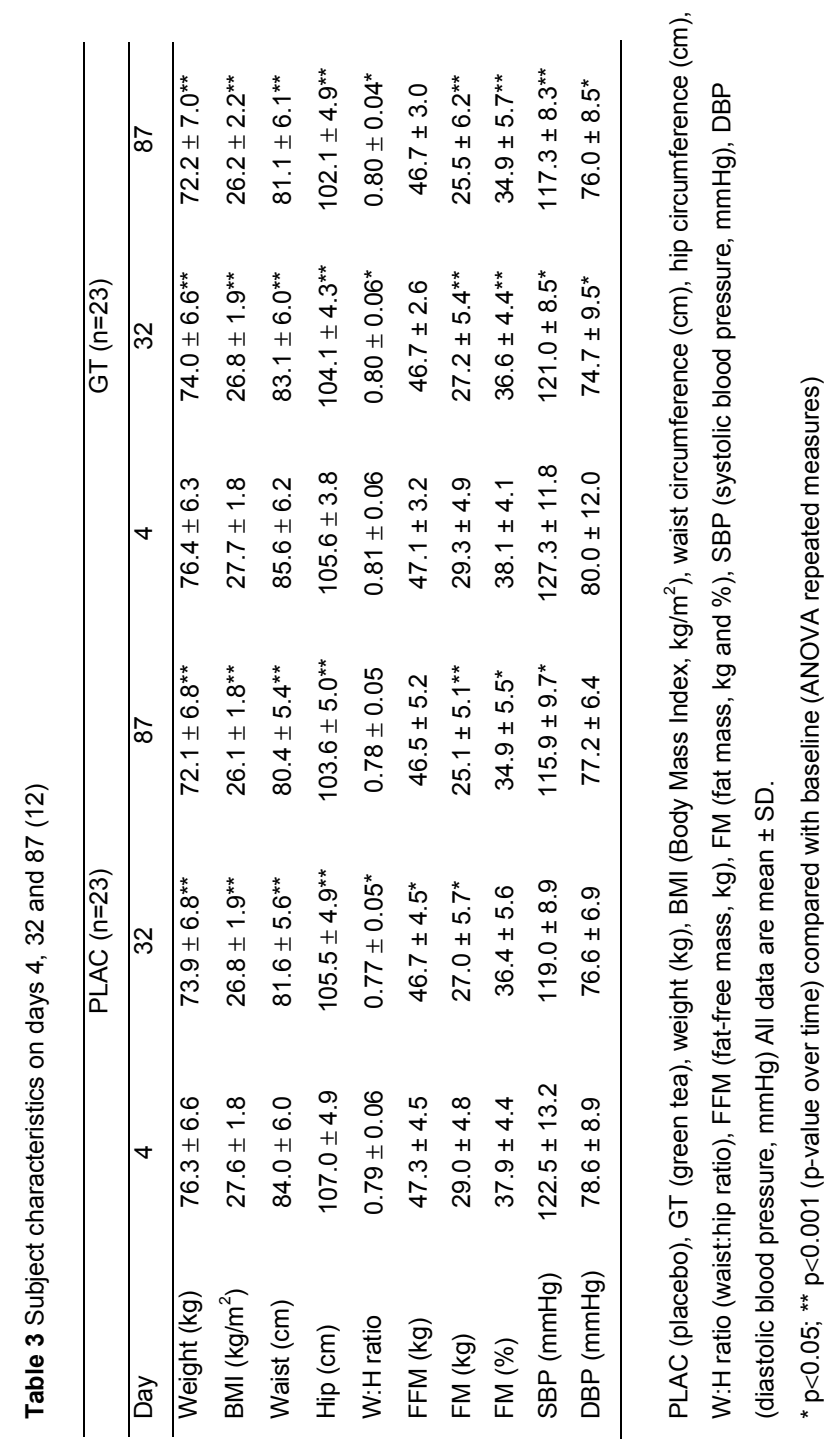




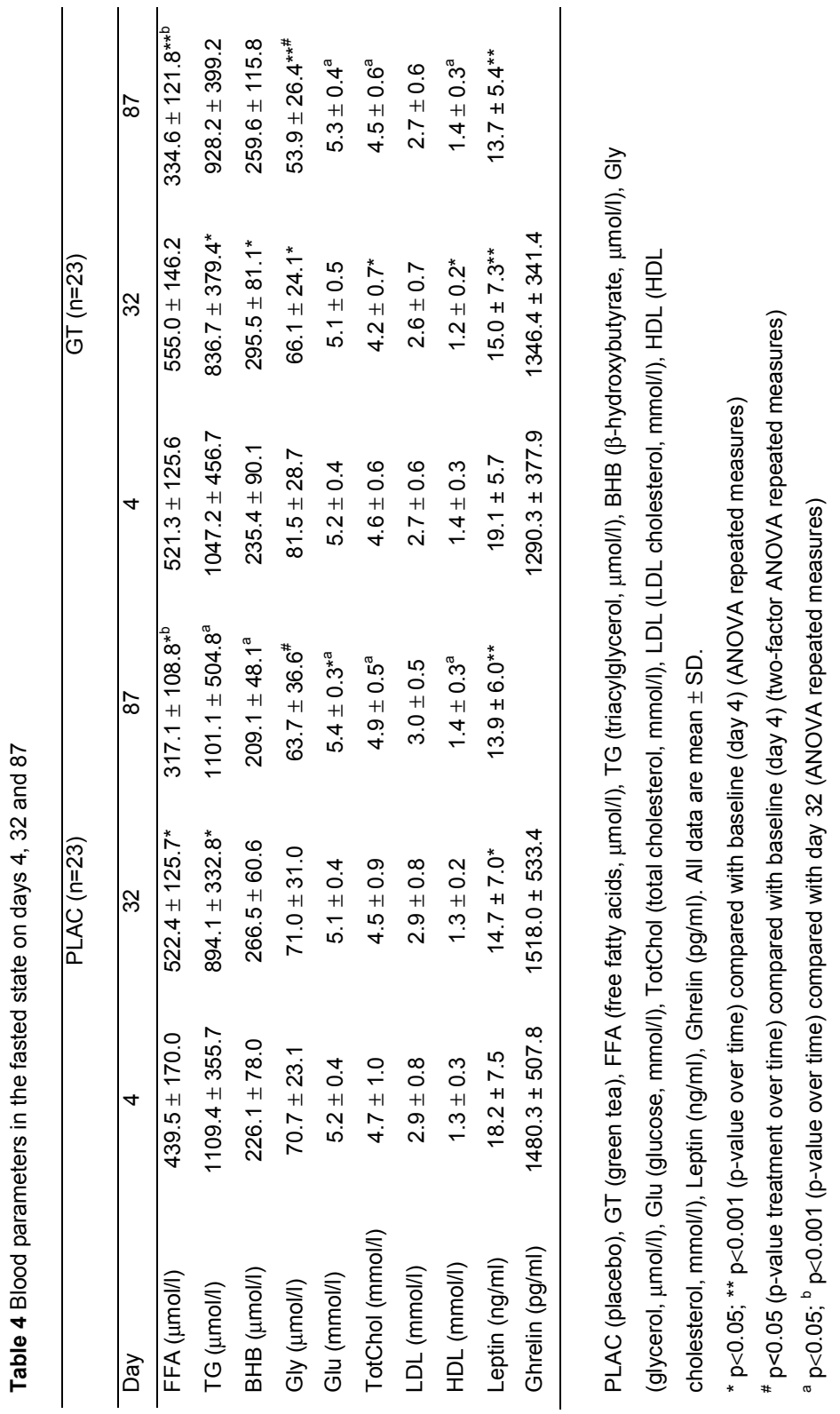


Leptin concentrations decreased in both groups during the LED since the level of leptin is positively correlated with body fat mass $(29,30)$. In the present study, there was a weak though significant correlation between the change in leptin and the change in FM. Ghrelin levels seemed to increase in both groups during the LED, although this increase was not significant. This trend is in line with other studies that showed an increase in ghrelin concentrations after weight loss (31-33).

Given that the changes in metabolic parameters were similar for the two groups, and were not significantly different (except for Gly), data from the PLAC and GT group have been combined to elucidate the relationships among changes in metabolic parameters and phases of weight loss. That even small weight loss can induce beneficial metabolic changes was observed in phase 1 but surprisingly not in phase 2 . It was intriguing and interesting to note that a certain number of metabolic benefits observed during phase 1 were reversed during the second phase of the treatment. The reversal effects of TG, FFA, BHB, Glu, HDL and Totchol are notable. In contrast to other studies that have shown a return to baseline concentrations after a weight-maintenance period but not a weight-loss period, we observed the reversal during the weight-loss period (19). An explanation is that in the present study, the weight loss was significantly higher in phase 1 compared to phase 2 , so phase 2 might be considered more like a weight-stabilization period. Figure 1a shows the reversal effect on TG. This effect can in part be explained by considering the dynamics of changes in FFA (figure 1b) and BHB (figure 1c). FFA increased during phase 1 showing increased fat oxidation and TG significantly decreased. When the energy balance became less negative in phase 2, TG rose again and FFA decreased. Thus, a negative energy balance resulting in modest weight loss induced an initial reduction in TG. However, marginal weight loss thereafter reversed this, showing homeostasis. The increase in FFA in phase 1 and the return to baseline in phase 2 (figure $1 \mathrm{~b}$ ) is also visible in the figure of BHB. BHB (figure 1c) is a ketone considered as a marker for fat oxidation. The dynamics of Glu parallel this phenomenon (figure 1d).

Dattilo et al. give a possible explanation for the reversal of HDL (34). During active weight loss (phase 1), tissue concentrations of lipoprotein lipase have been reported to decrease by $50-80 \%$ (35). Because of the decrease, TG-rich lipoprotein synthesis is likely diminished and VLDL-C catabolism impaired. Thus, transfer of lipids to HDL-C is limited, resulting in decreased HDL concentrations. However, when weight stabilizes at a reduced level (phase 2), lipoprotein lipase has been reported to increase, with an associated increased hydrolysis of VLDL-C and transfer of lipids to HDL-C (34). In the present study, when subjects were in a reduced and almost stabilized weight (phase 2), HDL was significantly increased $(p<0.001$, figure 2$)$.

Another beneficial health effect of modest weight loss is the reduction in systolic blood pressure after 12 weeks weight loss (table 3) (4). 
Since Dulloo et al. showed a fat-free mass sparing effect in his review of the Minnesota starvation experiments, we investigated the effect of phases of weight loss on body composition (18). The loss of FFM was $21 \%$ of the total weight loss in phase 1 which is typical (36). In phase 2, the loss of FFM was only $7 \%$ of the total weight loss. Although our results seem to reflect a progressive FFM sparing effect, the difference in rate of FFM loss between phase 1 and 2 did not reach statistical significance. The initial fatness of the subject and the severity of the weight reducing regimen are also factors in the composition of weight loss during weight reduction $(36,37)$. Furthermore, the mild weight loss in the present study is very different from starvation in lean men.

In conclusion, GT supplementation during a LED had no effect on health-related blood parameters. Initial improvements in several blood measures seen at day 32 were reversed by day 87 , despite continued weight loss. Modest weight loss improved HDL cholesterol and systolic blood pressure.

\section{ACKNOWLEDGEMENTS}

We thank Tanja Adam, Dave Mela, Ilse Nijs, Joan Senden, Jos Stegen and Loek Wouters for their contribution to the study. This study was supported by Unilever Food and Health Research Institute, Unilever R\&D Vlaardingen, Vlaardingen, The Netherlands. The Slim.Fast products were donated by Unilever Bestfoods Nederland BV.

\section{REFERENCES}

1. WHO. Obesity: preventing and managing the global epidemic. Report of a WHO consultation. World Health Organ Tech Rep Ser 2000;894:i-xii, 1-253.

2. Weight cycling: National task force on the prevention and treatment of obesity. JAMA 1994;272:1196-1202.

3. Stunkard AJ. Current views on obesity. Am J Med 1996;100:230-236.

4. Goldstein DJ. Beneficial health effects of modest weight loss. Int J Obes Relat Metab Disord 1992;16:397-415.

5. Van Gaal LF, Wauters MA, De Leeuw IH. The beneficial effects of modest weight loss on cardiovascular risk factors. Int J Obes Relat Metab Disord 1997;21 Suppl 1:S5-9.

6. Hase $T$, Komine $\mathrm{Y}$, Meguro $\mathrm{S}$, et al. Anti-obesity effects of tea catechins in humans. $\mathrm{J}$ Oleo Sci 2001;50:599-605.

7. Kao Y-H, Hiipakka RA, Liao S. Modulation of endocrine systems and food intake by green tea epigallocatechin gallate. Endocrinology 2000;141:980-987.

8. Chantre P, Lairon D. Recent findings of green tea extract AR25 (Exolise) and its activity for the treatment of obesity. Phytomedicine 2002;9:3-8. 
9. Dulloo AG, Duret C, Rohrer D, et al. Efficacy of a green tea extract rich in catechinpolyphenols and caffeine in increasing 24-h energy expenditure and fat oxidation in humans. Am J Clin Nutr 1999;70:1040-1045.

10. Dulloo AG, Seydoux J, Girardier L, Chantre P, Vandermander J. Green tea and thermogenesis: interactions between catechin-polyphenols, caffeine and sympathetic activity. Int J Obes 2000;24:252-258.

11. Berube-Parent S, Pelletier C, Dore J, Tremblay A. Effects of encapsulated green tea and Guarana extracts containing a mixture of epigallocatechin-3-gallate and caffeine on $24 \mathrm{~h}$ energy expenditure and fat oxidation in men. $\mathrm{Br} J$ Nutr 2005;94:432-6.

12. Diepvens K, Kovacs EM, Nijs IM, Vogels N, Westerterp-Plantenga MS. Effect of green tea on resting energy expenditure and substrate oxidation during weight loss in overweight females. Br J Nutr 2005;94:1026-34.

13. Murase T, Nagasawa A, Suzuki J, Hase T, Tokimitsu I. Beneficial effects of tea catechins on diet-induced obesity: stimulation of lipid catabolism in the liver. Int J Obes 2002;26:1459-1464.

14. Muramatsu K, Fukuyo M, Hara Y. Effect of green tea catechins on plasma cholesterol level in cholesterol-fed rats. J Nutr Sci Vitaminol (Tokyo) 1986;32:613-22.

15. Murase T, Nagasawa A, Hase T, Tokimitsu I, Shimasaki H, Itakura H. Dietary tea catechins reduce development of obesity accompanied with gene expression of lipidmetabolizing enzymes in mice. J Oleo Sci 2001;50:711-715.

16. Mitscher LA, Jung M, Shankel D, Dou JH, Steele L, Pillai SP. Chemoprotection: a review of the potential therapeutic antioxidant properties of green tea (Camellia sinensis) and certain of its constituents. Med Res Rev 1997;17:327-65.

17. Yang CS, Landau JM. Effects of tea consumption on nutrition and health. J Nutr 2000;130:2409-12.

18. Dulloo $A G$, Jacquet $J$. The control of partitioning between protein and fat during human starvation: its internal determinants and biological significance. Br J Nutr 1999;82:339-56.

19. Kovacs EM, Lejeune MP, Nijs I, Westerterp-Plantenga MS. Effects of green tea on weight maintenance after body-weight loss. Br J Nutr 2004;91:431-7.

20. van Dam RM, Feskens EJ. Coffee consumption and risk of type 2 diabetes mellitus. Lancet 2002;360:1477-8.

21. van Boxtel MP, Schmitt JA, Bosma $\mathrm{H}$, Jolles J. The effects of habitual caffeine use on cognitive change: a longitudinal perspective. Pharmacol Biochem Behav 2003;75:921-7.

22. Hulshof KF, Brussaard JH, Kruizinga AG, Telman J, Lowik MR. Socio-economic status, dietary intake and 10 y trends: the Dutch National Food Consumption Survey. Eur J Clin Nutr 2003;57:128-37.

23. Westerterp KR, Donkers JHHLM, M. FEWH, Boekhoudt P. Energy intake, physical activity and body weight: a simulation model. Br J Nutr 1995;73:337-347.

24. Westerterp KR, Wouters L, van Marken Lichtenbelt WD. The maastricht protocol for the measurement of body composition and energy expenditure with labeled water. Obes Res 1995;3 (suppl 1):49-57.

25. van Marken Lichtenbelt WD, Westerterp KR, Wouters $L$. Deuterium dilution as a method for determining total body water: effect of test protocol and sampling time. $\mathrm{Br} \mathrm{J}$ Nutr 1994;72:491-497.

26. Schoeller DA, van Santen E, Peterson DW, Dietz W, Jaspan J, Klein PD. Total body water measurement in humans with 180 and $2 \mathrm{H}$ labeled water. Am J Clin Nutr 1980;33:2686-2693.

27. Friedewald WT, Levy RI, Fredrickson DS. Estimation of the concentration of low-density lipoprotein cholesterol in plasma, without use of the preparative ultracentrifuge. Clin Chem 1972;18:499-502.

28. Kono S, Shinchi K, Wakabayashi K, et al. Relation of green tea consumption to serum lipids and lipoproteins in Japanese men. J Epidemiol 1996;6:128-33. 
29. Inui A. Cancer anorexia-cachexie syndrome: are neuropeptides the key? Cancer Res 1999;59:4493-4501.

30. Trayhurn P, Hoggard N, Mercer JG, Rayner DV. Leptin: fundamental aspects. Int J Obes 1999;23 (suppl 1):22-28.

31. Hansen TK, Dall R, Hosoda H, et al. Weight loss increases circulating levels of ghrelin in human obesity. Clin Endocrinol (Oxf) 2002;56:203-6.

32. Cummings DE, Weigle DS, Frayo RS, et al. Plasma ghrelin levels after diet-induced weight loss or gastric bypass surgery. N Engl J Med 2002;346:1623-30.

33. Stoeckli R, Chanda R, Langer I, Keller U. Changes of body weight and plasma ghrelin levels after gastric banding and gastric bypass. Obes Res 2004;12:346-50.

34. Dattilo AM, Kris-Etherton PM. Effects of weight reduction on blood lipids and lipoproteins: a meta-analysis. Am J Clin Nutr 1992;56:320-8.

35. Taskinen MR, Nikkila EA. Effects of caloric restriction on lipid metabolism in man: changes of tissue lipoprotein lipase activities and of serum lipoproteins. Atherosclerosis 1979;32:289-99.

36. Prentice AM, Goldberg GR, Jebb SA, Black AE, Murgatroyd PR, Diaz EO. Physiological responses to slimming. Proc Nutr Soc 1991;50:441-58.

37. Forbes GB. Lean body mass-body fat interrelationships in humans. Nutr Rev $1987 ; 45: 225-31$ 


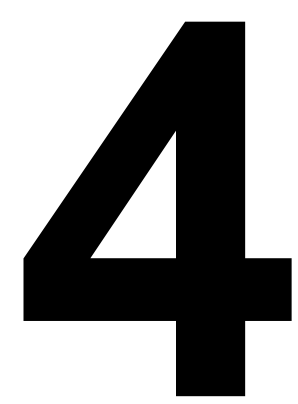

\section{Obesity and thermogenesis related to the consumption of caffeine, ephedrine, capsaicin, and green tea}

Kristel Diepvens, Klaas R Westerterp, Margriet S Westerterp-Plantenga Am J Physiol Regul Integr Comp Physiol 2007; 292: R77-R85 


\begin{abstract}
The global prevalence of obesity has increased considerably in the last decade. Tools for obesity management, including caffeine, ephedrine, capsaicin and green tea have been proposed as strategies for weight loss and weight maintenance, since they may increase energy expenditure and have been proposed to counteract the decrease in metabolic rate that is present during weight loss. A combination of caffeine and ephedrine has shown to be effective in long-term weight management, likely due to different mechanisms that may operate synergistically, e.g. respectively inhibiting the phosphodiesteraseinduced degradation of CAMP and enhancing the sympathetic release of catecholamines. However, adverse effects of ephedrine prevent the feasibility of this approach. Capsaicin has been shown to be effective, yet when it is used clinically it requires a strong compliance to a certain dosage, that has not been shown to be feasible yet. Also positive effects on body-weight management have been shown using green tea mixtures. Green tea, by containing both tea catechins and caffeine, may act through inhibition of catechol O-methyltransferase, and inhibition of phosphodiesterase. Here, the mechanisms may also operate synergistically. In addition, tea catechins have antiangiogenic properties that may prevent development of overweight and obesity. Furthermore, the sympathetic nervous system is involved in the regulation of lipolysis, and the sympathetic innervation of white adipose tissue may play an important role in the regulation of total body fat in general.
\end{abstract}

Keywords: sympathetic nervous system, energy expenditure, body weight, adverse effects 


\section{INTRODUCTION}

Overweight and obesity represent a threat to the health of populations in an increasing number of countries (1). Obesity is the outcome of a prolonged positive energy balance, due to an excess energy intake over energy expenditure $(E E)$, or vice versa. A negative energy balance is needed to produce weight loss and can be achieved by either decreasing intake or increasing expenditure. Tools for obesity management, including agents like caffeine, ephedrine, capsaicin and green tea have been proposed as strategies for weight loss and weight maintenance, since they may increase EE and have been proposed to counteract the decrease in metabolic rate that is present during weight loss.

This review examines the thermogenic properties of caffeine, ephedrine, capsaicin, and green tea in relation to the regulation of body weight. Furthermore, we discuss the role of the sympathetic nervous system in obesity.

THERMOGENIC PROPERTIES OF CAFFEINE, EPHEDRINE, CAPSAICIN, AND GREEN TEA IN THE PERSPECTIVE OF BODY WEIGHT REGULATION

Evidence for the mechanisms behind thermogenic properties of caffeine, ephedrine, capsaicin, and green tea is controversial and will be discussed more thoroughly in the final discussion. Here, a few most likely mechanisms for the observed thermogenic properties are included where appropriate.

\section{$\underline{\text { Caffeine }}$}

Caffeine as a thermogenic agent has been investigated for potential use in body weight reduction. A possible mechanism by which caffeine affects thermogenesis involves inhibiting the phosphodiesterase-induced degradation of intracellular cyclic AMP (cAMP) (2). Presently, possible evidence for the metabolic response to caffeine from mechanisms involving catecholaminergic stimulation of adipocyte or other cellular metabolism seems less convincing (35) (see also Discussion). Dulloo et al. concluded that the ability of methylxanthines to potentiate the thermogenic effect of ephedrine, particularly under conditions of caloric restriction, involves a minor contribution of adenosine antagonism, but it could mainly be explained by the inhibition of phosphodiesterase activity (6). Furthermore, it has been reported that the thermogenic impact of methylxanthines may be due to stimulation of substrate cycles like the Cori cycle (conversion of glycogen and glucose to lactate) and FFA-triglyceride cycle (7-9). Hepatic thermogenic processes triggered by lactate and the formation of triglyceride after hepatic reesterfication may explain the thermogenic contribution to the effect of caffeine (8). 
The stimulatory effect of caffeine on thermogenesis in man is well established $(3,8,10-12)$. Reduced food intake after caffeine consumption has been shown as well $(13,14)$. Thus caffeine can influence both $E E$ and energy intake. Although a nonhuman animal model showed that caffeine decreased body fat deposition (15), long-term intervention studies in humans showed no effect of caffeine consumption on body weight (16-18). A possible explanation for the lack of a long-term effect of caffeine is the development of insensitivity to its effects.

\section{Ephedrine}

Ephedra Sinica is a shrub native to China and Mongolia that contains sympathomimetic compounds referred to as ephedra alkaloids (19). Ephedra contains four isomers of which ephedrine is believed to be the alkaloid most responsible for the thermogenic effects (20). The thermogenic effect of ephedrine can be potentiated by caffeine $(16,21)$. Ephedrine mediates its thermogenic effects primarily by enhancement of sympathetic neuronal release of norepinephrine (NE) and epinephrine $(2,6)$. However, in vitro research showed that ephedrine stimulates brown adipocyte respiration directly via $\beta$ adrenoceptors (22). The rapid development of tolerance to the pressor effects, but not to its thermogenic effects, suggests that ephedrine influences the cardiovascular system via adrenergic mechanisms not entirely similar to those mediating thermogenesis. The suggestion, therefore, arises that thermogenesis is mediated only partly by classical adrenoceptors (23).

In a nonhuman animal study, treatment with ephedrine caused an increase in EE of about $10 \%$, which resulted in body weight loss and body fat loss (24). Intervention studies in humans showed similar effects (25-27). Thus ephedrine stimulates EE, and the effect is maintained for several months after administration (28).

The long-term use of ephedrine, however, does not necessarily lead to an increase in weight loss. Authors of the studies with favorable effects also reported studies without these effects $(16,29)$. The disparate findings may be due to the independent thermogenic actions of ephedrine, which enhance sympathetic neuronal release of $\mathrm{NE}$, to the stimulating effects of the $\beta$ adrenoceptors, or adaptation to ephinephrine after some months, unless ephedrine is combined with caffeine (see below).

\section{Ephedrine and caffeine}

The thermogenic effect of ephedrine can be markedly potentiated by methylxanthines, such as caffeine. Indeed, nonhuman animal studies showed that the effect after an ephedrine/caffeine mixture was larger than that with ephedrine or caffeine alone (24, 30-32). 
The interaction between ephedrine and caffeine in the effect on EE and weight loss has been confirmed in human studies $(7,16,33-37)$ (see Astrup et al. for review (38)). In a long-term study (6 months) of 167 obese subjects, the ephedrine/caffeine mixture group lost significantly more weight than the placebo group (39). Thus, with respect to the longer-term use of caffeine or ephedrine, it is theoretically recommended to combine these agents, based upon several longer-term experiments with a positive outcome and likely due to synergistic mechanisms. However, because of adverse effects (see below), the Food and Drug Administration (FDA) has banned the sale of ephedra-containing dietary supplements.

\section{$\underline{\text { Capsaicin }}$}

Capsaicin is the major pungent principle in red hot peppers. In rats, capsaicin has been reported to increase thermogenesis by dose dependently enhancing catecholamine secretion from the adrenal medulla $(40,41)$. It has been suggested that specific capsaicin-sensitive neurons are involved in this process (42). In addition, a warming action via adrenal catecholamine secretion is induced (43). Osaka et al. reported that the critical locus that mediates the capsaicin-induced thermogenesis in the brain stem is in the premotor area of sympathoadrenal preganglionic neurons, that is, the rostral ventrolateral medulla (44).

Yoshioka et al. observed in humans a larger increase in EE immediately after a meal containing red pepper vs. control. In addition, both nonhuman animal and human studies showed that the increase in thermogenesis is abolished after administration of $\beta$-adrenergic blockers such as propranolol $(40,45)$, which implies that capsaicin-induced thermogenesis is likely to be based upon $\beta$ adrenergic stimulation.

The nonhuman animal studies also showed that injection or oral treatment with capsaicin stimulates the sympathetic nervous system activity $(40-42,46)$. Thus administration of capsaicin favors an increase in lipid mobilization and a decrease in adipose tissue mass $(40,47)$.

In studies with humans, red pepper induced a reduction of ad libitum food intake and an increased postprandial EE and lipid oxidation (45, 48-52). Participants in a 2-week study, in which capsaicin was administered in combination with green tea and chicken essence, showed a reduction in body fat (53). In a long-term study, a relatively more sustained fat oxidation in the capsaicin group was observed compared with the placebo group, consistent with nonhuman animal studies (54). Weight regain, however, was similar in both groups and was assumed to be due to lack of full compliance, that is, ingestion of half the prescribed dosage (54). Thus the longer-term use of capsaicin may be limited by its strong pungency. A possible solution for this may be using $\mathrm{CH}-19$ Sweet. $\mathrm{CH}-19$ Sweet is the fruit of a nonpungent cultivar of pepper. In a human study, 
$\mathrm{CH}-19$ Sweet increased oxygen consumption and body temperature. These effects are thought to be caused by capsiate, which has a structure similar to capsaicin but no pungency $(55,56)$.

\section{Green tea}

Green tea contains high quantities of several polyphenolic components, such as epicatechin, epicatechin gallate, epigallocatechin, and, the most abundant and probably the most pharmacologically active, epigallocatechin gallate (EGCG) (57). The catechins in green tea may stimulate thermogenesis and fat oxidation through inhibition of catechol O-methyl-transferase (COMT), an enzyme that degrades NE (58). In humans, Dulloo et al. showed that a green tea extract results in an increase in EE and fat oxidation in the short-term (59). Green tea extract also contains caffeine. As described above, caffeine has been shown to stimulate thermogenesis. The fact that a green tea extract stimulates thermogenesis cannot be completely attributed to its caffeine content because the thermogenic effect of green tea is greater than an equivalent amount of caffeine (59). Indeed, studies in humans showed that green tea has thermogenic properties beyond that explained by its caffeine content per se (59, $60)$. Thus green tea, by containing both tea catechins and caffeine, may act at different steps of modulatory pathways, that is, via phosphodiesterase, and via COMT, and in this way exert a thermogenic and possibly an antiobesity effect $(57,59,61)$.

Studies in rats and mice showed an EGCG-induced reduction in food intake and/or an increase in $\operatorname{EE}(57,62,63)$. Studies conducted over 3 months or more showed that the consumption of tea catechins induces a notable reduction of body weight and body fat (64-68), and increases EE (69).

Green tea has also successfully been applied as an agent to limit weight regain after weight loss $(18,70)$. Here, the suggested mechanism is that green tea ingestion during a low-energy diet offsets the expected reduction in EE. Indeed, resting $E E$ as a function of fat-free mass and fat mass did not decrease significantly over time when green tea was ingested together with a low-energy diet (71).

A different approach to treatment of overweight and prevention of obesity is represented by the antiangiogenic effects of EGCG. It appears that modulation of angiogenic factors during development of adipose tissue plays an important functional role in prevention of obesity (72). The importance of this role is indicated by the phenomenon that angiogenic factors are elevated in overweight and obese individuals (73). Even an angiogenesis inhibitor, TNP-470, has been shown to prevent diet-induced and genetic obesity in mice (74). Findings suggest that adipose tissue growth is dependent on angiogenesis, which is similar to growth and organogenesis in other tissues. Leptin also appears to play a role in this process, as adipogenesis and angiogenesis are tightly 
correlated during the fat mass development. In vitro experiments have shown that leptin, via activation of the endothelial $O b-R$, generates a growth signal involving a tyrosine kinase-dependent intracellular pathway and promotes angiogenic processes. It is speculated that this leptin-mediated stimulation of angiogenesis might represent not only a key event in the settlement of obesity but may also contribute to the modulation of growth under physiological and pathophysiological conditions (75).

From this viewpoint, inhibition of angiogenesis may be a different pathway to prevent further development of overweight or obesity. Indeed, a mixture containing ascorbic acid, lysine, proline, and green tea extract appeared to have an inhibitory effect on critical parameters in angiogenesis (76). Mechanisms of antiangiogenic effects may involve inhibition of endothelial cell proliferation in response to stimulation with angiogenic growth factors (77). This can be exerted by inhibition of vascular endothelial growth factor (VEGF) receptors and suppression of vascular endothelial cadherin and protein kinase B (Akt) phosphorylation (78). Activation of certain transcription factors, such as NF- $\mathrm{BB}$ and E26 transformation-specific-1 and activating protein-1 is also blunted (79), and the production of metalloproteinases necessary for endothelial cell migration and invasion is attenuated (80-82). In addition, EGCG can also inhibit the production of VEGF, basic fibroblast growth factor, and interleukin-8 (IL-8) (83-85).

\section{ADVERSE EFFECTS OF THERMOGENIC AGENTS}

Caffeine appears to be a safe thermogenic agent for weight control. In adults, the short-term lethal dose for caffeine is estimated at 5-10 g per day (either intravenously or orally), which is equivalent to 75 cups of coffee, 125 cups of tea, or 200 cola beverages (86). Long-term ingestion of caffeine has been suggested to have some minor adverse effects on human health. Astrup et al. observed only small and insignificant changes in blood pressure and pulse rate after 100 and $200 \mathrm{mg}$ caffeine. In contrast, $400 \mathrm{mg}$ caffeine significantly increased systolic and diastolic blood pressure by an average value of 6.3 $\mathrm{mmHg}$. Furthermore, after $400 \mathrm{mg}$ caffeine, significantly more subjects reported side effects such as palpitation, anxiety, headache, restlessness, dizziness compared to placebo (8). Robertson et al. administrated $250 \mathrm{mg}$ oral caffeine to nine subjects who were not used to coffee. Systolic blood pressure increased $10 \mathrm{mmHg} 1 \mathrm{~h}$ after caffeine consumption. Heart rate showed a decrease after the first hour followed by an increase above baseline after $2 \mathrm{~h}$ (87). However, in a subsequent study that examined the chronic effects of caffeine ingestion (150 $\mathrm{mg} /$ day for 7 days), tolerance to these effects was developed after 1-4 days (88). Thus no long-term effects of caffeine on blood pressure, heart rate or plasma renin activity were demonstrated. Furthermore in the short term, Bracco 
et al. did not find a significantly altered heart rate during the day after $4 \mathrm{mg}$ caffeine per $\mathrm{kg}$ body weight was consumed 5 times daily (3). Accordingly, the use of caffeine is relatively safe, as it is quite certain that, although acute caffeine consumption may alter some cardiovascular variables, chronic ingestion of caffeine has little or no health consequences.

In contrast, a number of safety concerns have been raised about the use of ephedrine and ephedrine-containing mixtures. In a FDA-sponsored analysis, Haller \& Benowitz reviewed 140 reports of adverse events related to the use of dietary supplements containing ephedra alkaloids. They concluded that the use of ephedra alkaloids may pose a health risk to some persons, since ephedra and related alkaloids have been associated with adverse cardiovascular events (89). Haller et al. found that consumption of two doses (5 hours apart) of an ephedra/caffeine mixture $(325 / 90 \mathrm{mg}$ ) resulted in persistent increases in heart rate, blood pressure, and glucose concentrations, and decreases in potassium concentrations (90). Further evidence was found in a meta-analysis by Shekelle et al. to conclude that ephedrine and ephedra are associated with increased risk of psychiatric symptoms, autonomic symptoms, upper gastrointestinal symptoms, and heart palpitations (91). Given the frequency of reports of adverse cardiovascular effects, the FDA has banned the sale of ephedracontaining dietary supplements (92). Other research however, observed no significant adverse effects or only temporary minor adverse effects with the consumption of ephedra alkaloids $(16,33,34,37,39,93)$. Given these contrary results, consideration should be given to whether these adverse effects occur at a higher rate than that of a matched, untreated group (39). Thus the use of products containing ephedra alkaloids remains controversial and warrants further research.

As mentioned previously, the long-term use of capsaicin may be limited by its strong pungency. An alternative is using $\mathrm{CH}-19$ Sweet, the nonpungent cultivar of red pepper (55).

Green tea has been widely consumed in China and Japan for many centuries and is regarded as safe. A possible side effect of green tea consumption is a minor increase in blood pressure as seen by Berube-Parent et al. They observed a nonsignificant increase $(7 \mathrm{mmHg})$ in $24 \mathrm{~h}$ systolic blood pressure accompanied by a significant increase $(5 \mathrm{mmHg})$ in $24 \mathrm{~h}$ diastolic blood pressure. No increase in heart rate was seen (60). This small short-term increase in blood pressure induced by green tea might be neglected since systolic blood pressure, diastolic blood pressure, and heart rate were not affected by green tea in other short-term $(59)$ or long-term research $(66,71)$.

Taking adverse effects into account, although the use of ephedrine or capsaicin in treatments seems effective, it is contraindicated by adverse effects of these agents. Thus, the remaining combination of caffeine and green tea may be recommended for body-weight management. 


\section{DISCUSSION: OBESITY AND SYMPATHETIC NERVOUS SYSTEM ACTIVITY}

Convincing evidence for body-weight management using caffeine, green tea, ephedrine and capsaicin has been shown. Caffeine stimulates thermogenesis by inhibiting the phosphodiesterase-induced degradation of CAMP, and catechins in green tea through inhibition of COMT, an enzyme that degrades $\mathrm{NE}$. Moreover, tea catechins have antiangiogenic effects that may prevent development of overweight and obesity. The thermogenic effect of caffeine can be potentiated by ephedrine, which mediates its effects by enhancement of sympathetic neuronal release of NE, or by stimulating $\beta$-adrenoceptors directly. Furthermore, capsaicin may increase thermogenesis by enhancing catecholamine secretion from the adrenal medulla.

The sympathetic nervous system (SNS) has been considered as an essential component of the autonomic nervous system, playing an important role in maintaining energy homeostasis by hormonal and neural control (94-96). The SNS has been described as a complex regulatory system, involving direct effects of sympathetic nerves, which supply most body tissues and, indirect effects of the catecholamines, epinephrine, and, to a lesser extent, NE, which are released into the blood from the adrenal medulla (97). It is important to realize that the SNS does not produce uniform activation of all body tissues, which have a sympathetic nerve supply, but rather that in any particular situation, there is selective activation of specific tissues or systems, with either no effect or even inhibition of other areas (97). It should be appreciated, therefore, that renal or brown fat or muscle changes in electrophysiological activity of efferent nerves innervating these tissues is specific to that tissue, as well as the NE turnover. In addition, there are not only differences in SNS outflow to different tissues but also within the same tissue type (98). For instance, among white adipose tissue (WAT) depots in humans, the measures of sympathetic drive can be quite different (98).

Sympathetic activity to effector organs of metabolism is considered to be a key factor for maintenance of body weight (98). Effects imply thermogenic effects of increased sympathetic activity, as well as regulation of fat metabolism.

Examples of thermogenic effects are sympathomimetic-induced changes in energy balance through increases in EE (99-101). It has been shown that SNS activity (determined by NE concentrations) modulates resting EE (resting metabolic rate measured after an overnight fast), the largest component of daily EE $(102,103)$. Since NE has the ability to increase the use of ATP, for example, through ion pumping and substrate cycling, or to increase the rate of mitochondrial oxidation with poor coupling of ATP synthesis leading to increased heat production, it is speculated that the SNS is involved in thermogenesis $(95,96)$. Indeed, human studies have demonstrated that thermogenesis, measured by whole body calorimetry, increased significantly 
during the infusion of NE or epinephrine $(104,105)$. Tissue-specific effects included an increase in skeletal muscle oxygen uptake, and the triglyceride-fatty acid cycle contributed to the NE-induced increase in EE of nonmuscular tissue in healthy, normal-weight subjects $(104,105)$. The thermogenic response to catecholamines has been shown to be mediated by a combination of $\beta 1-, \beta 2$ and $\beta 3$-receptors (38). The activity of the SNS has been assessed in several ways, including plasma catecholamine levels, catecholamine turnover, urinary catecholamine excretion, and muscle sympathetic nerve activity. However, results are contradictory because of methodological differences $(106,107)$. For instance, the viewpoint of Eikelis and Esler is that earlier ideas that SNS activity is low in human obesity, contributing to weight gain through the absence of sympathetically mediated thermogenesis should be discounted. Application of new techniques, such as sympathetic nerve recording and isotope dilution, quantifying neurotransmitter release from sympathetic nerves, have shown that peripheral sympathetic outflows to, for example, the kidneys and skeletal muscle vasculature are activated in obese humans (106). In addition, according to Eikelis and Esler, the demonstration that the suppressed sympathetic tone characterizing animal models of obesity, largely based on brown fat recordings (108), is not present in humans weakens the case for the use of $\beta 3$-adrenergic agonists as thermogenic agents to facilitate weight loss. Moreover, Dulloo et al. (2) proposed that a possible mechanism by which caffeine affects thermogenesis involves inhibiting the phosphodiesterase-induced degradation of intracellular cyclic AMP (cAMP) and to a lesser extent antagonizing adenosine-inhibitory effects on NE release. Also, other human research did not observe a smaller thermogenic effect after treatment with $\beta$-blockers (5). Thus thermogenesis can be affected by caffeine and green tea-caffeine mixtures via pathways different from antagonizing adenosine-inhibitory effects on NE release. These pathways are inhibiting the phosphodiesterase-induced degradation of intracellular CAMP (caffeine) and inhibition of COMT, an enzyme that degrades NE (catechins).

From our viewpoint, stronger evidence is present with respect to sensitivity of SNS to positive energy balances. In nonhuman animals, Landsberg and Young showed that SNS activation is a key element of the counterregulatory response to excessive food intake in heart and brown adipose tissue (109-111). Moreover, human studies have demonstrated that SNS activation is an important aspect of the response to overfeeding (112-114). McCargar et al. showed that urinary NE levels were increased during overeating, suggesting sympathetic activation (112). SNS activation increases thermogenesis and wastes excess energy as heat, and thereby compensates for surplus energy intake. The result is the prevention of body weight gain. This hypothesis is also supported by Vaz et al. and Grassi et al., who indicated in humans that, on the basis of sympathetic nerve recording in skeletal muscle and skin areas and isotope dilution-derived measurements of renal and cardiac NE release to 
plasma, human obesity is accompanied by activation of the SNS rather than its suppression $(115,116)$. In human obesity, the whole body NE spillover rate, which is an indication of overall sympathetic activity, is typically normal (116118). Renal NE spillover, indicative of renal sympathetic activity is approximately doubled, while cardiac sympathetic activity is reduced $(98,116-$ 118).

This renal sympathetic activation is primarily pathophysiological in obesityrelated hypertension. The higher renal and lower cardiac sympathetic nerve activity in overweight people represents a differentiation of central nervous system sympathetic nerves and reduced cardiac sympathetic nerve firing. One of the candidates for activation of renal sympathetic outflow is hyperleptinemia, given that administration of leptin in animal models increases renal sympathetic activity (119).

Only during negative energy balance, SNS activity seems to be negatively affected. Spraul et al. measured fasting skeletal muscle sympathetic nerve activity and its relation with EE. In this condition, obese subjects are acutely in a negative energy balance. They showed in obesity-prone subjects that a low resting muscle sympathetic nerve activity (an indicator of reduced SNS activity) was related to a reduced EE, which is responsible for weight gain and obesity (120). Furthermore, a negative energy balance was associated with a reduction of sympathetic activity at the muscular level, which reduces resting EE and thus prolongs survival. In addition, a negative energy balance was associated with an increased lipolysis in response to catecholamines in adipose tissue (121123).

The SNS undoubtedly plays a role in the regulation of fat metabolism. Given the importance of muscle lipolysis for EE, low sympathetically mediated EE is considered as being a risk factor for body weight gain (124). Several studies, however, have reported increased musce sympathetic nerve activity (MSNA) in obese subjects $(125,126)$, while total body NE spillover is similar in lean and obese subjects (118). Nevertheless, the combination of these effects in a compensatory mechanism is possible, that is, an initially low sympathetic activity results in fat accumulation, which in turn augments sympathetic outflow through compensatory endocrine mechanisms (98). One such compensatory mechanism could be increased leptin release from larger fat depots, an endocrine signal known to increase sympathetic activity via hypothalamic mechanisms in rats $(127,128)$ (see below). Moreover, it should be stressed that sympathetic excitation may be an unspecific secondary consequence of obesity, e.g., the obstructive sleep apnea syndrome that increases MSNA (119). Thus when discussing the role of sympathetic activity in the control of fat and body mass, it must be taken into account that the findings of unaltered total body NE spillover and increased MSNA in obesity do not unequivocally exclude the possibility that a selective reduction in sympathetic discharge to fat depots could contribute to an accumulation of fat mass and weight gain in general (98). 
Physiological and neurological evidence strongly suggests that the SNS is involved in the regulation of lipolysis (129). Bartness et al. reviewed the SNS innervation of WAT. They suggest that in addition to the stimulation of lipolysis by catecholamines in vitro (130), implying that lipid mobilization may be primarily controlled via blood-borne catecholamines, SNS innervation of WAT takes place directly (129). They provide extensive evidence that supports the role of the SNS innervation of WAT in lipid mobilization (129). The physiological evidence includes electrophysiological recording, denervation studies, and electrical stimulation of the nerves innervating this tissue. The neuroanatomical evidence that supports the role of the SNS innervation of WAT is highlighted by the use of a viral transneuronal tract tracer to define the chain of functionally connected neurons that comprise the SNS outflow from brain to WAT. Bartness and Bamshad conclude that the direct innervation of WAT by the SNS could play a role in the regulation of total body fat in general $(98,129)$. There are precious few studies, however, where WAT electrical activity or NE turnover is measured. When measured, it is often the case that among WAT depots, these measures of sympathetic drive can be quite different. Thus the role of sympathetic nerves in the control of lipolysis in human WAT, which is sparsely innervated, has not been fully clarified (98).

Dodt et al. provide a human in vivo model for further studies of neural control of lipolysis (98). They combined intraneural electrical stimulation of human cutaneous nerve fascicles supplying WAT on the thigh with microdialytic evaluation of glycerol release within the territory innervated by the stimulated nerve fascicle. They demonstrated that lipolysis can be neurally induced and that this neural effect can be blunted in obese subjects (98). These are the first steps to clarify the discrepancies between in vivo and in vitro findings concerning human lipolysis, that is, that lean and obese do not differ in relative lipolysis (131), but that isolated fat cells from obese subjects show an increased basal lipolysis, a reduced antilipolytic response to insulin and to $\beta$-adrenoceptor stimulation (98).

As indicated above, there may be a two-way interaction between leptin and the SNS, perhaps constituting a regulatory feedback loop, with leptin acting within the hypothalamus to cause activation of central sympathetic outflow and stimulation of adrenal medullary release of epinephrine (132) and conversely with the SNS-inhibiting leptin release (133).

It is assumed, from the increases in renal nerve activity, as well as brown fat, that leptin turns on the SNS outflow (134). This is likely very tissue-specific, as leptin administration did not significantly affect NE turnover in WAT (134). On the other hand, it has been demonstrated that the SNS inhibits leptin release from WAT $(133,135,136)$. In addition, Ramsey et al. showed that administration of an ephedrine/caffeine mixture resulted in decreased serum leptin concentrations in monkeys (32). Others have shown that activation of $\beta_{3^{-}}$ adrenergic receptors suppresses leptin gene expression (135-137). 
Accordingly, the stimulating effect of sympathomimetic agents on the SNS may lead to a downregulation of leptin release $(18,32,138)$. Consequent decreased leptin concentrations may increase food intake, which would diminish the effect of SNS activation on weight loss. However, the satiety effect of, for example, caffeine appeared to dominate the possible effect of downregulated leptin in overweight subjects, since the subjects with highest habitual caffeine intake were significantly more satiated and lost more weight (18). Findings by Eikelis et al. in humans, however, do not support the proposition that the SNS inhibits leptin release (139). They examined the leptin overflow from different organs and reported that whole body leptin secretion rate correlated directly with whole body and renal NE spillover, indicating that hyperleptinemia may be the prime mover underlying the sympathetic nervous activation present in human obesity and particularly in the sympathetic outflow to the kidneys (140). In addition, they found that the whole body leptin secretion rate was unrelated to cardiac NE spillover or to the secretion of epinephrine.

Taken together, evidence for the following thermogenic mechanisms has been shown: caffeine stimulates thermogenesis by inhibiting the phosphodiesteraseinduced degradation of cAMP, and catechins in green tea through inhibition of COMT. Moreover, tea catechins have antiangiogenic effects, which may prevent development of overweight and obesity. This is related to leptin, since leptin has been shown to promote angiogenesis. Ephedrine and capsaicin mediate their effects by enhancement of sympathetic release of catecholamines or by stimulating $\beta$-adrenoceptors directly (ephedrine). In addition, the SNS is involved in the regulation of lipolysis, and the SNS innervation of WAT may play an important role in the regulation of total body fat in general.

\section{CONCLUSION}

In conclusion, treatment of overweight, and thus prevention of obesity, requires a multifactorial approach. This may be possible by applying sympathomimetics such as caffeine, ephedrine, capsaicin, and green tea. A combination of caffeine and ephedrine has shown to be effective in long-term weight management, likely due to different mechanisms that may operate synergistically, for example, inhibiting the phosphodiesterase-induced degradation of cAMP and enhancing the sympathetic release of catecholamines, respectively. However, adverse effects of ephedrine prevent the feasibility of this approach. Capsaicin has been shown to be effective, yet when it is used clinically, it requires a strong compliance to a certain dosage, which has not been shown to be feasible yet. Also, positive effects on bodyweight management have been shown using green tea. Green tea, by containing both tea catechins and caffeine, may act through inhibition of COMT and inhibition of phosphodiesterase. Here, the mechanisms may also operate 
synergistically. In addition, tea catechins have antiangiogenic properties that may prevent development of overweight and obesity. This is related to leptin, as leptin has been shown to promote angiogenesis. Furthermore, the SNS is involved in the regulation of lipolysis, and the SNS innervation of WAT may play an important role in the regulation of total body fat in general.

\section{REFERENCES}

1. WHO. Obesity: preventing and managing the global epidemic. Report of a WHO consultation. World Health Organ Tech Rep Ser 2000;894:i-xii, 1-253.

2. Dulloo AG. Ephedrine, xanthines and prostaglandin-inhibitors: actions and interactions in the stimulation of thermogenesis. Int J Obes Relat Metab Disord 1993;17 Suppl 1:S35-40.

3. Bracco D, Ferrarra J-M, Arnaud MJ, Jequier E, Schutz Y. Effects of caffeine on energy metabolism, heart rate, and methylxanthine metabolism in lean and obese women. Am J Physiol 1995;269:E671-E678.

4. van Soeren M, Mohr T, Kjaer M, Graham TE. Acute effects of caffeine ingestion at rest in humans with impaired ephedrine responses. J Appl Physiol 1996;80:999-1005.

5. Jung RT, Shetty PS, James WPT, Barrand MA, Callingham BA. Caffeine: its effect on catecholamines and metabolism in lean and obese humans. Clin Sci 1981;60:527-535.

6. Dulloo AG, Seydoux J, Girardier L. Potentiation of the thermogenic antiobesity effects of ephedrine by dietary methylxanthines: adenosine antagonism or phosphodiesterase inhibition. Metabolism 1992;41:1233-1241.

7. Astrup A, Toubro S. Thermogenic, metabolic, and cardiovascular responses to ephedrine and caffeine in man. Int J Obes Relat Metab Disord 1993;17 Suppl 1:S41-3.

8. Astrup A, Toubro S, Cannon S, Hein P, Breum L, Madsen J. Caffeine: a double-blind, placebo-controlled study of its thermogenic, metabolic, and cardiovascular effects in healthy volunteers. Am J Clin Nutr 1990;51:759-767.

9. Yoshida T, Sakane N, Umekawa T, Kondo M. Relationship between basal metabolic rate, thermogenic response to caffeine, and body weight loss following combined low calorie and exercise treatment in obese women. Int J Obes 1994;18:345-350.

10. Acheson KJ, Zahorska-Markiewics B, Pittet P, Anantharaman K, Jequier E. Caffeine and coffee: their influence on metabolic rate and substrate oxidation in normal weight and obese individuals. Am J Clin Nutr 1980;33:989-997.

11. Hollands MA, Arch JRS, Phil D, Cawthorne MA. A simple apparatus for comparative measurements of energy expenditure in human subjects: the thermic effect of caffeine. Am J Clin Nutr 1981;34:2291-2294.

12. Dulloo AG, Geissler CA, Horton T, Collins A, Miller DS. Normal caffeine consumption: influence on thermogenesis and daily energy expenditure in lean and postobese human volunteers. Am J Clin Nutr 1989;49:44-50.

13. Racotta IS, Leblanc J, Richard D. The effect of caffeine on food intake in rats: involvement of corticotropin-releasing factor and the sympatho-adrenal system. Pharmacology Biochemistry and Behavior 1994;48:887-892.

14. Tremblay A, Masson E, Leduc S, Houde A, Despres J-P. Caffeine reduces spontaneous energy intake in men but not in women. Nutr Res 1988;8:553-558.

15. Chen MD, Lin WH, Song YM, Lin PY, Ho LT. Effect of caffeine on the levels of brain serotonin and catecholamine in the genetically obese mice. Zhonghua Yi Xue Za Zhi (Taipei) 1994;53:257-61.

16. Astrup A, Breum L, Toubro S, Hein P, Quaade F. The effect and safety of an ephedrine/caffeine compound compared to ephedrine, caffeine and placebo in obese subjects on an energy-restricted diet. A double blind trial. Int J Obes 1992;16:269-277. 
17. Pasman WJ, Westerterp-Plantenga MS, Saris WHM. The effectiveness of long-term supplementation of carbohydrate, chromium, fibre and caffeine on weight maintenance. Int J Obes 1997;21:1143-1151.

18. Westerterp-Plantenga MS, Lejeune MP, Kovacs EM. Body weight loss and weight maintenance in relation to habitual caffeine intake and green tea supplementation. Obes Res 2005;13:1195-204.

19. Saper RB, Eisenberg DM, Phillips RS. Common dietary supplements for weight loss. Am Fam Physician 2004;70:1731-8.

20. Vansal SS, Feller DR. Direct effects of ephedrine isomers on human beta-adrenergic receptor subtypes. Biochem Pharmacol 1999;58:807-10.

21. Dulloo AG, Miller DS. The thermogenic properties of ephedrine/methylxanthine mixtures: human studies. Int J Obes 1986;10:467-81.

22. Bukowiecki L, Jahjah L, Follea N. Ephedrine, a potential slimming drug, directly stimulates thermogenesis in brown adipocytes via beta-adrenoreceptors. Int J Obes 1982;6:343-50

23. Dulloo AG, Seydoux J, Girardier L. Peripheral mechanisms of thermogenesis induced by ephedrine and caffeine in brown adipose tissue. Int J Obes 1991;15:317-26.

24. Dulloo AG, Miller DS. The thermogenic properties of ephedrine/methylxanthine mixtures: animal studies. Am J Clin Nutr 1986;43:388-94.

25. Pasquali R, Casimirri F, Melchionda N, et al. Effects of chronic administration of ephedrine during very-low-calorie diets on energy expenditure, protein metabolism and hormone levels in obese subjects. Clin Sci (Lond) 1992;82:85-92.

26. Pasquali R, Cesari MP, Melchionda N, Stefanini C, Raitano A, Labo G. Does ephedrine promote weight loss in low-energy-adapted obese women? Int J Obes 1987;11:163-8.

27. Shannon JR, Gottesdiener K, Jordan J, et al. Acute effect of ephedrine on 24-h energy balance. Clin Sci (Lond) 1999;96:483-91.

28. Astrup A, Lundsgaard C, Madsen J, Christensen NJ. Enhanced thermogenic responsiveness during chronic ephedrine treatment in man. Am J Clin Nutr 1985;42:8394.

29. Pasquali R, Baraldi G, Cesari MP, et al. A controlled trial using ephedrine in the treatment of obesity. Int J Obes 1985;9:93-8.

30. Tulp OL, Buck CL. Caffeine and ephedrine stimulated thermogenesis in LA-corpulent rats. Comp Biochem Physiol C 1986;85:17-9.

31. Dulloo AG, Miller DS. Reversal of obesity in the genetically obese fa/fa Zucker rat with an ephedrine/methylxanthines thermogenic mixture. J Nutr 1987;117:383-9.

32. Ramsey JJ, Colman RJ, Swick AG, Kemnitz JW. Energy expenditure, body composition, and glucose metabolism in lean and obese rhesus monkeys treated with ephedrine and caffeine. Am J Clin Nutr 1998;68:42-51.

33. Toubro S, Astrup AV, Breum L, Quaade F. safety and efficacy of long-term treatment with ephedrine, caffeine and an ephedrine/caffeine mixture. Int J Obes 1993;17 (suppl 1):S69S72.

34. Toubro S, Astrup AV, Breum L, Quaade F. The acute and chronic effects of ephedrine/caffeine mixtures on energy expenditure and glucose metabolism in humans. Int J Obes 1993;17 (suppl 3):S73-S77.

35. Horton TJ, Geissler CA. Post-prandial thermogenesis with ephedrine, caffeine and aspirin in lean, pre-disposed obese and obese women. Int $\mathrm{J}$ Obes Relat Metab Disord 1996;20:91-7.

36. Molnar D, Torok K, Erhardt E, Jeges S. Safety and efficacy of treatment with an ephedrine/caffeine mixture. The first double-blind placebo-controlled pilot study in adolescents. Int J Obes Relat Metab Disord 2000;24:1573-8.

37. Boozer CN, Nasser JA, Heymsfield SB, Wang V, Chen G, Solomon JL. An herbal supplement containing Ma Huang-Guarana for weight loss: a randomized, double-blind trial. Int J Obes Relat Metab Disord 2001;25:316-24. 
38. Astrup A. Thermogenic drugs as a strategy for treatment of obesity. Endocrine 2000;13:207-12.

39. Boozer CN, Daly PA, Homel P, et al. Herbal ephedra/caffeine for weight loss: a 6-month randomized safety and efficacy trial. Int J Obes Relat Metab Disord 2002;26:593-604.

40. Kawada T, Watanabe T, Takaishi T, Tanaka T, Iwai K. Capsaicin-induced beta-adrenergic action on energy metabolism in rats: influence of capsaicin on oxygen consumption, the respiratory quotient, and substrate utilization. Proc Soc Exp Biol Med 1986;183:250-6.

41. Watanabe T, Kawada T, Yamamoto M, Iwai K. Capsaicin, a pungent principle of hot red pepper, evokes catecholamine secretion from the adrenal medulla of anesthetized rats. Biochem Biophys Res Commun 1987;142:259-64.

42. Watanabe T, Kawada T, Kurosawa M, Sato A, Iwai K. Adrenal sympathetic efferent nerve and catecholamine secretion excitation caused by capsaicin in rats. Am J Physiol 1988;255:E23-7.

43. Kawada T, Sakabe S, Watanabe T, Yamamoto M, Iwai K. Some pungent principles of spices cause the adrenal medulla to secrete catecholamine in anesthetized rats. Proc Soc Exp Biol Med 1988;188:229-33.

44. Osaka T, Lee TH, Kobayashi A, Inoue S, Kimura S. Thermogenesis mediated by a capsaicin-sensitive area in the ventrolateral medulla. Neuroreport 2000;11:2425-8.

45. Yoshioka M, Lim K, Kikuzato S, et al. Effects of red-pepper diet on the energy metabolism in men. J Nutr Sci Vitaminol (Tokyo) 1995;41:647-56.

46. Yoshida T, Yoshioka K, Wakabayashi Y, Nishioka H, Kondo M. Effects of capsaicin and isothiocyanate on thermogenesis of interscapular brown adipose tissue in rats. J Nutr Sci Vitaminol (Tokyo) 1988;34:587-94.

47. Kawada T, Hagihara K, Iwai K. Effects of capsaicin on lipid metabolism in rats fed a high fat diet. J Nutr 1986;116:1272-8.

48. Henry CJ, Emery B. Effect of spiced food on metabolic rate. Hum Nutr Clin Nutr 1986;40:165-8.

49. Yoshioka M, St-Pierre S, Suzuki M, Tremblay A. Effects of red pepper added to high-fat and high-carbohydrate meals on energy metabolism and substrate utilization in Japanese women. Br J Nutr 1998;80:503-10.

50. Yoshioka M, St-Pierre S, Drapeau V, et al. Effects of red pepper on appetite and energy intake. Br J Nutr 1999;82:115-23.

51. Yoshioka M, Doucet E, Drapeau V, Dionne I, Tremblay A. Combined effects of red pepper and caffeine consumption on $24 \mathrm{~h}$ energy balance in subjects given free access to foods. Br J Nutr 2001;85:203-211.

52. Westerterp-Plantenga MS, Smeets A, Lejeune MP. Sensory and gastrointestinal satiety effects of capsaicin on food intake. Int J Obes (Lond) 2005;29:682-8.

53. Tsi D, Nah AK, Kiso Y, Moritani T, Ono H. Clinical study on the combined effect of capsaicin, green tea extract and essence of chicken on body fat content in human subjects. J Nutr Sci Vitaminol (Tokyo) 2003;49:437-41.

54. Lejeune MPGM, Kovacs EMR, Westerterp-Plantenga MS. Effect of capsaicin on substrate oxidation and weight maintenance after modest body-weight loss in human subjects. $\mathrm{Br} \mathrm{J}$ Nutr 2003;90:1-10.

55. Ohnuki K, Niwa S, Maeda S, Inoue N, Yazawa S, Fushiki T. CH-19 sweet, a non-pungent cultivar of red pepper, increased body temperature and oxygen consumption in humans. Biosci Biotechnol Biochem 2001;65:2033-6.

56. Ohnuki K, Haramizu S, Oki K, Watanabe T, Yazawa S, Fushiki T. Administration of capsiate, a non-pungent capsaicin analog, promotes energy metabolism and suppresses body fat accumulation in mice. Biosci Biotechnol Biochem 2001;65:2735-40.

57. Kao Y-H, Hiipakka RA, Liao S. Modulation of endocrine systems and food intake by green tea epigallocatechin gallate. Endocrinology 2000;141:980-987. 
58. Borchardt RT, Huber JA. Catechol O-methyltransferase. Structure-activity relationships for inhibition by flavonoids. J Med Chem 1975;18:120-122.

59. Dulloo AG, Duret C, Rohrer D, et al. Efficacy of a green tea extract rich in catechinpolyphenols and caffeine in increasing 24-h energy expenditure and fat oxidation in humans. Am J Clin Nutr 1999;70:1040-1045.

60. Berube-Parent S, Pelletier C, Dore J, Tremblay A. Effects of encapsulated green tea and Guarana extracts containing a mixture of epigallocatechin-3-gallate and caffeine on $24 \mathrm{~h}$ energy expenditure and fat oxidation in men. $\mathrm{Br} J$ Nutr 2005;94:432-6.

61. Dulloo AG, Seydoux J, Girardier L, Chantre P, Vandermander J. Green tea and thermogenesis: interactions between catechin-polyphenols, caffeine and sympathetic activity. Int J Obes 2000;24:252-258.

62. Choo JJ. Green tea reduces body fat accretion caused by high-fat diet in rats through beta-adrenoceptor activation of thermogenesis in brown adipose tissue. J Nutr Biochem 2003;14:671-6.

63. Zheng G, Sayama K, Okubo T, Juneja LR, Oguni I. Anti-obesity effects of three major components of green tea, catechins, caffeine and theanine, in mice. In Vivo 2004;18:5562.

64. Hase $T$, Komine $\mathrm{Y}$, Meguro $\mathrm{S}$, et al. Anti-obesity effects of tea catechins in humans. J Oleo Sci 2001;50:599-605.

65. Nagao T, Meguro S, Soga S, et al. Tea catechins suppress accumulation of body fat in humans. J Oleo Sci 2001;50:717-728.

66. Chantre P, Lairon D. Recent findings of green tea extract AR25 (Exolise) and its activity for the treatment of obesity. Phytomedicine 2002;9:3-8.

67. Tsuchida $\mathrm{T}$, Itakura $\mathrm{H}$, Nakamura $\mathrm{H}$. Reduction of body fat in humans by long-term ingestion of catechins. Prog Med 2002;22:2189-2203.

68. Nagao T, Komine $\mathrm{Y}$, Soga $\mathrm{S}$, et al. Ingestion of a tea rich in catechins leads to a reduction in body fat and malondialdehyde-modified LDL in men. Am J Clin Nutr 2005;81:122-9.

69. Harada U, Chikama A, Saito S, et al. Effects of the long-term ingestion of tea catechins on energy expenditure and dietary fat oxidation in healthy subjects. J Health Sci 2005;51:248-252.

70. Kovacs EM, Lejeune MP, Nijs I, Westerterp-Plantenga MS. Effects of green tea on weight maintenance after body-weight loss. Br J Nutr 2004;91:431-7.

71. Diepvens K, Kovacs EM, Nijs IM, Vogels N, Westerterp-Plantenga MS. Effect of green tea on resting energy expenditure and substrate oxidation during weight loss in overweight females. Br J Nutr 2005;94:1026-34.

72. Voros G, Maquoi E, Demeulemeester D, Clerx N, Collen D, Lijnen HR. Modulation of angiogenesis during adipose tissue development in murine models of obesity. Endocrinology 2005; 146:4545-54.

73. Silha JV, Krsek M, Sucharda P, Murphy LJ. Angiogenic factors are elevated in overweight and obese individuals. Int J Obes (Lond) 2005;29:1308-14.

74. Brakenhielm E, Cao R, Gao B, et al. Angiogenesis inhibitor, TNP-470, prevents dietinduced and genetic obesity in mice. Circ Res 2004;94:1579-88.

75. Bouloumie A, Drexler HC, Lafontan M, Busse R. Leptin, the product of Ob gene, promotes angiogenesis. Circ Res 1998;83:1059-66.

76. Roomi MW, Roomi N, Ivanov V, Kalinovsky T, Niedzwiecki A, Rath M. Inhibitory effect of a mixture containing ascorbic acid, lysine, proline and green tea extract on critical parameters in angiogenesis. Oncol Rep 2005;14:807-15.

77. Kojima-Yuasa A, Hua JJ, Kennedy DO, Matsui-Yuasa I. Green tea extract inhibits angiogenesis of human umbilical vein endothelial cells through reduction of expression of VEGF receptors. Life Sci 2003;73:1299-313. 
78. Tang FY, Nguyen N, Meydani M. Green tea catechins inhibit VEGF-induced angiogenesis in vitro through suppression of VE-cadherin phosphorylation and inactivation of Akt molecule. Int J Cancer 2003;106:871-8.

79. Lai HC, Chao WT, Chen YT, Yang VC. Effect of EGCG, a major component of green tea, on the expression of Ets-1, c-Fos, and c-Jun during angiogenesis in vitro. Cancer Lett 2004;213:181-8.

80. Fassina G, Vene R, Morini M, et al. Mechanisms of inhibition of tumor angiogenesis and vascular tumor growth by epigallocatechin-3-gallate. Clin Cancer Res 2004;10:4865-73.

81. Oku N, Matsukawa M, Yamakawa S, et al. Inhibitory effect of green tea polyphenols on membrane-type 1 matrix metalloproteinase, MT1-MMP. Biol Pharm Bull 2003;26:1235-8.

82. Yamakawa S, Asai T, Uchida T, Matsukawa M, Akizawa T, Oku N. (-)-Epigallocatechin gallate inhibits membrane-type 1 matrix metalloproteinase, MT1-MMP, and tumor angiogenesis. Cancer Lett 2004;210:47-55

83. Sartippour MR, Heber D, Henning S, et al. cDNA microarray analysis of endothelial cells in response to green tea reveals a suppressive phenotype. Int J Oncol 2004;25:193-202.

84. Sartippour MR, Heber D, Zhang L, et al. Inhibition of fibroblast growth factors by green tea. Int J Oncol 2002;21:487-91.

85. Trompezinski S, Denis A, Schmitt D, Viac J. Comparative effects of polyphenols from green tea (EGCG) and soybean (genistein) on VEGF and IL-8 release from normal human keratinocytes stimulated with the proinflammatory cytokine TNFalpha. Arch Dermatol Res 2003;295:112-6.

86. Curatolo PW, Robertson D. The health consequences of caffeine. Ann Intern Med 1983;98:641-53.

87. Robertson D, Frolich JC, Carr RK, et al. Effects of caffeine on plasma renin activity, catecholamines and blood pressure. N Engl J Med 1978;298:181-6.

88. Robertson D, Wade D, Workman R, Woosley RL, Oates JA. Tolerance to the humoral and hemodynamic effects of caffeine in man. J Clin Invest 1981;67:1111-7.

89. Haller CA, Benowitz NL. Adverse cardiovascular and central nervous system events associated with dietary supplements containing ephedra alkaloids. N Engl J Med 2000;343:1833-8.

90. Haller CA, Jacob P, Benowitz NL. Short-term metabolic and hemodynamic effects of ephedra and guarana combinations. Clin Pharmacol Ther 2005;77:560-71.

91. Shekelle PG, Hardy ML, Morton SC, et al. Efficacy and safety of ephedra and ephedrine for weight loss and athletic performance: a meta-analysis. Jama 2003;289:1537-45.

92. Rados C. Ephedra ban: no shortage of reasons. FDA Consum 2004;38:6-7.

93. Ray S, Phadke S, Patel C, Hackman RM, Stohs S. Short-term and long-term in vivo exposure to an ephedra- and caffeine-containing metabolic nutrition system does not induce cardiotoxicity in B6C3F1 mice. Arch Toxicol 2005;79:330-40.

94. Dodt C, Lonnroth $\mathrm{P}$, Fehm HL, Elam M. The subcutaneous lipolytic response to regional neural stimulation is reduced in obese women. Diabetes 2000;49:1875-9.

95. Dulloo AG. Biomedicine. A sympathetic defense against obesity. Science 2002;297:7801.

96. Dulloo AG, Seydoux J, Jacquet J. Adaptive thermogenesis and uncoupling proteins: a reappraisal of their roles in fat metabolism and energy balance. Physiol Behav 2004;83:587-602.

97. Macdonald IA. Advances in our understanding of the role of the sympathetic nervous system in obesity. Int J Obes Relat Metab Disord 1995;19 Suppl 7:S2-S7.

98. Dodt C, Lonnroth P, Wellhoner JP, Fehm HL, Elam M. Sympathetic control of white adipose tissue in lean and obese humans. Acta Physiol Scand 2003;177:351-7.

99. Bray GA. Reciprocal relation of food intake and sympathetic activity: experimental observations and clinical implications. Int J Obes 2000;24 (suppl 2):S8-S17. 
100. Astrup A. The sympathetic nervous system as a target for intervention in obesity. Int $\mathrm{J}$ Obes Relat Metab Disord 1995;19 Suppl 7:S24-S28.

101. Snitker S, Macdonald I, Ravussin E, Astrup A. The sympathetic nervous system and obesity: role in aetiology and treatment. Obes Rev 2000;1:5-15.

102. Saad MF, Alger SA, Zurlo F, Young JB, Bogardus C, Ravussin E. Ethnic differences in sympathetic nervous system-mediated energy expenditure. Am J Physiol 1991;261:E78994.

103. Toth MJ, Poehlman ET. Sympathetic nervous system activity and resting metabolic rate in vegetarians. Metabolism 1994;43:621-5.

104. Kurpad AV, Khan K, Calder AG, Elia M. Muscle and whole body metabolism after norepinephrine. Am J Physiol 1994;266:E877-84.

105. Simonsen L, Bulow J, Madsen J, Christensen NJ. Thermogenic response to epinephrine in the forearm and abdominal subcutaneous adipose tissue. Am $\mathrm{J}$ Physiol 1992;263:E850-5.

106. Eikelis N, Esler M. The neurobiology of human obesity. Exp Physiol 2005;90:673-82.

107. Young JB, Macdonald IA. Sympathoadrenal activity in human obesity: heterogeneity of findings since 1980. Int J Obes Relat Metab Disord 1992;16:959-67.

108. Bray GA. Autonomic and endocrine factors in the regulation of energy balance. Fed Proc 1986;45:1404-10.

109. Landsberg L. The sympathoadrenal system, obesity and hypertension: an overview. J Neurosci Methods 1990;34:179-86.

110. Landsberg L, Young JB. Diet and the sympathetic nervous system: relationship to hypertension. Int J Obes 1981;5 suppl 1:79-91.

111. Landsberg L, Young JB. Sympathoadrenal activity and obesity: physiological rationale for the use of adrenergic thermogenic drugs. Int J Obes Relat Metab Disord 1993;17 Suppl 1:S29-34.

112. McCargar LJ, Clandinin MT, Fawcett DM, Johnston JL. Short-term changes in energy intake and serum insulin, neutral amino acids, and urinary catecholamine excretion in women. Am J Clin Nutr 1988;47:932-41.

113. Dulloo AG, Jacquet J. An adipose-specific control of thermogenesis in body weight regulation. Int J Obes Relat Metab Disord 2001;25 Suppl 5:S22-9.

114. Bazelmans J, Nestel PJ, O'Dea K, Esler MD. Blunted norepinephrine responsiveness to changing energy states in obese subjects. Metabolism 1985;34:154-60.

115. Grassi G, Colombo M, Seravalle G, Spaziani D, Mancia G. Dissociation between muscle and skin sympathetic nerve activity in essential hypertension, obesity, and congestive heart failure. Hypertension 1998;31:64-7.

116. Vaz M, Jennings G, Turner A, Cox H, Lambert G, Esler M. Regional sympathetic nervous activity and oxygen consumption in obese normotensive human subjects. Circulation 1997;96:3423-9.

117. Purdham DM, Zou MX, Rajapurohitam V, Karmazyn M. Rat heart is a site of leptin production and action. Am J Physiol Heart Circ Physiol 2004;287:H2877-84.

118. Rumantir MS, Vaz M, Jennings GL, et al. Neural mechanisms in human obesity-related hypertension. J Hypertens 1999;17:1125-33.

119. Narkiewicz K, van de Borne PJ, Cooley RL, Dyken ME, Somers VK. Sympathetic activity in obese subjects with and without obstructive sleep apnea. Circulation 1998;98:772-6.

120. Spraul M, Ravussin E, Fontvieille AM, Rising R, Larson DE, Anderson EA. Reduced sympathetic nervous activity. A potential mechanism predisposing to body weight gain. $\mathrm{J}$ Clin Invest 1993;92:1730-1735.

121. Andersson B, Elam M, Wallin BG, Bjorntorp P, Andersson OK. Effect of energy-restricted diet on sympathetic muscle nerve activity in obese women. Hypertension 1991;18:783-9. 
122. Bobbioni-Harsch E, Bongard O, Habicht F, et al. Relationship between sympathetic reactivity and body weight loss in morbidly obese subjects. Int J Obes Relat Metab Disord 2004;28:906-11.

123. Flechtner-Mors M, Ditschuneit HH, Yip I, Adler G. Sympathetic modulation of lipolysis in subcutaneous adipose tissue: effects of gender and energy restriction. J Lab Clin Med 1999;134:33-41.

124. Ravussin E. Low resting metabolic rate as a risk factor for weight gain: role of the sympathetic nervous system. Int J Obes Relat Metab Disord 1995;19 Suppl 7:S8-S9.

125. Grassi G, Seravalle G, Cattaneo BM, et al. Sympathetic activation in obese normotensive subjects. Hypertension 1995;25:560-3.

126. Scherrer U, Randin D, Tappy L, Vollenweider P, Jequier E, Nicod P. Body fat and sympathetic nerve activity in healthy subjects. Circulation 1994;89:2634-40.

127. Haynes WG, Morgan DA, Djalali A, Sivitz WI, Mark AL. Interactions between the melanocortin system and leptin in control of sympathetic nerve traffic. Hypertension 1999;33:542-7.

128. Haynes WG, Morgan DA, Walsh SA, Mark AL, Sivitz WI. Receptor-mediated regional sympathetic nerve activation by leptin. J Clin Invest 1997;100:270-8.

129. Bartness TJ, Bamshad M. Innervation of mammalian white adipose tissue: implications for the regulation of total body fat. Am J Physiol 1998;275:R1399-411.

130. White JE, Engel FL. A lipolytic action of epinephrine and norepinephrine on rat adipose tissue in vitro. Proc Soc Exp Biol Med 1958;99:375-8.

131. Jansson PA, Larsson A, Smith U, Lonnroth P. Glycerol production in subcutaneous adipose tissue in lean and obese humans. J Clin Invest 1992;89:1610-7.

132. Elmquist JK, Maratos-Flier E, Saper CB, Flier JS. Unraveling the central nervous system pathways underlying responses to leptin. Nat Neurosci 1998;1:445-50.

133. Trayhurn P, Duncan JS, Hoggard N, Rayner DV. Regulation of leptin production: a dominant role for the sympathetic nervous system? Proc Nutr Soc 1998;57:413-9.

134. Collins S, Kuhn CM, Petro AE, Swick AG, Chrunyk BA, Surwit RS. Role of leptin in fat regulation. Nature 1996;380:677.

135. Rayner DV, Trayhurn P. Regulation of leptin production: sympathetic nervous system interactions. J Mol Med 2001;79:8-20.

136. Trayhurn P, Hoggard N, Mercer JG, Rayner DV. Leptin: fundamental aspects. Int J Obes 1999;23 (suppl 1):22-28.

137. Mantzoros CS, Qu D, Frederich RC, et al. Activation of beta(3) adrenergic receptors suppresses leptin expression and mediates a leptin-independent inhibition of food intake in mice. Diabetes 1996;45:909-14.

138. Hongu N, Sachan DS. Caffeine, carnitine and choline supplementation of rats decreases body fat and serum leptin concentration as does exercise. J Nutr 2000;130:152-7.

139. Eikelis N, Schlaich M, Aggarwal A, Kaye D, Esler M. Interactions between leptin and the human sympathetic nervous system. Hypertension 2003;41:1072-9.

140. Eikelis N, Lambert G, Wiesner G, et al. Extra-adipocyte leptin release in human obesity and its relation to sympathoadrenal function. Am $\mathrm{J}$ Physiol Endocrinol Metab 2004;286:E744-52. 


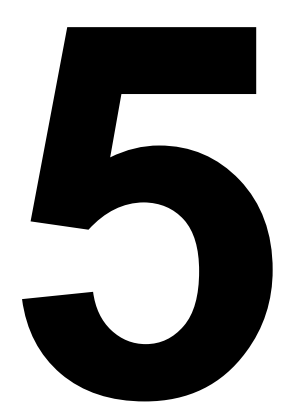

\section{Long-term effects of consumption of a novel fat emulsion in relation to body-weight management}

Kristel Diepvens, Stijn Soenen, Jan Steijns, Myrtha Arnold, Margriet S Westerterp-Plantenga

Int J Obes 2007; 31: 942-949 


\section{ABSTRACT}

Objective: To assess weight maintenance after weight loss by consumption of yoghurt with a novel fat emulsion (Olibra ${ }^{\circledR}$ ) including effects on body composition, resting energy expenditure (REE), fat oxidation, hunger feelings and satiety hormones.

Design: A randomized, placebo-controlled, double-blind, parallel design. A 6week weight-loss period (2.1 MJ/day) was followed by 18 weeks weight maintenance with test $\left(\mathrm{Olibra}^{\circledR}\right)$ or placebo yoghurt.

Subjects: Fifty overweight women (age: $18-58$ years, BMI $25-32 \mathrm{~kg} / \mathrm{m}^{2}$ ).

Measurements: In weeks 1,7 and 25, a satiety test with questionnaires and blood samples for analysis of satiety hormones. In weeks 2, 8 and 26, REE, body weight and body composition.

Results: During weight maintenance after significant body weight reduction, there was no significant increase in body weight in the test group $(1.1 \pm 3.4 \mathrm{~kg})$; the placebo group did gain weight $(3.0 \pm 3.1 \mathrm{~kg}, \mathrm{p}<0.001)$. Compared to the placebo group, the test group was less hungry $4 \mathrm{~h}$ after yoghurt consumption in week $25(p<0.05)$ and showed increased glucagon-like peptide 1 values 180 min after yoghurt consumption (week 25 vs. week $1, p<0.05$ ). Measured REE as a function of fat-free mass (FFM) was significantly higher than predicted REE $(p<0.05)$ in week 26 for the test group, but not for the placebo group. Fat mass (FM) was significantly more decreased in the test group $(6.5 \pm 4.1 \mathrm{~kg})$ compared to the placebo group $(4.1 \pm 3.6 \mathrm{~kg})$ (week $26 \mathrm{vs}$. week $2, \mathrm{p}<0.05)$.

Conclusion: Consumption of Olibra ${ }^{\circledR}$ yoghurt improved weight maintenance compared to placebo, which can be explained by the relatively higher REE as a function of FFM, relatively higher decrease in FM and the relatively lower increase in hunger.

Keywords: fat, emulsion, weight maintenance, body composition, resting energy expenditure, satiety 


\section{INTRODUCTION}

The prevalence of obesity has increased worldwide during the past few decades (1). Obesity is a major causative factor for a number of diseases, including coronary heart disease, hypertension, non-insulin-dependent diabetes mellitus, pulmonary dysfunction and certain types of cancer (2). Obesity develops when the equilibrium between energy intake (EI) and energy expenditure (EE) shifts towards a positive energy balance.

Treatment of obesity is beneficial in that weight loss reduces the risk for mortality and morbidity. Even modest weight loss, such as $5-10 \%$ of the initial body weight, has beneficial health effects $(3,4)$. Body weight loss and prevention of body weight (re)gain can be achieved by reducing El and/or increasing $\mathrm{EE}$, or promoting fat oxidation.

Previously an Irish research group showed that, in comparison with a yoghurt containing only dairy fat, consumption of a $200 \mathrm{~g}$ yoghurt containing a novel fat emulsion (Olibra ${ }^{\circledR}$ ) significantly increased satiety and subsequently decreased $\mathrm{El}$ in non-obese, overweight and obese subjects, at a meal $4 \mathrm{~h}$ later, and that the decreased intake persisted for the rest of the day (5-7). This novel fat emulsion consists of a mixture of fractionated palm oil $(40 \%)$ and fractionated oat oil $(2.5 \%)$ in water, whereby $5 \mathrm{~g}$ of emulsion corresponds to about $2 \mathrm{~g}$ of fat. Until now, a possible long-term effect of Olibra ${ }^{\circledR}$ has not been assessed. This study was executed in order to investigate the long-term effect of Olibra ${ }^{\circledR}$, and to improve understanding of the possible mechanisms underlying the observed short-term reduction in El owing to Olibra ${ }^{\circledR}$ consumption. Primary end points of the study were to assess possible weight maintenance (after a very-low-energy diet (VLED)) by consumption of Olibra ${ }^{\circledR}$ up till 18 weeks including effects on body composition, fat oxidation, and resting energy expenditure (REE). Furthermore, hunger feelings as well as satiety-related hormones after consumption of an Olibra ${ }^{\circledR}$-containing serving were assessed.

\section{SUBJECTS AND METHODS}

\section{Subjects}

Fifty female overweight subjects, aged $18-58$ years and with a body mass index (BMI) between 25 and $32 \mathrm{~kg} / \mathrm{m}^{2}$ participated in this study. The subjects were recruited by advertisements in local newspapers. All subjects participated in an initial screening that involved measurement of body weight, height, waist:hip circumference, and completion of a questionnaire related to health, use of medication, smoking behavior, alcohol consumption and physical activity. All subjects were in good health, non-smokers, not using medication and at most 
Table 1 Subject characteristics at baseline

\begin{tabular}{lcc}
\hline & Test group $(\mathrm{n}=22)$ & Placebo group $(\mathrm{n}=28)$ \\
\hline Age (years) & $40.3 \pm 9.7$ & $41.2 \pm 9.3$ \\
Weight $(\mathrm{kg})$ & $81.3 \pm 8.6$ & $79.0 \pm 8.6$ \\
Height $(\mathrm{cm})$ & $167.6 \pm 7.8$ & $166.3 \pm 7.4$ \\
BMI $\left(\mathrm{kg} / \mathrm{m}^{2}\right)$ & $28.9 \pm 1.7$ & $28.5 \pm 2.2$ \\
Waist circumference $(\mathrm{cm})$ & $91.1 \pm 5.6$ & $91.5 \pm 7.7$ \\
Hip circumference $(\mathrm{cm})$ & $108.8 \pm 4.3$ & $108.1 \pm 7.1$ \\
Waist:Hip ratio & $0.84 \pm 0.04$ & $0.85 \pm 0.06$ \\
\hline
\end{tabular}

moderate alcohol users. The subjects were stratified for age, BMI, weight, height, waist and hip circumference in two groups, which were randomly assigned to the two treatments: the test treatment $\left(\right.$ Olibra $^{\circledR} n=22$ ) and the placebo treatment $(n=28)$. Baseline characteristics of the subjects are presented in table 1.

The subjects gave their written informed consent and the Medical Ethical Committee of Maastricht University approved the study.

\section{Experimental design}

The study followed a randomized, placebo-controlled, double-blind, parallel design and lasted 26 weeks. Subjects were instructed to maintain their normal physical activity level during the whole study period.

Measurements took place in weeks 1, 2, 7, 8, 25 and 26. In week 1, subjects came to the laboratory for a satiety test (hormones, hunger and satiety questionnaires) and determination of free fatty acids (FFA), triglycerides (TG), glycerol (Gly) and $\beta$-hydroxybutyrate (BHB). This test is described below. During 3 days before the next measurement in week 2 , the subjects consumed a standardized energy balance diet (energy $\%$ C/P/F: 53/12/35) at $100 \%$ of predicted EE (8). All food was supplied to the subjects. Anthropometry and REE were measured in week 2. During the following 6 weeks (weeks 2-8), the subjects consumed a VLED (Modifast, Novartis Nutrition, Breda, The Netherlands). This Modifast diet provided $2.1 \mathrm{MJ} /$ day (energy\% C/P/F: 42/44/14) and was supplied in three sachets daily, dissolved in water to obtain milk shake, pudding, soup or muesli. Subjects were instructed that vegetables and 2 pieces of fruit per day were allowed in addition to the VLED. Subjects could phone when they had remaining questions. The weight-loss-related measurements followed in weeks 7 and 8 . These were the same measurements as during weeks 1 and 2. During the subsequent 18 weeks (weeks 8-26), the subjects stopped the VLED and entered the weight-maintenance phase. The subjects resumed their habitual eating patterns during the weight-maintenance 
phase and obtained either test $(250 \mathrm{~g}$ yoghurt containing $3 \mathrm{~g}$ milk fat and $2 \mathrm{~g}$ vegetable fat, provided by $5 \mathrm{~g}$ Olibra $^{\circledR}$ emulsion (Lipid Technologies Provider $\mathrm{AB}$, Karlshamn, Sweden)) or placebo yoghurt ( $250 \mathrm{~g}$ yoghurt containing $5 \mathrm{~g}$ milk fat) for daily use. Subjects were instructed to use $250 \mathrm{~g}$ in the morning (breakfast time) and $250 \mathrm{~g}$ in the afternoon (around $16.00 \mathrm{~h}$ ) to aim at a possible decreased food intake at lunch as well as at dinner after consumption of the test yoghurt. Food intake compliance for yoghurt was evaluated every week by a personal interview by the dietician. The composition of both yoghurts was matched for energy and macronutrient content. Yoghurt consumption (500 g) provided $2.0 \mathrm{MJ} /$ day $=476 \mathrm{kcal} / \mathrm{day}(406 \mathrm{~kJ} / 97 \mathrm{kcal}$ per $100 \mathrm{~g}$, energy\% C/P/F: 69/12/19). In weeks 25 and 26 the weight maintenance measurements followed. These were the same as during weeks 1 and 2 .

\section{Satiety tests (weeks 1,7 and 25 )}

The subjects arrived at $08.00 \mathrm{~h}$ in a fasted state at the laboratory. An intravenous catheter was inserted. After collection of the baseline blood sample $(\mathrm{t}=0 \mathrm{~min})$, the subjects received either test or placebo yoghurt. For these test days, the same yoghurts were used as during the weight-maintenance period. In total, $250 \mathrm{~g}$ yoghurt was provided as breakfast. The subjects were instructed to consume the yoghurt within $5 \mathrm{~min}$. For the satiety tests, blood sampling was repeated after 90 and $180 \mathrm{~min}$. The catheter was removed after the last blood sample had been taken. Ghrelin (Ghr), glucagon-like peptide 1 (GLP-1) and cholecystokinin (CCK) were measured in the fasted state, and after 90 and 180 min to determine short-term satiety effects.

As part of the satiety tests, hunger was recorded hourly by Visual Analogue Scales (mmVAS) until $13.00 \mathrm{~h}$.

The subjects were not allowed to eat during the morning and had only access to drinking water.

\section{Blood parameters (weeks 1,7 and 25)}

In weeks 1,7 and 25 , a 46-ml blood sample was taken for hunger and satietyrelated hormones (Ghr, GLP-1 and CCK) and FFA, TG, Gly and BHB. FFA, TG, Gly and BHB were measured in the fasted state only to determine the long-term effects. The hormones were determined in the fasted state as well as 90 and $180 \mathrm{~min}$ after yoghurt consumption as previously mentioned, to determine the long- as well as the short-term effects. The blood samples were mixed with ethylenediaminetetraacetate (EDTA) to prevent clotting. Samples for GLP-1 (4 $\mathrm{ml}$ ) analysis were mixed with $40 \mu \mathrm{l}$ of a dipeptidyl peptidase IV (DPP-IV) inhibitor (Linco Research Inc., St Charles, Missouri, USA) to prevent degradation. Samples for CCK analysis $(4 \mathrm{ml})$ were mixed with $2000 \mathrm{KIU}$ trasylol (Bayer Diagnostics Europe Ltd, the Netherlands). Plasma was obtained 
by centrifugation $\left(4^{\circ} \mathrm{C}, 3000 \mathrm{rpm}, 10 \mathrm{~min}\right)$, frozen in liquid nitrogen and stored at $-20^{\circ} \mathrm{C}$ until further analysis. Plasma $\mathrm{Ghr}$ samples were mixed with $\mathrm{HCl}$, methanol and phenylmethanesulfonyl fluoride (PMSF, Sigma-Aldrich, The Netherlands).

TG was measured using the GPO-trinder kit (Sigma Diagnostics Inc., St.Louis, USA), FFA were determined with the Wako NEFA C-kit (Wako chemicals, Neuss, Germany), Gly with the glycerolkinase method (Boehringer Mannheim $\mathrm{GmBH}$, Mannheim, Germany), and BHB with the $\beta$-hydroxybutyrate dehydrogenase method (Sigma Diagnostics Inc., St.Louis, USA). Plasma concentrations of active Ghr were measured by RIA (Linco Research Inc., St Charles, Missouri, USA). Plasma active GLP-1 samples were analyzed using ELISA (EGLP-35K; Linco Research Inc., St Charles, Missouri, USA). CCK was determined using RIA (Euria-CCK, Euro-Diagnostica AB, Malmö, Sweden).

\section{Questionnaires (weeks 1,7 and 25)}

Attitude towards eating was analyzed in weeks 1,7 and 25 in the fasted state using a validated Dutch translation of the Three Factor Eating Questionnaire (TFEQ) (9). Cognitive restrained and unrestrained eating behavior (F1), emotional eating and disinhibition (F2), and subjective feeling of hunger (F3) were scored 0 and 1 and summed. Higher scores denote higher levels of restrained eating, disinhibited eating and predisposition to hunger, respectively. In addition, as previously mentioned, during the satiety tests, hunger ratings were scored in the fasted state and every hour after yoghurt consumption until $13.00 \mathrm{~h}$ since the subjective measurement represents in a robust and reproducible way the condition of the subject in this respect (10). Subjects rated their hunger on visual analoque scales (VAS; in $\mathrm{mm}$ ) by the pen and paper method. Hunger was rated on a $100 \mathrm{~mm}$ line preceded by the question "How hungry do you feel?" and anchored on the left by "not at all hungry" and on the right by "as hungry as I have ever felt". Subjects were instructed to make a single vertical mark at the appropriate point between the two anchors on each scale to indicate their subjective feeling of hunger at defined time points.

Changes in mood and tolerance of the treatment were determined in weeks 1, 7 and 25 in the fasted state. Mood (relaxed, gloomy, pleasant, angry, afraid, sad) was assessed with $100 \mathrm{~mm}$ VAS, and tolerance was determined using a questionnaire on the occurrence of complaints (headache, fatigue, nausea, stomach ache, constipation, diarrhoea, etc.) and scored. Frequency classification was: 0 , never; 1 , seldom; 2 , sometimes; 3 , relatively often; 4 , often (five-point scale). 
Anthropometric measurements were taken in the fasted state during screening and in weeks 2, 8 and 26. Body weight was measured using a digital balance accurate to $0.02 \mathrm{~kg}$ (Chyo-MW-150K, Chyo, Japan) with subjects in underwear after voiding their bladder. Height was measured to the nearest $0.1 \mathrm{~cm}$ using a wall-mounted stadiometer (only during screening). The ratio of waist:hip circumference is an estimate of the distribution of body fat. The waist:hip ratio was calculated by dividing the waist circumference by the hip circumference. The waist circumference was measured at the site of the smallest circumference between the rib cage and the iliac crest, and the hip circumference was measured at the site of the largest circumference between the waist and the thighs. Both measurements were performed with subjects in standing position.

Body composition was measured in weeks 2, 8 and 26 using the ${ }^{2} \mathrm{H}_{2} \mathrm{O}$ dilution technique (11-13). The dilution of the ${ }^{2} \mathrm{H}$ isotope is a measure for total body water (12). In the evening, the subjects ingested a dose of ${ }^{2} \mathrm{H}$-enriched water $\left({ }^{2} \mathrm{H}_{2} \mathrm{O}\right)$ after collecting a background urine sample. After ingestion of the ${ }^{2} \mathrm{H}$ solution, no further fluid or food consumption was permitted. The following morning, the second urine sample (second voiding) was collected. Deuterium concentration in the urine samples was measured using an isotope ratio mass spectrometer (Micromass Optima, Manchester, UK). Total body water was obtained by dividing the measured ${ }^{2} \mathrm{H}$ dilution space by 1.04 to correct for exchange of the ${ }^{2} \mathrm{H}$ label with nonaqueous hydrogen of body solids (11). Fatfree mass (FFM) was calculated by dividing the total body water by hydrating factor 0.73. By subtracting FFM from body weight, fat mass (FM) was obtained. FM expressed as a percentage of body weight gives percentage of body fat. The analytic precision for ${ }^{2} \mathrm{H}$ is $0.2 \mathrm{ppm}$ (14).

\section{Open-circuit, ventilated-hood test (weeks 2, 8 and 26)}

In weeks 2, 8 and 26, the following EE and substrate oxidation variables were measured: REE, fat and carbohydrate oxidation for $30 \mathrm{~min}$. The subjects were requested to arrive in the morning at the laboratory in the fasted state. REE and substrate oxidation were measured by means of an open-circuit, ventilatedhood system with subjects lying supine for $30 \mathrm{~min}$ (15). Gas analysis was performed by a paramagnetic oxygen analyzer (omnical type 1155B, Crowborough Sussex, UK) and an infrared carbon dioxide analyzer (omnical type 1520/1507). EE was calculated using Weir's formula (16). The respiratory quotient (RQ) was calculated as $\mathrm{CO}_{2}$ produced/ $\mathrm{O}_{2}$ consumed. 


\section{Statistical analysis}

Data are presented as means and standard deviations. Data were analyzed using Statview SE + Graphics (Abacus Concepts, Berkeley, CA, USA, 1988). Differences over time and between the treatments (test or placebo yoghurt) over time were determined using one- and two-factor ANOVA with repeated measures. Differences between groups were analyzed using factorial ANOVA. Univariate linear regression was used to determine the relationship between selected variables. The level for establishing significant differences was taken at $p<0.05$.

\section{RESULTS}

Characteristics of the subjects at baseline and after 6 weeks of weight loss are shown in table 2 (anthropometric, eating behavior, tolerance, plasma lipids) and table 3 (satiety-related hormones). As presented in table 2, there was a significant reduction in body weight during the VLED in both groups $(p<0.05)$. The test and placebo group lost $7.76 \pm 1.5 \mathrm{~kg}$ and $7.65 \pm 1.4 \mathrm{~kg}$, respectively. Apart from the decreased body weight, there were also reductions $(p<0.05)$ in BMI, waist and hip circumference, FFM (kg), FM (kg and \%), REE and RQ in both groups. FFM (\%) was significantly increased in both groups after weight loss. The F1 score increased and the F2 score of the TFEQ decreased significantly in both groups $(p<0.05)$. The F3 score was significantly decreased in the placebo group after weight loss $(p<0.05)$. FFA were significantly increased after 6 weeks weight loss $(p<0.05)$. Fasted blood values of $B H B$ and TG, respectively, increased and decreased in both groups significantly $(p<0.05)$. As presented in table 3 , there was, respectively, a significant decrease and increase in Ghr values at time point 0 and 180 during the weight-loss period in the placebo group.

Figure 1 and table 2 show the changes in body weight during the 18 weeks weight maintenance following weight loss. Surprisingly, there was no significant increase in body weight in the test group $(1.13 \pm 3.4 \mathrm{~kg})$, whereas the placebo group showed a significant increase in body weight of $2.95 \pm 3.1 \mathrm{~kg}$ (figure 1 , $\mathrm{p}<0.001$ ). A difference in weight regain was shown between both groups (figure $1, p=0.05$ ANOVA two-factor repeated measures). Regain as $\%$ of weight loss was lower with test (15\%) as compared to placebo yoghurt $(40 \%) \quad(p=0.055$ factorial ANOVA).

As presented in table 2, BMI and waist circumference did not increase in the test group, but significantly increased in the placebo group $(p<0.05)$ during the weight-maintenance period. For waist circumference, a treatment over time effect was seen during weight maintenance $(p<0.05)$. FFM $(k g)$ significantly increased in both groups during weight maintenance. As an overall effect, a 


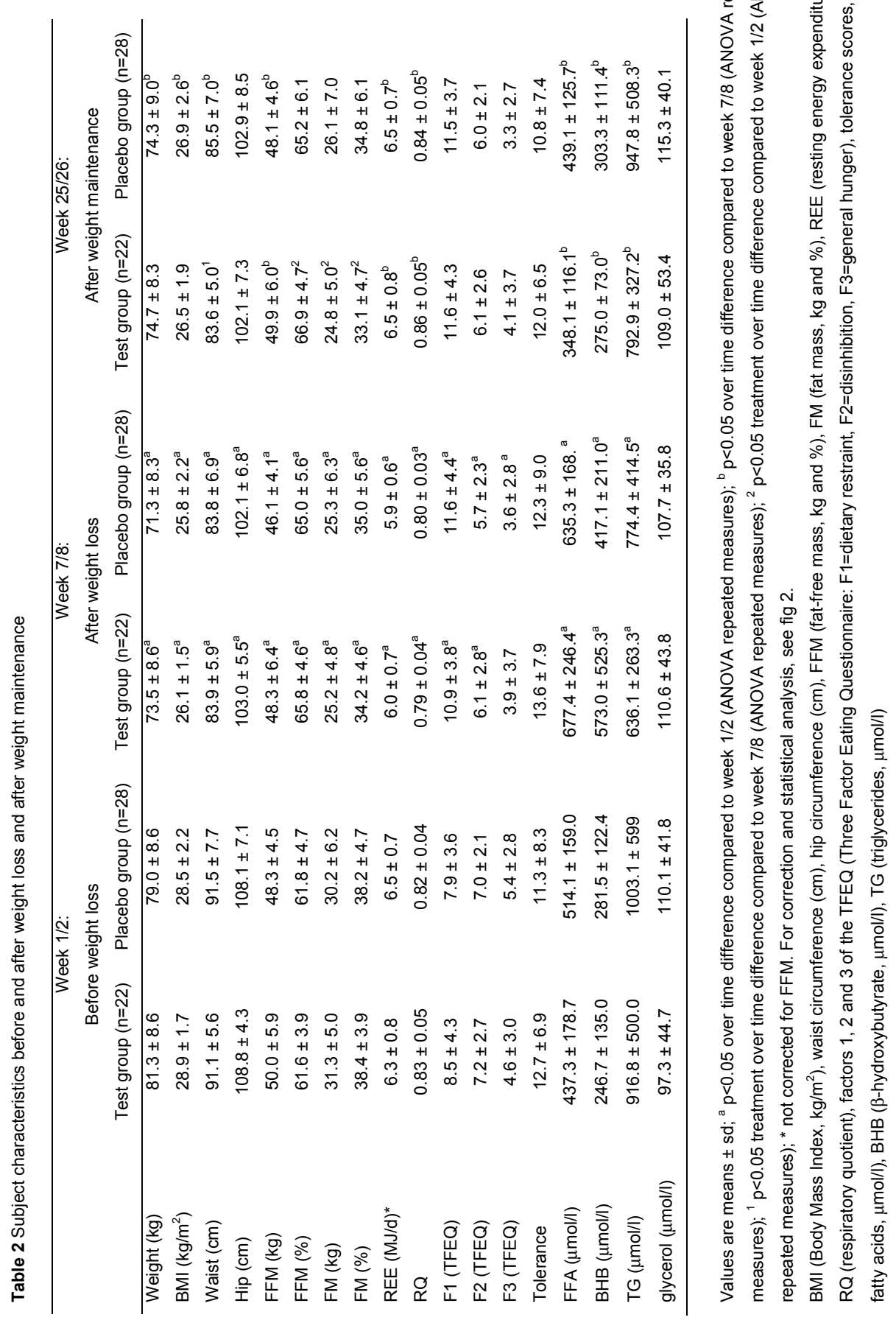




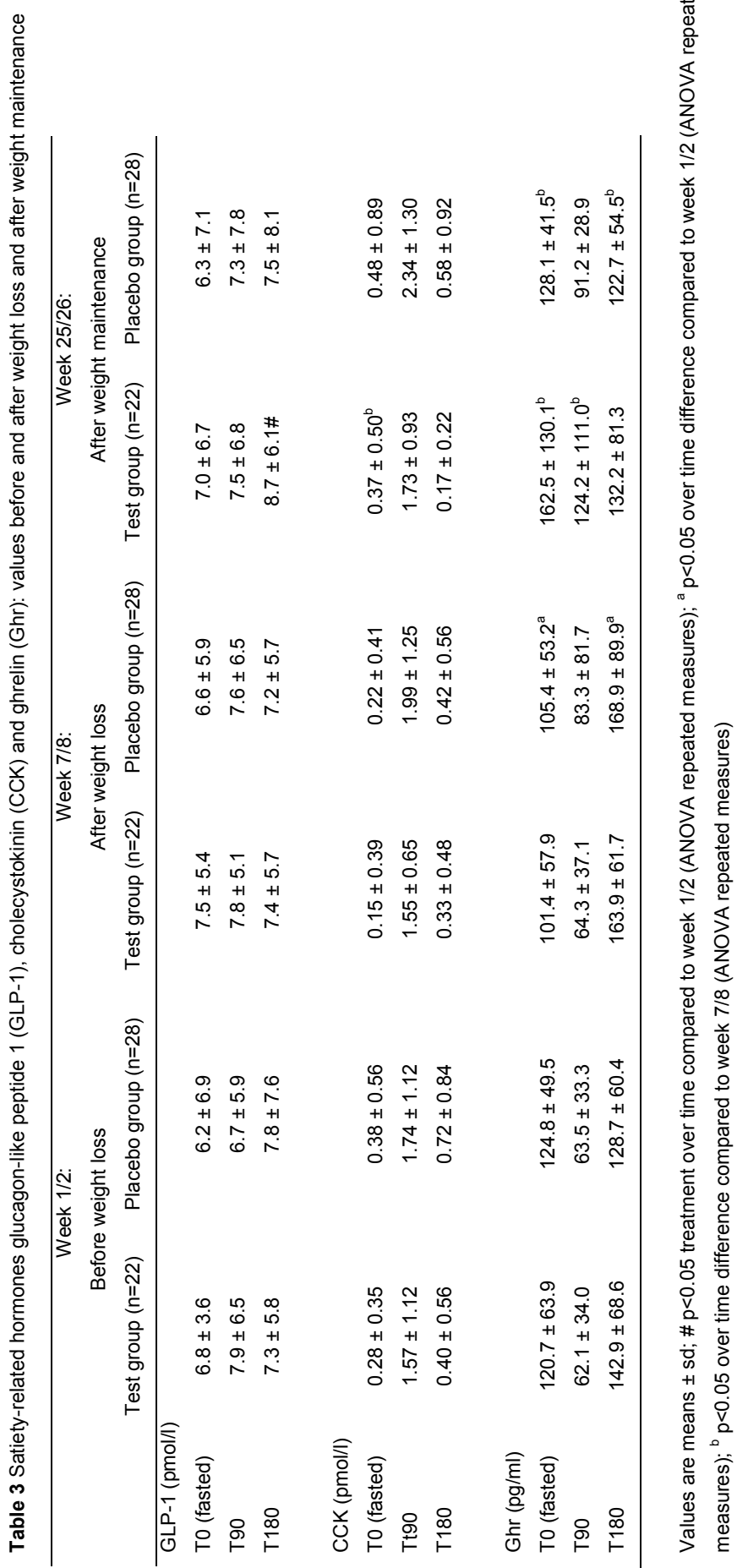




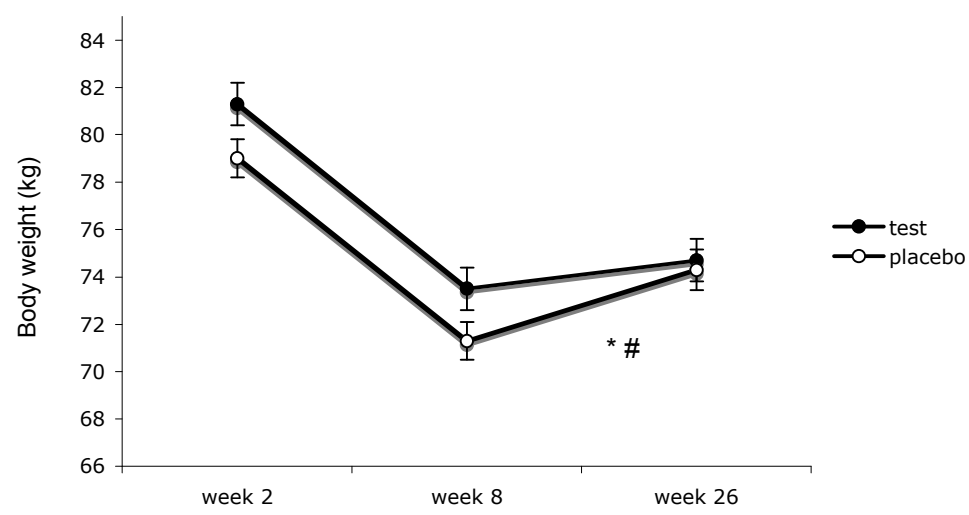

Figure 1 Changes in body weight $(\mathrm{kg})$. Values are means \pm sem.

${ }^{*} p<0.001$ regain $(\mathrm{kg})$ in placebo group (over time effect, ANOVA repeated measures)

$\# p=0.05$ treatment over time (ANOVA repeated measures)

treatment over time effect (week 26 compared to week 2) was seen for FFM (\%) and FM $(\mathrm{p}<0.05)$, in that the test group increased in FFM (\%) and decreased in FM compared to placebo. $R Q$ was significantly increased during the weightmaintenance period, in both groups $(p<0.05)$. Fasted values of FFA and BHB decreased in both groups, and TG increased in both groups during weight maintenance $(p<0.05)$. Hip circumference, F1, F2 and F3 (TFEQ), tolerance and glycerol showed no significant over time differences. Concerning mood values, no significant differences between groups were seen (data not shown).

There was a significant linear relation between REE (MJ/d) and FFM $(\mathrm{kg})$ in week 2 and 26 in both groups, $p<0.05$, figure $2 a$ and $2 b$. To determine for each group whether changes in REE took place over time as a function of FFM (REE regressed against FFM), FFM of week 26 was filled in the regression equation of week 2 to calculate the "predicted" REE (MJ/d). ANOVA repeated measures showed that the measured REE in week 26 was significantly higher $(p<0.05)$ than the predicted REE in week 26 for the test group, but not for the placebo group (figure 2c). A comparison of the two groups with regard to differences between the predicted and measured REE in week 26 did not reach a significantly different treatment over time effect.

Table 3 presents the GLP-1, CCK and Ghr values at baseline and before and after weight maintenance. GLP-1 values at 180 min after yoghurt consumption were significantly increased at week 25 compared to week 1 in the test group, but not in the placebo group (treatment over time effect, $p<0.05$ ). During weight maintenance, CCK in the fasted state was significantly increased in the test group $(p<0.05)$. Ghr was significantly increased in both groups in the fasted 
(a)

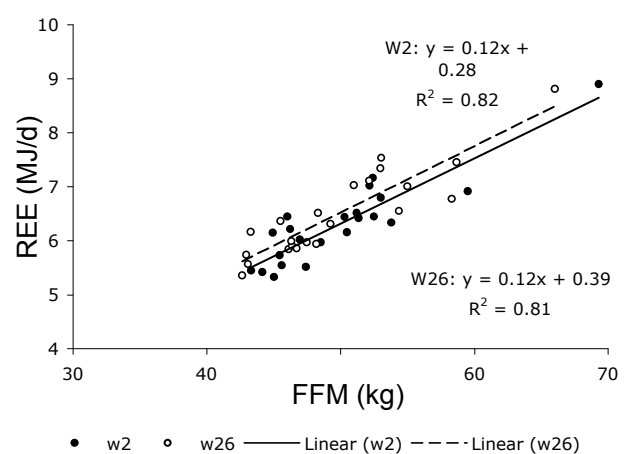

(c) (b)

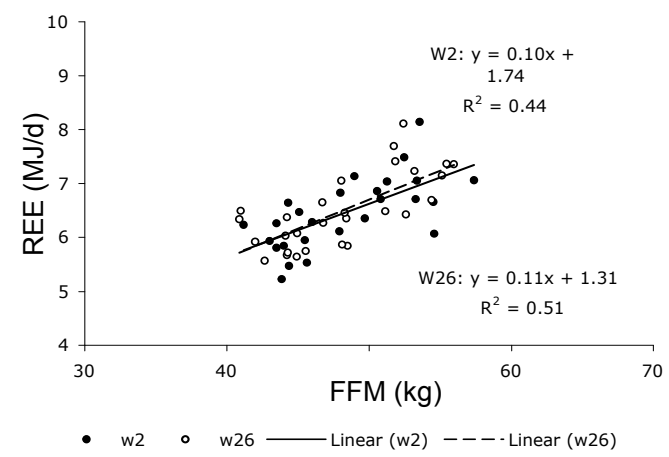

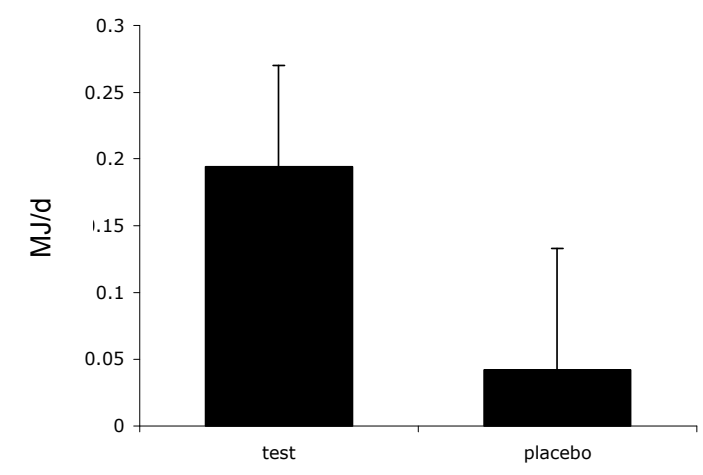

Figure 2 (a) REE (MJ/d) as a function of FFM (kg) plotted for week 2 and week 26 in the test group, (b) REE (MJ/d) as a function of FFM (kg) plotted for week 2 and week 26 in the placebo group,

(c) Week 26: measured REE minus predicted REE.

Values are means \pm sem.

state, was significantly increased in the test group at 90 min after yoghurt consumption, and was significantly decreased in the placebo group at $180 \mathrm{~min}$ after yoghurt consumption $(p<0.05)$.

Hunger ratings (average hunger from $09.00 \mathrm{~h}-13.00 \mathrm{~h}$ ) at baseline and before and after weight maintenance are presented in table 4 and figure 3 . A significant difference was found between the test and placebo group in week 25, in that the test group was less hungry $4 \mathrm{~h}$ after yoghurt consumption (table $4, p<0.05$ factorial ANOVA). 
Table 4 Hunger scores at baseline (week 1) and before (week 7 ) and after (week 25) weight maintenance

\begin{tabular}{lcc}
\hline & \multicolumn{2}{c}{ Average hunger from 09.00 $\mathrm{h}-13.00 \mathrm{~h}$} \\
& Test group $(\mathrm{n}=22)$ & Placebo group $(\mathrm{n}=28)$ \\
\hline Week 1/2 & $29.4 \pm 24.9$ & $34.5 \pm 33.2$ \\
Week 7/8 & $26.1 \pm 24.5$ & $30.3 \pm 22.3$ \\
Week 25/26 & $29.4 \pm 21.8$ & $45.6 \pm 30.0^{*}$ \\
\hline
\end{tabular}

Values are means \pm sd.

$09.00 \mathrm{~h}$ : hunger score before yoghurt consumption

$10.00 \mathrm{~h}$ : hunger score $1 \mathrm{~h}$ after yoghurt consumption

$13.00 \mathrm{~h}$ : hunger score $4 \mathrm{~h}$ after yoghurt consumption

${ }^{*} p<0.05$ test group compared to placebo group, factorial ANOVA

\section{DISCUSSION}

The present study shows that daily consumption of $500 \mathrm{~g}$ Olibra ${ }^{\circledR}$ yoghurt (with $10 \mathrm{~g} \mathrm{Olibra}^{\circledR}$ emulsion) during approximately 4 months supported moderate overweight subjects in maintaining their loss in body weight without inducing macronutrient imbalance.

The better weight maintenance upon consumption of test $\left(\right.$ Olibra $\left.^{\circledR}\right)$ yoghurt compared to placebo $(1.2 \mathrm{~kg}$ vs. $3.0 \mathrm{~kg}$ regain), as well as the sustained reduced waist circumference, is explained by the relatively lower increase in hunger paralleled by a higher increase in GLP-1 during weight maintenance and by the relatively higher REE as a function of FFM.

As FFM is the main determinant of REE, REE should be corrected for FFM (17). We corrected REE for FFM by expressing REE as a function of FFM. The present study shows that REE as a function of FFM did increase significantly (measured REE vs. predicted REE) in the test group during the study period, whereas no significant increase in the placebo group was seen. As our data were analyzed with REE corrected for FFM, the increase in REE in the test group could not be explained by changes in FFM and therefore is attributed to the Olibra $^{\circledR}$ yoghurt. More research, however, is needed to elucidate the mechanism.

Our interpretation is that when weight maintenance starts, it is supported when at the same time a so-called fat-free mass sparing effect occurs. Previously, Dulloo et al. described this sparing effect in which the body composition of a given individual changes continuously towards a leaner body composition during the course of starvation (18). In our study, we found that FM is more 


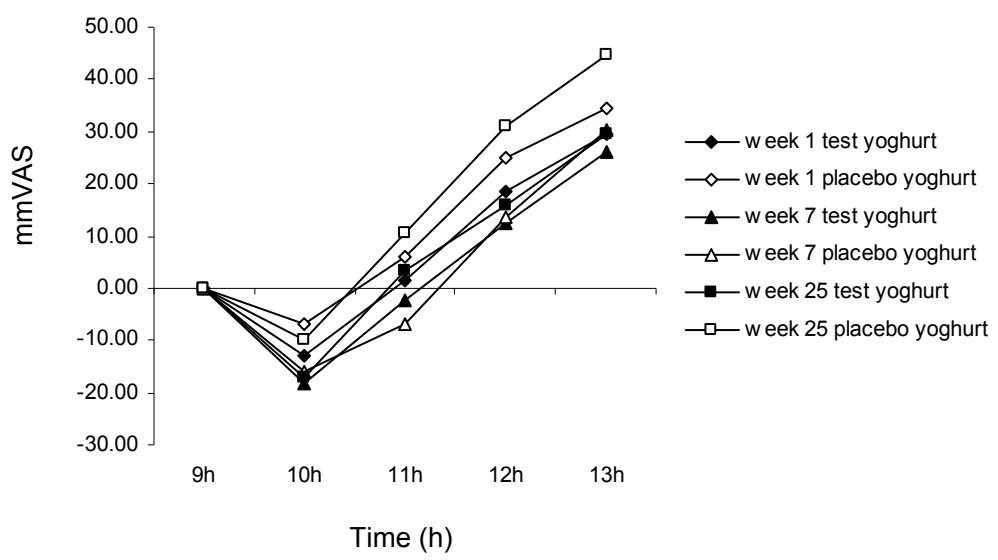

Figure 3 Hunger scores in week 1, 7 and 25. Values are means. $09.00 \mathrm{~h}$ : hunger score before yoghurt consumption. $10.00 \mathrm{~h}$ : hunger score $1 \mathrm{~h}$ after yoghurt consumption. $13.00 \mathrm{~h}$ : hunger score 4h after yoghurt consumption.

decreased in the test group compared to the placebo group during the whole study period, which implies a higher percentage FFM in the test group. This FFM sparing effect stimulates REE and thus prevents a decreased REE. A decreased REE is responsible for the weight cycling effect. A reduction in REE usually causes weight regain as, during weight maintenance, subjects start eating again as usual while the energy requirement has been reduced (19). Accordingly, fat oxidation is sustained. These factors seem to be the condition for weight maintenance, as we showed before (20-23).

During weight maintenance, the waist circumference is decreased $(-0.3 \mathrm{~cm})$ in the test group, while it is increased $(+1.7 \mathrm{~cm})$ in the placebo group $(p<0.05)$. Visscher et al. concluded that waist circumference is a better indicator of changes in energy balance and energy-balance-related behavior than BMI (24). This finding supports the beneficial effects of the test yoghurt. Furthermore, waist circumference reflects abdominal or intra-abdominal fat and this fat has been associated with adverse clinical effects, characterized by hyperinsulinemia, dyslipidemia, glucose intolerance, diabetes, cardiovascular diseases and some cancers (25). Therefore, waist circumference for given levels of BMI can be used to predict health risks associated with overweight and obesity (26).

No effect of the test yoghurt on fat oxidation or fat-related blood parameters (FFA, BHB, TG and Gly) was seen. Furthermore, mood and tolerance were not affected by test yoghurt consumption. The changes in dietary restraint (F1), emotional eating (F2) and the general feeling of hunger (F3) did not differ 
between the groups and cannot explain the better weight maintenance with test yoghurt.

A group of Irish researchers conducted three short-term human studies with a double-blind, placebo-controlled, within-subject cross-over design in which participants were offered $200 \mathrm{~g}$ portions of either placebo or Olibra ${ }^{\circledR}$ yoghurt (with either 5, 10, 12.5 or $15 \mathrm{~g}$ emulsion equaling 2, 4, 5 or $6 \mathrm{~g} \mathrm{Olibra}^{\circledR}$ fat, respectively). They investigated the hunger feelings after consumption of Olibra $^{\circledR}$ yoghurt. Despite reduced subsequent energy intake, contradictory results were seen in hunger and satiety recordings (5-7). A study by Logan et al. failed to confirm the short-term reduction in food intake. Furthermore, the Olibra $^{\circledR}$ emulsion did not appear to exert any suppressive effects on appetite ratings in the medium-term (up to 3 weeks) (27). In the present study, hunger scores during $4 \mathrm{~h}$ after morning consumption of test yoghurt were decreased at the end of the weight-maintenance period, but not at baseline or after weight loss. Food intake was not evaluated in this study.

The mechanism of action of the novel fat emulsion is not precisely understood. It is thought that the satiating power of the Olibra ${ }^{\circledR}$ emulsion is owing to the physio-chemical stability of the emulsion, rather than the constituent of the emulsion per se (27). The observed effects of the novel fat emulsion have been suggested to be the result of the "ileal brake" mechanism (5-7). This ileal brake, for which fat is the most important trigger, initiates a feedback loop that inhibits upper gut motility (to slow gastric emptying and intestinal transit) in response to nutrients in the distal small intestine (28-30). The palm oil core of the relatively small emulsion particles is covered by hydrophilic galactolipids derived from the fractionated oat oil. Owing to this particular combination of triglyceride oils, resulting in delayed digestion compared to the milk fat particles, (partly) undigested particles may penetrate more distal parts of the small intestine, where sensors will detect unabsorbed fat and send satiety signals to the brain. As the ileal brake mechanism appears to be related to the release of one or more satiety hormones from the distal intestine (29, 31, 32), Ghr, GLP-1 and CCK were determined in this study. Indeed, in the long-term, GLP-1 values at $180 \mathrm{~min}$ after test yoghurt consumption in week 25 were significantly increased compared to baseline levels. Thus our findings may support the ileal brake theory indirectly as an explanation for the Olibra ${ }^{\circledR}$ effects in the longer term. The increased GLP-1 values after weight maintenance are in line with the reduced hunger feelings after consumption of test yoghurt at that time point.

Taken together, our results show that the previously observed short-term effects of Olibra ${ }^{\circledR}$-containing yoghurts on energy intake and hunger/satiety scores are not counteracted by compensation behavior during long-term use. Furthermore, long-term use has beneficial effects on body composition and weight maintenance. 


\section{ACKNOWLEDGEMENTS}

We gratefully acknowledge Roy Langeveld, Manuela Lejeune, Natalie Luscombe-Marsh, Joan Senden, Wendy Sluijsmans, Astrid Smeets, Jos Stegen, Loek Wouters and Peter Zuurendonk. The study was funded by Campina Innovation, Wageningen, The Netherlands. The Olibra ${ }^{\circledR}$ fat emulsion was provided by Lipid Technologies Provider AB, Karlshamn, Sweden.

\section{REFERENCES}

1. Seidell JC. Dietary fat and obesity: an epidemiologic perspective. Am J Clin Nutr 1998;67:546S-550S.

2. Stunkard AJ. Current views on obesity. Am J Med 1996;100:230-236.

3. Goldstein DJ. Beneficial health effects of modest weight loss. Int J Obes Relat Metab Disord 1992;16:397-415.

4. Van Gaal LF, Wauters MA, De Leeuw IH. The beneficial effects of modest weight loss on cardiovascular risk factors. Int J Obes Relat Metab Disord 1997;21 Suppl 1:S5-9.

5. Burns AA, Livingstone MB, Welch RW, Dunne A, Reid CA, Rowland IR. The effects of yoghurt containing a novel fat emulsion on energy and macronutrient intakes in nonoverweight, overweight and obese subjects. Int $\mathrm{J}$ Obes Relat Metab Disord 2001;25:1487-96.

6. Burns AA, Livingstone MB, Welch RW, et al. Short-term effects of yoghurt containing a novel fat emulsion on energy and macronutrient intakes in non-obese subjects. Int J Obes Relat Metab Disord 2000;24:1419-25.

7. Burns AA, Livingstone MB, Welch RW, Dunne A, Rowland IR. Dose-response effects of a novel fat emulsion (Olibra) on energy and macronutrient intakes up to $36 \mathrm{~h}$ postconsumption. Eur J Clin Nutr 2002;56:368-77.

8. Harris JA, Benedict FG. A biometric study of basal metabolism in man. Washington: Carnegia Institution 1919.

9. Stunkard AJ, Messick S. The three-factor eating questionnaire to measure dietary restraint, disinhibition and hunger. J Psychosom Res 1985;29:71-83.

10. Raben A, Holst JJ, Christensen NJ, Astrup A. Determinants of postprandial appetite sensations: macronutrient intake and glucose metabolism. Int J Obes Relat Metab Disord 1995;20:161-169.

11. Schoeller DA, van Santen E, Peterson DW, Dietz W, Jaspan J, Klein PD. Total body water measurement in humans with 180 and $2 \mathrm{H}$ labeled water. Am J Clin Nutr 1980;33:2686-2693.

12. van Marken Lichtenbelt WD, Westerterp KR, Wouters L. Deuterium dilution as a method for determining total body water: effect of test protocol and sampling time. $\mathrm{Br} \mathrm{J} \mathrm{Nutr}$ 1994;72:491-497.

13. Westerterp KR, Wouters L, van Marken Lichtenbelt WD. The maastricht protocol for the measurement of body composition and energy expenditure with labeled water. Obes Res 1995;3 (suppl 1):49-57.

14. Forsum E, Kabir N, Sadurskis A, Westerterp K. Total energy expenditure of healthy Swedish women during pregnancy and lactation. Am J Clin Nutr 1992;56:334-42.

15. Adriaens MP, Schoffelen PF, Westerterp KR. Intra-individual variation of basal metabolic rate and the influence of daily habitual physical activity before testing. $\mathrm{Br} \mathrm{J} \mathrm{Nutr}$ 2003;90:419-23. 
16. Weir JBDV. New methods for calculating meatbolic rate with special references to protein metabolism. J Physiol 1949;109:1-9.

17. Ravussin E, Bogardus C. A brief overview of human energy metabolism and its relationship to essential obesity. Am J Clin Nutr 1992;55:242S-245S.

18. Dulloo AG, Jacquet J. The control of partitioning between protein and fat during human starvation: its internal determinants and biological significance. Br J Nutr 1999;82:339-56.

19. Kempen KP, Saris WH, Westerterp KR. Energy balance during an 8-wk energy-restricted diet with and without exercise in obese women. Am J Clin Nutr 1995;62:722-9.

20. Adam TC, Westerterp-Plantenga MS. Nutrient-stimulated GLP-1 release in normal-weight men and women. Horm Metab Res 2005;37:111-7.

21. Lejeune MP, Kovacs EM, Westerterp-Plantenga MS. Additional protein intake limits weight regain after weight loss in humans. Br J Nutr 2005;93:281-9.

22. Westerterp-Plantenga MS, Lejeune MP, Kovacs EM. Body weight loss and weight maintenance in relation to habitual caffeine intake and green tea supplementation. Obes Res 2005;13:1195-204.

23. Westerterp-Plantenga MS, Lejeune MP, Nijs I, van Ooijen M, Kovacs EM. High protein intake sustains weight maintenance after body weight loss in humans. Int $\mathrm{J}$ Obes 2004;28:57-64.

24. Visscher TL, Seidell JC. Time trends (1993-1997) and seasonal variation in body mass index and waist circumference in the Netherlands. Int $\mathrm{J}$ Obes Relat Metab Disord 2004;28:1309-16.

25. Bigaard J, Tjonneland A, Thomsen BL, Overvad K, Heitmann BL, Sorensen TI. Waist circumference, BMI, smoking, and mortality in middle-aged men and women. Obes Res 2003;11:895-903.

26. Bigaard J, Frederiksen $\mathrm{K}$, Tjonneland $\mathrm{A}$, et al. Waist circumference and body composition in relation to all-cause mortality in middle-aged men and women. Int $\mathrm{J}$ Obes (Lond) 2005;29:778-84.

27. Logan CM, McCaffrey TA, Wallace JM, et al. Investigation of the medium-term effects of Olibratrade mark fat emulsion on food intake in non-obese subjects. Eur J Clin Nutr 2006;60:1081-91.

28. Spiller RC, Trotman IF, Higgins BE, et al. The ileal brake--inhibition of jejunal motility after ileal fat perfusion in man. Gut 1984;25:365-74.

29. Van Citters GW, Lin HC. The ileal brake: a fifteen-year progress report. Curr Gastroenterol Rep 1999;1:404-9.

30. Symerski T, Kee B, Haddeman E, Peters H, Masclee A. lleal brake effects on satiety and meal intake in humans after a meal replacer (abstract). Int J Obes 2004;28 suppl 1:S148.

31. Aponte GW, Fink AS, Meyer JH, Tatemoto K, Taylor IL. Regional distribution and release of peptide YY with fatty acids of different chain length. Am J Physiol 1985;249:G745-50.

32. Jin $\mathrm{H}$, Cai $\mathrm{L}$, Lee $\mathrm{K}$, et al. A physiological role of peptide $\mathrm{YY}$ on exocrine pancreatic secretion in rats. Gastroenterology 1993;105:208-15. 



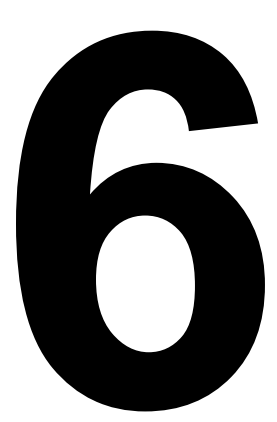

\section{Short-term effects of a novel fat emulsion on appetite and food intake in different weight and age groups}

Kristel Diepvens, Jan Steijns, Peter Zuurendonk, Margriet S Westerterp-

Plantenga

Submitted for publication 


\begin{abstract}
The objective of the study was to confirm the satiety/energy intake effect of a novel fat emulsion (Olibra ${ }^{\circledR}$ ) versus placebo in the short term in different age and weight groups. A randomized, double-blind, placebo-controlled, crossover design was used. 41 subjects participated in the study (young-normal weight: age $23.7 \pm 2.8$ years; $\mathrm{BMl}: 22.0 \pm 1.6 \mathrm{~kg} / \mathrm{m}^{2}$; old-overweight: age $43.6 \pm 4.9$ years; BMl: $27.7 \pm 1.6 \mathrm{~kg} / \mathrm{m}^{2}$ ). An energy intake and satiety test (with questionnaires) took place on 2 occasions, with placebo or test yoghurt as breakfast. In the young-normal weight subjects, consumption of test yoghurt reduced hunger and desire to eat during the morning (area under curve, $p<0.05)$, increased fullness $3 \mathrm{~h}$ after consumption $(p<0.05)$ and increased the intermeal interval (time elapsed between consumption of the yoghurt and the point at which hunger scores returned to baseline; $3.7 \pm 1.2 \mathrm{~h}$ in test group compared to $2.9 \pm 1.0 \mathrm{~h}$ in placebo group, $\mathrm{p}<0.05)$. Furthermore, the test yoghurt reduced desire to eat $(1 \mathrm{~h}$ and $3 \mathrm{~h}$ after yoghurt, $\mathrm{p}<0.05)$ and prospective food consumption ( $1 \mathrm{~h}$ after yoghurt, $\mathrm{p}<0.05$ ) in the total group. No significant differences in appetite scores between the test and placebo yoghurt were seen for the old-overweight subjects. No effect on energy intake was seen in the total group, in the young-normal weight and old-overweight subjects. In conclusion, the Olibra ${ }^{\circledR}$ emulsion exerted a suppressive effect on appetite ratings in the short term. These effects were only expressed in normal-weight women aged 18 to 30 years.
\end{abstract}

Keywords: fat, emulsion, hunger, food intake, intermeal interval 


\section{INTRODUCTION}

The global prevalence of overweight and obesity has increased considerably in the last decade (1). Obesity raises the risk for developing diseases such as coronary heart disease, hypertension, non-insulin-dependent diabetes mellitus, pulmonary dysfunction and certain types of cancer (2). Treatment of obesity is beneficial in that weight loss reduces the risk for mortality and morbidity $(3,4)$. Body weight loss and prevention of body weight (re)gain can be achieved by reducing energy intake (EI) and/or increasing energy expenditure.

Olibra $^{\circledR}$, a novel fat emulsion consisting of a mixture of fractionated palm oil $(40 \%)$ and fractionated oat oil $(2.5 \%)$ in water, is an example of an active ingredient that aims to promote reduction of El by promoting and maintaining satiety.

Previously an Irish research group showed that, in comparison with a yoghurt containing only dairy fat, consumption of a $200 \mathrm{~g}$ yoghurt containing the novel fat emulsion significantly increased satiety and subsequently decreased $\mathrm{El}$ in non-obese, overweight and obese subjects, at a meal $4 \mathrm{~h}$ later, and that the decreased intake persisted for the rest of the day (5-7). However, the magnitude of the responses observed $4 \mathrm{~h}$ post-consumption were not as significant in the overweight (27.6\% reduction in El, p<0.05; El: $4.4 \mathrm{MJ}$ after test yoghurt compared to $6.1 \mathrm{MJ}$ after placebo yoghurt) and obese group (13.1\% reduction in $\mathrm{El}$, ns; El: $4.6 \mathrm{MJ}$ after test yoghurt compared to $5.3 \mathrm{MJ}$ after placebo yoghurt) compared to the non-overweight group (30.2\% reduction in El, $\mathrm{p}<0.05$; El: $3.8 \mathrm{MJ}$ after test yoghurt compared to $5.4 \mathrm{MJ}$ after placebo yoghurt) (5). Also age may have contributed to the differences seen, as the overweight (33 y) and obese (39 y) subjects were older than the non-overweight (28 y) subjects (5). Furthermore, despite reduced subsequent El, contradictory results were seen in hunger and satiety recordings (5-7). In addition, a longer-term study by Logan et al. failed to confirm the short-term reduction in El (8).

Until now, the results by Burns et al. (5-7) have not been confirmed by other studies. Consequently, the aim of the present study was to confirm and unravel the satiety/El effect of Olibra $^{\circledR}$ versus placebo in the short term and to investigate these effects in different age and weight groups.

\section{SUBJECTS AND METHODS}

\section{Subjects}

Forty-one female subjects participated in this study: 21 subjects (young-normal weight group), aged $18-30$ years, were non-overweight (BMI $\left.20-25 \mathrm{~kg} / \mathrm{m}^{2}\right) ; 20$ subjects (old-overweight group), aged 30-50 years, were overweight (BMI 25-30 $\mathrm{kg} / \mathrm{m}^{2}$ ). The subjects were recruited by advertisement in local newspapers and 
by poster advertisement from the student and staff population. All subjects participated in an initial screening that involved measurement of body weight, height, body composition, waist:hip circumference, blood pressure, heart rate, completion of a questionnaire related to eating behavior (Three Factor Eating Questionnaire, TFEQ (9)) and completion of a questionnaire related to health, use of medication, smoking behavior, alcohol consumption and physical activity. All subjects were in good health, at most moderate alcohol users, unrestrained eaters (as assessed by factor 1 of the TFEQ) and had a stable body weight $(<3$ $\mathrm{kg}$ change) over the last 6 months. Other exclusion criteria were smoking, using prescription medication and having metabolic disorders (except being overweight for the old-overweight group). The $24 \mathrm{~h}$ energy requirement (MJ/day) of the subjects was calculated from Harris \& Benedict and physical activity level (PAL) was estimated as $1.6(10)$. Baseline characteristics of the subjects are presented in table 1.

Table 1 Subjects characteristics at baseline

\begin{tabular}{lccc}
\hline & Young-normal weight $(\mathrm{n}=21)$ & Old-overweight $(\mathrm{n}=20)$ & Total $(\mathrm{n}=41)$ \\
\hline Age $(\mathrm{y})$ & $23.7 \pm 2.8$ & $43.6 \pm 4.9^{*}$ & $33.4 \pm 10.8$ \\
Body weight $(\mathrm{kg})$ & $62.0 \pm 5.0$ & $76.8 \pm 8.3^{*}$ & $69.2 \pm 10.1$ \\
Height $(\mathrm{m})$ & $1.68 \pm 0.05$ & $1.66 \pm 0.08$ & $1.67 \pm 0.07$ \\
BMI $\left(\mathrm{kg} / \mathrm{m}^{2}\right)$ & $22.0 \pm 1.6$ & $27.7 \pm 1.6^{*}$ & $24.8 \pm 3.3$ \\
Waist $(\mathrm{cm})$ & $73.7 \pm 3.9$ & $88.9 \pm 5.2^{*}$ & $81.1 \pm 8.9$ \\
Hip (cm) & $91.7 \pm 3.8$ & $106.8 \pm 5.7^{*}$ & $99.1 \pm 9.0$ \\
Waist:Hip ratio & $0.80 \pm 0.04$ & $0.83 \pm 0.04^{*}$ & $0.82 \pm 0.04$ \\
SBP (mmHg) & $120.2 \pm 10.0$ & $129.3 \pm 11.4^{*}$ & $124.6 \pm 11.5$ \\
DBP (mmHg) & $73.6 \pm 6.9$ & $85.3 \pm 10.6^{*}$ & $79.3 \pm 10.6$ \\
Heart rate (beats/min) & $72.7 \pm 13.1$ & $71.2 \pm 11.5$ & $72.0 \pm 12.2$ \\
F1 (TFEQ) & $5.6 \pm 2.2$ & $5.2 \pm 2.3$ & $5.4 \pm 2.2$ \\
F2 (TFEQ) & $4.3 \pm 2.0$ & $5.4 \pm 2.8$ & $4.8 \pm 2.4$ \\
F3 (TFEQ) & $3.7 \pm 2.7$ & $4.8 \pm 3.0$ & $4.2 \pm 2.9$ \\
24h energy requirement ${ }^{*}$ & $9.7 \pm 0.4$ & $10.0 \pm 0.7$ & $9.8 \pm 0.5$ \\
(MJ/day) & & & \\
\hline
\end{tabular}

Values are means \pm sd.

BMI (Body Mass Index, $\mathrm{kg} / \mathrm{m}^{2}$ ), waist circumference $(\mathrm{cm})$, hip circumference $(\mathrm{cm})$, SBP (systolic blood pressure, mmHg), DBP (diastolic blood pressure, $\mathrm{mmHg}$ ), F1, F2, F3 (factor 1, 2 and 3 of the Three Factor Eating Questionnaire) ${ }^{*} p<0.05$ factorial ANOVA (difference between the young-normal weight and old-overweight group)

\# Calculated from Harris \& Benedict (10); physical activity level (PAL) estimated as 1.6 
The subjects gave their written informed consent and the Medical Ethical Committee of Maastricht University approved the study.

\section{Experimental design}

A randomized, double-blind, placebo-controlled, crossover design was used. A satiety and energy intake test took place on 2 occasions, with a one-week interval between crossover. Subjects were asked to fast from $22.00 \mathrm{~h}$ on the evening before the each study day and to refrain from moderate-to-heavy exercise during the whole study period.

\section{$\underline{\text { Satiety and energy intake test }}$}

The subjects arrived at $08.00 \mathrm{~h}$ in a fasted state at the laboratory. The subjects received $250 \mathrm{~g}$ test yoghurt $(250 \mathrm{~g}$ yoghurt containing $0.2 \mathrm{~g}$ milk fat and $4 \mathrm{~g}$ vegetable fat, provided by adding $10 \mathrm{~g}$ Olibra $^{\circledR}$ emulsion (Lipid Technologies Provider AB, Karlshamn, Sweden) to the yoghurt) or placebo yoghurt (250 g yoghurt containing $4.2 \mathrm{~g}$ milk fat) as breakfast. Olibra ${ }^{\circledR}$ is a novel fat emulsion consisting of a mixture of fractionated palm oil $(40 \%)$ and fractionated oat oil $(2.5 \%)$ in water. The composition of both yoghurts was matched for energy and macronutrient content. Yoghurt consumption $(250 \mathrm{~g})$ provided $0.9 \mathrm{MJ} /$ day (energy\% C/P/F: 68/14/18). The yoghurt was served in randomized order and consumed within $5 \mathrm{~min}$. After eating the yoghurt, subjects resumed their normal routine for the morning and they were instructed not to eat or drink anything, except water if required. An appetite questionnaire was completed before breakfast, and 60, 120, 180 and 240 min after consumption of the yoghurt. At $13.00 \mathrm{~h}, 4 \mathrm{~h}$ after yoghurt consumption, subjects were provided with a lunch and $200 \mathrm{ml}$ water. Instructions were given to eat until comfortably satisfied. Food was removed after $20 \mathrm{~min}$. The ad libitum lunch consisted of $1000 \mathrm{~g}$ lasagna (0.65 MJ per $100 \mathrm{~g}$; en\% C/P/F: 33/20/47). Food was weighed prior to the meal and after the subjects left the laboratory. Food intake was assessed by difference. After lunch, subjects left the laboratory and were instructed not to eat or drink anything, except water, till $240 \mathrm{~min}$ after lunch and to complete the appetite questionnaire at 60, 120, 180 and $240 \mathrm{~min}$ after lunch.

\section{Calculation of intermeal interval}

The intermeal interval is the time elapsed between consumption of the yoghurt and the point at which hunger scores returned to baseline $(=08.00 \mathrm{~h})$. The intermeal intervals were divided into categories: back at baseline at $09.00 \mathrm{~h}$ $($ after $1 \mathrm{~h})=1$, at $10.00 \mathrm{~h}($ after $2 \mathrm{~h})=2$, at $11.00 \mathrm{~h}$ (after $3 \mathrm{~h})=3$, at $12.00 \mathrm{~h}$ (at lunchtime, after $4 \mathrm{~h}$ ) $=4$, at $12.00 \mathrm{~h}$ still not returned to baseline levels, thus less hungry than at baseline $=5$. 


\section{Anthropometry}

Body weight was measured using a digital balance accurate to $0.02 \mathrm{~kg}$ (ChyoMW-150K, Chyo, Japan) with subjects in underwear after voiding their bladder. Height was measured to the nearest $0.1 \mathrm{~cm}$ using a wall-mounted stadiometer. The waist:hip ratio was calculated by dividing the waist circumference by the hip circumference. The waist circumference was measured at the site of the smallest circumference between the rib cage and the iliac crest, and the hip circumference was measured at the site of the largest circumference between the waist and the thighs. Both measurements were performed with subjects in standing position. Systolic blood pressure, diastolic blood pressure and heart rate were recorded using an automatic blood pressure monitor (OSZ 5 easy; Spreidel \& Keller GmBH and Co. KG, Jungingen, Germany).

\section{$\underline{\text { Questionnaire }}$}

The appetite questionnaire is a Visual Analogue Scale questionnaire (VAS, in $\mathrm{mm}$ ) with questions about feelings of hunger, fullness, desire to eat and prospective food consumption. Opposing extremes of each feeling were described at either end of a $100 \mathrm{~mm}$ horizontal line, and subjects marked the line to indicate how they felt at that moment.

\section{$\underline{\text { Statistical analysis }}$}

Data are presented as means and standard deviations, unless otherwise indicated. Data were analyzed using Statview SE + Graphics (Abacus Concepts, Berkeley, CA, USA, 1988). Differences between groups were analyzed using factorial ANOVA. A one-factor repeated measures ANOVA was used to determine possible differences between the conditions. Univariate linear regression and multiple regression was used to determine the relationship between selected variables. The level for establishing significant differences was taken at $p<0.05$.

\section{RESULTS}

The baseline values of the measured variables from the appetite questionnaire (hunger, fullness, desire to eat and prospective food consumption) were not significantly different between treatments.

The appetite questionnaire results for the total group, the young-normal weight subjects and the old-overweight subjects are respectively presented in figure $1 \mathrm{a}, 1 \mathrm{~b}$ and $1 \mathrm{c}$ (hunger), figure $2 \mathrm{a}, 2 \mathrm{~b}$ and $2 \mathrm{c}$ (fullness), figure $3 \mathrm{a}, 3 \mathrm{~b}$ and $3 \mathrm{c}$ (desire to eat), figure $4 \mathrm{a}, 4 \mathrm{~b}$ and $4 \mathrm{c}$ (prospective food consumption) and table 2 


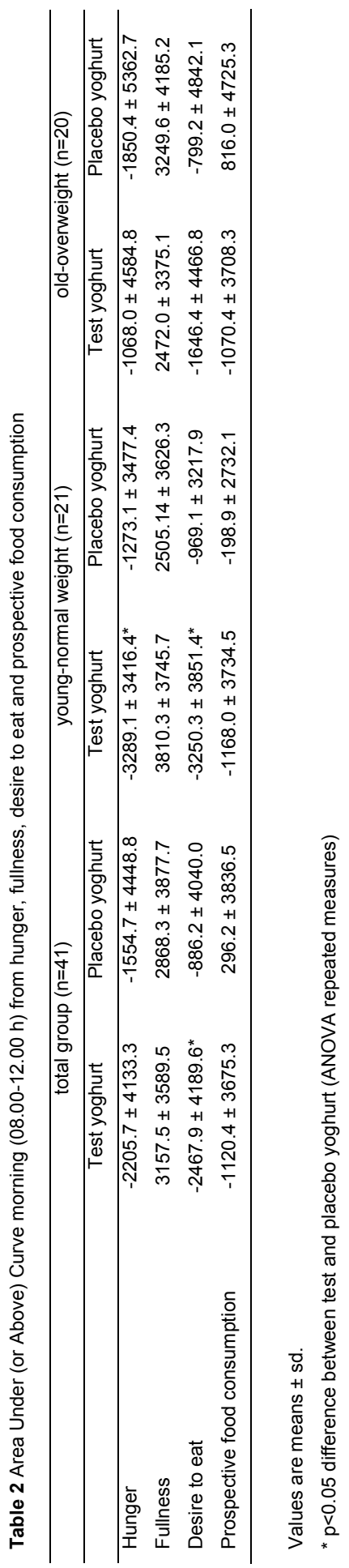


Chapter 6
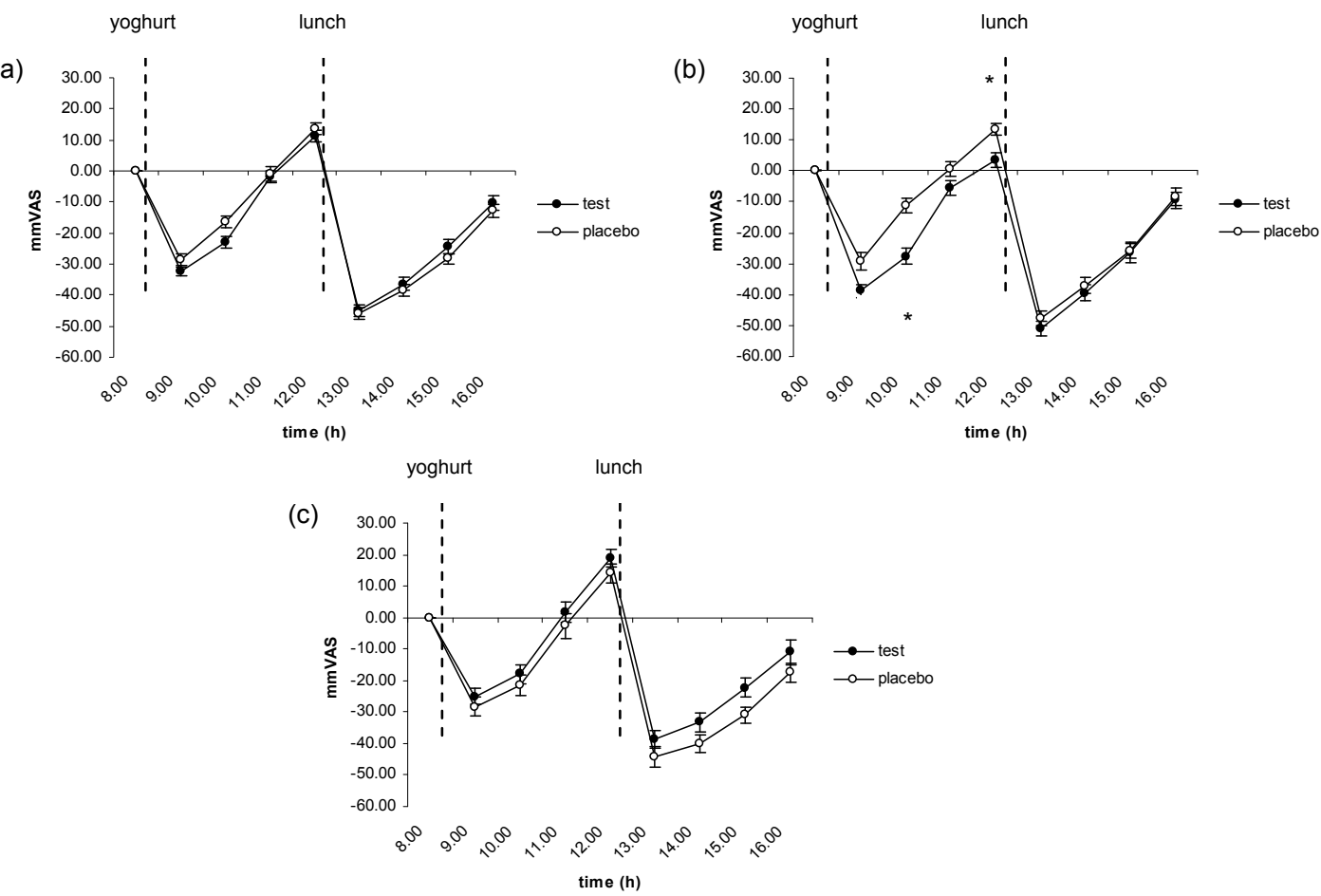

Figure 1 Hunger scores (changes from baseline, mmVAS).

(a) total group ( $n=41)$; (b) young-normal weight subjects ( $n=21)$; (c) old-overweight subjects $(n=20)$ Values are means \pm sem; ${ }^{*} p<0.05$ difference between test and placebo yoghurt (ANOVA repeated measures).
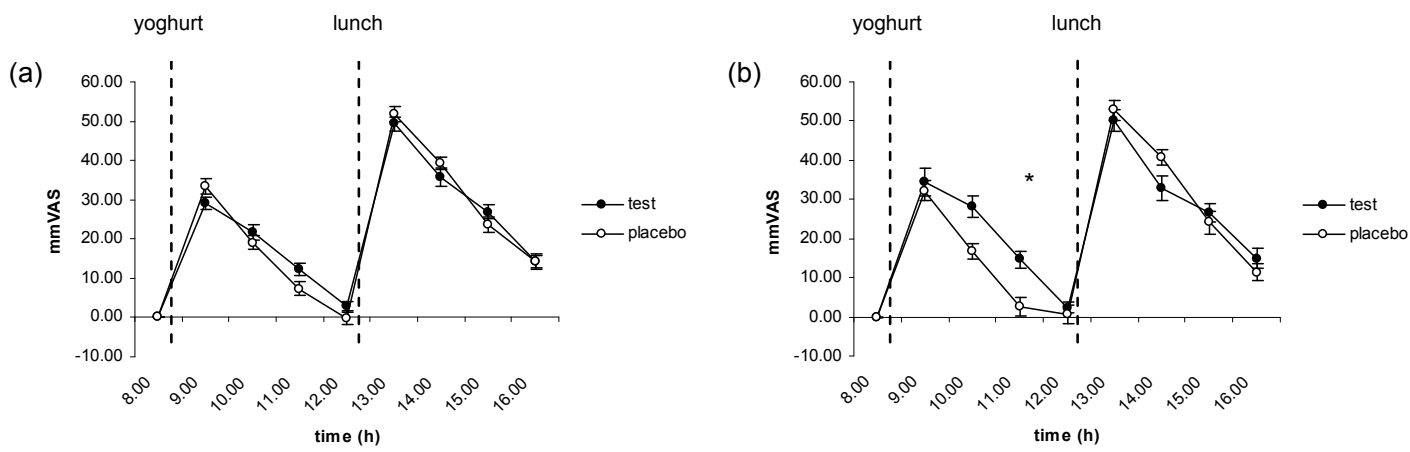


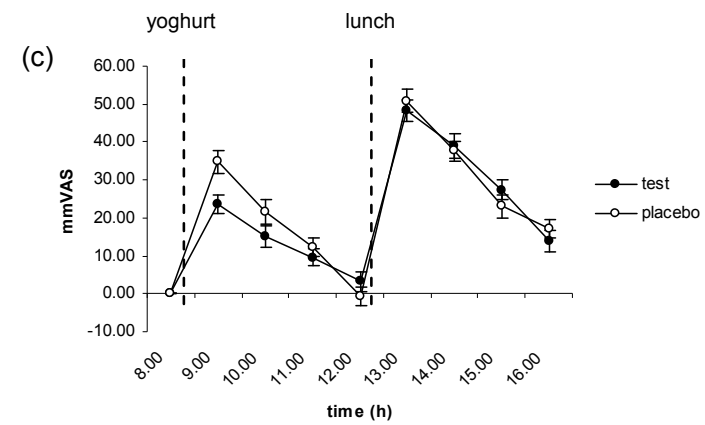

Figure 2 Fullness scores (changes from baseline, mmVAS).

(a) total group ( $n=41)$; (b) young-normal weight subjects ( $n=21)$; (c) old-overweight subjects $(n=20)$ Values are means \pm sem; ${ }^{*} p<0.05$ difference between test and placebo yoghurt (ANOVA repeated measures).
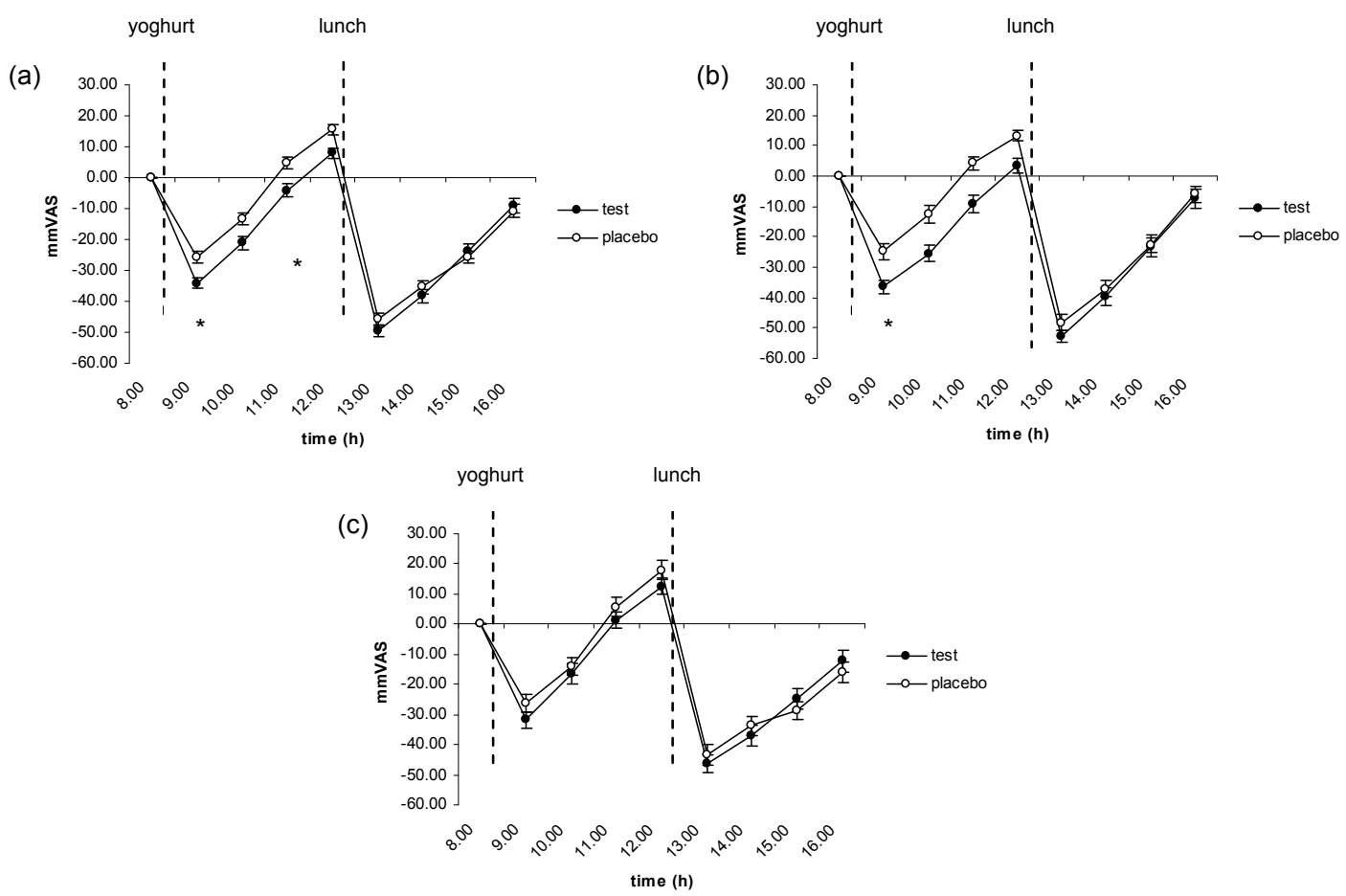

Figure 3 Desire to eat scores (changes from baseline, mmVAS).

(a) total group ( $n=41)$; (b) young-normal weight subjects $(n=21)$; (c) old-overweight subjects $(n=20)$ Values are means \pm sem; * $p<0.05$ difference between test and placebo yoghurt (ANOVA repeated measures). 

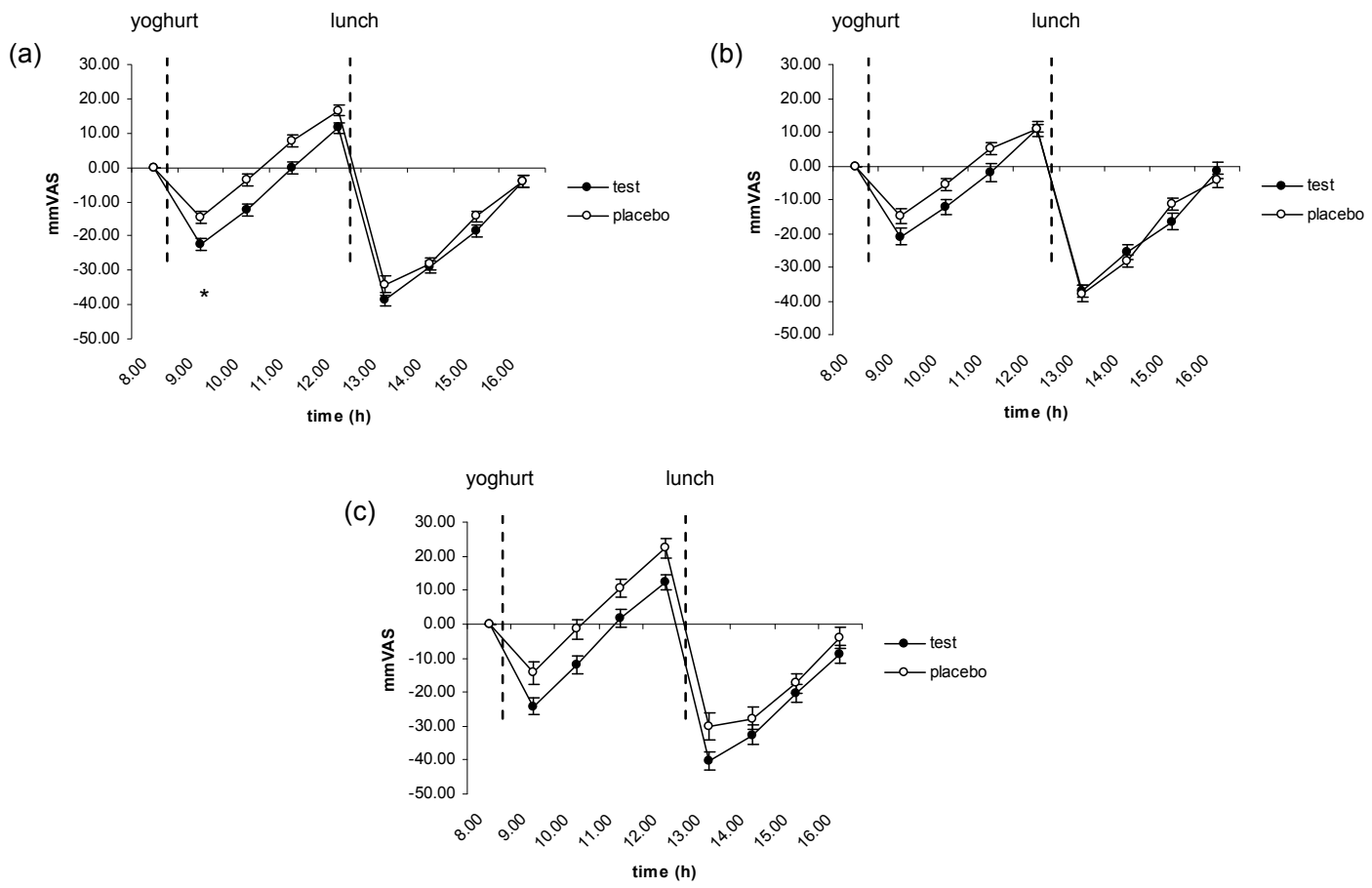

Figure 4 Prospective food consumption scores (changes from baseline, mmVAS).

(a) total group ( $n=41)$; (b) young-normal weight subjects ( $n=21)$; (c) old-overweight subjects $(n=20)$ Values are means \pm sem; * $p<0.05$ difference between test and placebo yoghurt (ANOVA repeated measures).

Table 3 Estimated intermeal interval based on hunger scores

\begin{tabular}{lcc}
\hline & Test yoghurt & Placebo yoghurt \\
\hline Total group $(n=41)$ & $3.5 \pm 1.3$ & $3.1 \pm 1.3$ \\
Young-normal weight $(n=21)$ & $3.7 \pm 1.2$ & $2.9 \pm 1.0^{*}$ \\
Old-overweight $(n=20)$ & $3.3 \pm 1.3$ & $3.5 \pm 1.4$ \\
\hline
\end{tabular}

Values are means $\pm s d$.

${ }^{*} p<0.05$ difference between test and placebo yoghurt (ANOVA repeated measures) 
(Area Under/Above Curve (AUC) 08.00-12.00 h). As presented in figure 1b, $2 \mathrm{~h}$ and $4 \mathrm{~h}$ after yoghurt consumption, less hunger (magnitude of difference is 1017 mmVAS) was reported after test yoghurt compared to placebo yoghurt in the young-normal weight subjects. Furthermore, the young-normal weight subjects showed less hunger during the morning after test yoghurt as determined by the higher Area Above Curve compared to the placebo group (table 2, $\mathrm{p}<0.05$ ). $3 \mathrm{~h}$ after the test yoghurt, more fullness was observed compared to the placebo yoghurt in the young-normal weight subjects (figure $2 \mathrm{~b}, \mathrm{p}<0.05$ ). $1 \mathrm{~h}$ after yoghurt consumption, a smaller desire to eat was seen in both the total group and the young-normal weight subjects after test yoghurt compared to placebo yoghurt $(p<0.05$, figure 3$)$ In the total group, this difference was also observed $3 \mathrm{~h}$ after yoghurt consumption ( $<<0.05$, figure $3 a$ ). In addition, in both the total group and the young-normal weight subjects, the Area Above Curve desire to eat was significantly higher for the test group compared to the placebo group during the morning, in that the test group showed less desire to eat (table 2, $p<0.05)$. As presented in figure $4 a$, the prospective food consumption was lower $1 \mathrm{~h}$ after test yoghurt compared to placebo yoghurt in the total group $(p<0.05)$. No significant differences in appetite questionnaire scores and AUC between the test and placebo yoghurt were seen for the old-overweight subjects (figure $1 \mathrm{c}, 2 \mathrm{c}, 3 \mathrm{c}$ and $4 \mathrm{c}$, table 2).

The intermeal intervals are shown in table 3 . In the young-normal weight subjects, the intermeal interval after consumption of the test yoghurt was significantly larger than after placebo yoghurt (table $3, p<0.05$ ).

$4 \mathrm{~h}$ after consumption of the test and placebo yoghurt, no difference in food intake $(\mathrm{g})$ at lunch was seen in the total group (test: $467.6 \pm 114.3$; placebo: $450.1 \pm 90.7$ ), the young-normal weight subjects (test: $430.4 \pm 84.6$; placebo: $421.5 \pm 79.6$ ) and the old-overweight subjects (test: $506.7 \pm 129.7$; placebo: $480.2 \pm 93.8)$. The young-normal weight group $(426.0 \pm 81.3)$ ate significantly $(p<0.05)$ less compared to the old-overweight group (493.4 \pm 112.5$)$.

For the total group, food intake at lunch was positive correlated with AUC Hunger $08.00-12.00 \mathrm{~h}$ after both the test $\left(p<0.05, r^{2}=0.15\right)$ and placebo yoghurt $\left(p<0.05, r^{2}=0.10\right)$.

In the total group, a multiple regression failed to show a relation between age, $\mathrm{BMI}$ and the difference in El (between test and placebo yoghurt) at the test lunch. Nevertheless, El at lunch was positively related to age in both conditions $\left(r^{2}=0.11\right.$ and $\left.0.15, p<0.05\right)$ and to BMI in the control condition $\left(r^{2}=0.10, p<0.05\right)$.

\section{DISCUSSION}

In the present study, the Olibra ${ }^{\circledR}$ emulsion exerted a suppressive effect on appetite ratings in the short-term, i.e. till $4 \mathrm{~h}$ after yoghurt consumption. However, the study failed to confirm the short-term reduction in El $4 \mathrm{~h}$ after 
yoghurt consumption which was seen in other studies (5-7). This may be due to the magnitude of the difference between the appetite ratings, the timing of the subsequent meal and the relationship between hunger and subsequent meal size.

In this study, consumption of $250 \mathrm{~g}$ yoghurt containing $10 \mathrm{~g}$ Olibra ${ }^{\circledR}$ fat emulsion reduced hunger and desire to eat during the morning (AUC), increased fullness $3 \mathrm{~h}$ after consumption and increased the intermeal interval $(3.7 \pm 1.2 \mathrm{~h}$ in test group compared to $2.9 \pm 1.0 \mathrm{~h}$ in placebo group) in 21 normal-weight women aged 18 to 30 years. Furthermore, the test yoghurt reduced desire to eat $(1 \mathrm{~h}$ and $3 \mathrm{~h}$ after yoghurt) and prospective food consumption (1h after yoghurt) in the total group (41 subjects, aged 18 to 50 years, BMl: $20-30 \mathrm{~kg} / \mathrm{m}^{2}$ ). The magnitude of reduced hunger, however, may have been too small to exert an effect on subsequent El. On the other hand, the increased intermeal interval after test yoghurt consumption in the young-normal weight subjects may have important implications as this, together with the lower hunger scores, is likely to delay the onset and size of the next meal when subjects are allowed to choose their own mealtimes and food composition. In this study, the maximal differences in hunger were observed after $2 \mathrm{~h}$, the intermeal interval was $3.7 \mathrm{~h}$ vs. $2.9 \mathrm{~h}$, and the subsequent meal was given $4 \mathrm{~h}$ after consumption of the yoghurt. It may be that if our subjects had consumed lunch $3 \mathrm{~h}$ after yoghurt consumption, a difference in El had occurred since hunger scores were back at

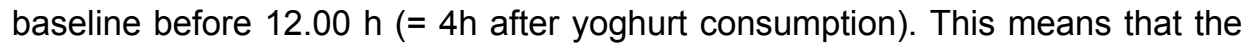
subjects were hungry at lunchtime at both occasions.

In the old-overweight subjects, overweight women aged 30-50 years, no effect of test yoghurt consumption on appetite ratings was seen. This is in accordance with the study of Burns et al. where the magnitude of the responses observed was not as significant in the overweight and obese group compared to the nonoverweight group (5). They suggested that with higher BMI the dose expressed to body weight might affect the magnitude of the treatment response to Olibra ${ }^{\circledR}$ emulsion (5). However, in a dose-response study comparing the effects of 5, 10 and $15 \mathrm{~g}$ Olibra ${ }^{\circledR}$ emulsion, no enhancement of responses proportional to dose was seen (7). Also age may play a role as our subjects in the overweight group (old-overweight; mean age $43.6 \mathrm{y}$ ) were older compared to the non-overweight group (young-normal weight; mean age $23.7 \mathrm{y}$ ). Aging is associated with a decrease in appetite and food intake, and with a slower gastric emptying (1113). However, it is noteworthy to mention here that the long-term study by our group demonstrated beneficial differences with yoghurt containing Olibra ${ }^{\circledR}$ in a group of subjects comparable to the old-overweight subjects (14).

In both the test and placebo group, a significant linear relation was found between hunger during the morning period and food intake at lunch, yet the explained variance $\left(r^{2}\right)$ was very small $\left(r^{2}=0.15\right.$ and 0.1$)$. The relation is too weak to cause differences in El. In contrast, Burns et al. showed that consumption of yoghurt containing the novel fat emulsion significantly 
decreased $\mathrm{El}$ in non-overweight, overweight and obese subjects at a meal $4 \mathrm{~h}$ later (5-7). A difference between the studies of Burns et al. and our study is that their subjects, in the same range of body weight as our subjects, ad libitum consumed very large lunches (5-6 MJ) (5-7) after control yoghurt while our subjects ad libitum consumed $3 \mathrm{MJ}$ at the lunch on the test day after both test and control yoghurt. Also, in a medium-term study by Logan et al., no difference in El was observed after Olibra ${ }^{\circledR}$ yoghurt (8). During test lunch, the young-normal weight group ate less compared to the old-overweight group. The higher body weight, and thus higher energy requirement $(9.7 \mathrm{MJ} /$ day for the young/normal weight compared to $10.0 \mathrm{MJ} /$ day for the old/overweight subjects) (10) of the old/overweight subjects is an explanation for this.

The mechanism of action of the novel fat emulsion is not precisely understood. The observed effect of Olibra ${ }^{\circledR}$ has been suggested to be the result of the ileal brake mechanism (5-7). This ileal brake, for which fat is the most important trigger, initiates a feedback loop that inhibits upper gut motility (to slow gastric emptying and intestinal transit) in response to nutrients in the distal small intestine (15-17). The palm oil core of the relatively small emulsion particles is covered by hydrophilic galactolipids derived from the fractionated oat oil. Due to this particular combination of triglyceride oils, resulting in delayed digestion compared to the milk fat particles, (partly) undigested particles may penetrate more distal parts of the small intestine, where sensors will detect unabsorbed fat and send satiety signals to the brain. The Olibra ${ }^{\circledR}$ emulsion has been shown to reduce El in controlled short-term studies (5-7) and to improve weight maintenance and body composition when used daily in free living situation for up to 18 weeks versus a placebo with milk fat (14).

In the present study, we investigated young-normal weight subjects and oldoverweight subjects. The constitution of these groups was based on the results by Burns et al. (5). We found that effects of age or BMI on El were sometimes present but rather weak. For future research, however, it appears necessary to study also young females with high BMI and older ones with normal body weight.

In conclusion, the Olibra $^{\circledR}$ emulsion exerted a suppressive effect on appetite ratings in the short-term. These effects were only expressed in normal-weight women aged 18 to 30 years. However, the magnitude of these effects as well as their relationship with subsequent food consumption did not affect El $4 \mathrm{~h}$ after yoghurt consumption. For this endpoint, it may be necessary to assess $\mathrm{El}$ at a timepoint before hunger scores were returned to baseline.

\section{ACKNOWLEDGEMENTS}

We gratefully acknowledge Annemiek Joosen, Margriet Veldhorst and Ananda Waelen. 
The study was funded by Campina Innovation, Wageningen, The Netherlands. The Olibra ${ }^{\circledR}$ fat emulsion was provided by Lipid Technologies Provider AB, Karlshamn, Sweden.

\section{REFERENCES}

1. Seidell JC. Dietary fat and obesity: an epidemiologic perspective. Am J Clin Nutr 1998;67:546S-550S.

2. Stunkard AJ. Current views on obesity. Am J Med 1996;100:230-236.

3. Goldstein DJ. Beneficial health effects of modest weight loss. Int J Obes Relat Metab Disord 1992;16:397-415.

4. Van Gaal LF, Wauters MA, De Leeuw IH. The beneficial effects of modest weight loss on cardiovascular risk factors. Int J Obes Relat Metab Disord 1997;21 Suppl 1:S5-9.

5. Burns AA, Livingstone MB, Welch RW, Dunne A, Reid CA, Rowland IR. The effects of yoghurt containing a novel fat emulsion on energy and macronutrient intakes in nonoverweight, overweight and obese subjects. Int $\mathrm{J}$ Obes Relat Metab Disord 2001;25:1487-96.

6. Burns AA, Livingstone MB, Welch RW, et al. Short-term effects of yoghurt containing a novel fat emulsion on energy and macronutrient intakes in non-obese subjects. Int J Obes Relat Metab Disord 2000;24:1419-25.

7. Burns AA, Livingstone MB, Welch RW, Dunne A, Rowland IR. Dose-response effects of a novel fat emulsion (Olibra) on energy and macronutrient intakes up to $36 \mathrm{~h}$ postconsumption. Eur J Clin Nutr 2002;56:368-77.

8. Logan CM, McCaffrey TA, Wallace JM, et al. Investigation of the medium-term effects of Olibratrade mark fat emulsion on food intake in non-obese subjects. Eur J Clin Nutr 2006;60:1081-91.

9. Stunkard AJ, Messick S. The three-factor eating questionnaire to measure dietary restraint, disinhibition and hunger. J Psychosom Res 1985;29:71-83.

10. Harris JA, Benedict FG. A biometric study of basal metabolism in man. Washington: Carnegia Institution 1919.

11. Clarkston WK, Pantano MM, Morley JE, Horowitz M, Littlefield JM, Burton FR. Evidence for the anorexia of aging: gastrointestinal transit and hunger in healthy elderly vs. young adults. Am J Physiol 1997;272:R243-8.

12. Horowitz M, Maddern GJ, Chatterton BE, Collins PJ, Harding PE, Shearman DJ. Changes in gastric emptying rates with age. Clin Sci (Lond) 1984;67:213-8.

13. Wurtman JJ, Lieberman H, Tsay R, Nader T, Chew B. Calorie and nutrient intakes of elderly and young subjects measured under identical conditions. J Gerontol 1988;43:B174-80.

14. Diepvens K, Soenen S, Steijns J, Arnold M, Westerterp-Plantenga M. Long-term effects of consumption of a novel fat emulsion in relation to body-weight management. Int $\mathrm{J}$ Obes (Lond) 2007;31:942-9.

15. Spiller RC, Trotman IF, Higgins BE, et al. The ileal brake--inhibition of jejunal motility after ileal fat perfusion in man. Gut 1984;25:365-74.

16. Van Citters GW, Lin HC. The ileal brake: a fifteen-year progress report. Curr Gastroenterol Rep 1999;1:404-9.

17. Symerski T, Kee B, Haddeman E, Peters H, Masclee A. Ileal brake effects on satiety and meal intake in humans after a meal replacer (abstract). Int J Obes 2004;28 suppl 1:S148. 


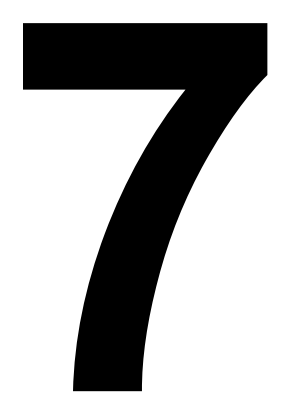

\section{Effects of different proteins and biopeptides on satiety and 'satiety' or 'orexigenic' hormones}

Kristel Diepvens, Doreen Häberer, Margriet S Westerterp-Plantenga

Submitted for publication 


\section{ABSTRACT}

Objective: We investigated the effects of whey protein (WP), pea protein hydrolysate (PPH), a combination of WP+PPH, and control (milk protein, MP) on appetite ratings, postprandial changes in hunger/satiety hormones and energy intake (EI).

Design: a randomized, crossover design which consisted of 2 parts (experiment 1 and 2). The peptides to be tested were provided as part of a shake (1024 kJ; en\% P/F/C: 25/33/42).

Subjects: 39 subjects (BMI: $27.6 \pm 1.7 \mathrm{~kg} / \mathrm{m}^{2}$; age $42.3 \pm 13.8$ years)

Measurements: In experiment 1, appetite profile was measured and blood samples were taken for analysis of hunger/satiety hormones and glucose. In experiment 2, appetite profile and El were measured.

Results: Some indications of lower hunger (experiment 1), desire to eat (experiment 2) and thirst (experiment 1 and 2) were shown after consumption of PPH compared to MP or WP+PPH $(p<0.05)$. A longer intermeal interval and a higher satiety index were suggested after consumption of PPH. Both PPH and WP lead to greater satiety (experiment 2 ) and fullness (experiment 2 ) compared to MP and WP+PPH $(p<0.05)$. For WP, a positive correlation between insulin and both CCK and GLP-1 was observed $(p<0.05)$. However, both CCK and GLP-1 were increased by MP $(p<0.05)$ and PYY and ghrelin were stimulated by $W P+P P H(p<0.05)$. No effect on El was seen.

Conclusion: There was modest evidence with respect to satiety by PPH consumption. Different exogenous biopeptides produced differences in release of endogenous peptides that had inconsistent relationships with satiety. Therefore, evidence derived from a supposed biomarker for satiety does not guarantee the highest satiety.

Keywords: protein source, peptides, overweight, appetite profile, satiety hormones, energy intake 


\section{INTRODUCTION}

Protein has been observed to have a more satiating effect than carbohydrate and fat and can therefore reduce energy intake $(\mathrm{EI})(1,2)$. The protein source may be a determinant of the satiating efficacy of protein, but very limited data from studies in humans exist on this topic, and the available evidence is inconsistent (3-9). Greater subjective satiety was found over a $3 \mathrm{~h}$ period when young men were fed a $50 \mathrm{~g}$ meal of lean fish compared to an equivalent amount of either beef or chicken (7). Other research showed that $48 \mathrm{~g}$ whey increased subjective satiety and decreased El more than $48 \mathrm{~g}$ casein at a buffet meal consumed 90 min later by healthy volunteers (4). In addition, whey consistently resulted in the greatest El suppression, decreased El relative to control and sucrose, as well as in comparison with egg albumin and soy protein in young men (8). In contrast, other studies found no difference in El after consumption of different types of protein $(5,6,9)$.

The mechanisms by which the peptide products of protein digestion exert their effect on El via the gastrointestinal tract may include stimulation of satiety hormones such as glucagon-like peptide 1 (GLP-1), cholecystokinine (CCK), peptide YY (PYY) or inhibition of the putative "orexigenic" hormone ghrelin (Ghr) $(3,10)$. Postprandial changes in the plasma concentrations of these hormones appear to be partially macronutrient- (and possibly protein source-) specific and may therefore contribute to differences in satiety (11-19).

In the present study, we investigated the satiating effects of pea protein hydrolysate (PPH) and whey protein (WP), based upon in vitro high throughput CCK-analysis (20) and based upon a rat study in which PPH and WP showed the highest El reduction and were speculated to have an even more pronounced effect, if administered together (personal communication Doreen Häberer, 2006).

The aims of this study were to examine the effects of WP, PPH, a combination of WP and $\mathrm{PPH}$, and control (milk protein, MP) on appetite ratings and postprandial changes in plasma Ghr, GLP-1, CCK and PYY (experiment 1) in human. Furthermore, in a second experiment, we assessed whether a possible appetite effect is reflected in the subsequent meal size.

\section{SUBJECTS AND METHODES}

\section{Subjects}

Thirty-nine overweight subjects (20 females, 19 males), aged 18 to 60 years and with a BMI between 25 and $31 \mathrm{~kg} / \mathrm{m}^{2}$ participated in this study. The subjects were recruited by advertisements in local newspapers. All subjects participated in an initial screening that involved measurement of body weight, height, body 
composition, waist:hip circumference, blood pressure as well as heart rate and included completion of a questionnaire related to eating behavior (Three Factor Eating Questionnaire, TFEQ (21)) and completion of a questionnaire related to health, use of medication, smoking behavior, alcohol consumption and physical activity. All subjects were in good health, non-smokers, not using medication, at most moderate alcohol users and unrestrained eaters (as assessed by factor 1 of the TFEQ). Baseline characteristics of the subjects are presented in table 1. The subjects gave their written informed consent and the Medical Ethical Committee of Maastricht University approved the study.

\section{Experimental design}

The study had a randomized, single-blind, crossover design and consisted of 2 parts (experiment 1 and experiment 2). Each subject participated in the two separate experiments and each experiment had a crossover design. In both experiment 1 and 2, subjects attended the university laboratory on four occasions with 1 week between visits. On each occasion, subjects arrived after fasting overnight. Body weight was measured on the first occasion of each experiment.

Table 1 Subject characteristics at baseline

\begin{tabular}{lc}
\hline & $\mathrm{n}=39(19$ males, 20 females $)$ \\
\hline Age $(\mathrm{y})$ & $42.3 \pm 13.8$ \\
Weight $(\mathrm{kg})$ & $82.5 \pm 9.8$ \\
Height $(\mathrm{m})$ & $1.73 \pm 0.08$ \\
BMI $\left(\mathrm{kg} / \mathrm{m}^{2}\right)$ & $27.6 \pm 1.7$ \\
Waist $(\mathrm{cm})$ & $92.7 \pm 7.6$ \\
Hip $(\mathrm{cm})$ & $105.9 \pm 5.9$ \\
Waist:Hip ratio & $0.88 \pm 0.08$ \\
Body fat $(\%)$ & $32.6 \pm 7.9$ \\
SBP $(\mathrm{mmHg})$ & $130.3 \pm 11.0$ \\
DBP $(\mathrm{mmHg})$ & $79.5 \pm 9.0$ \\
Heart rate $($ beats $/ \mathrm{min})$ & $74.3 \pm 12.3$ \\
F1 (TFEQ) & $5.9 \pm 2.3$ \\
\hline
\end{tabular}

Values are means \pm sd

BMI (Body Mass Index, $\mathrm{kg} / \mathrm{m}^{2}$ ), waist circumference $(\mathrm{cm})$, hip circumference $(\mathrm{cm})$, SBP (systolic blood pressure, $\mathrm{mmHg}$ ), DBP (diastolic blood pressure, $\mathrm{mmHg}$ ), F1 (factor 1 of the Three Factor Eating Questionnaire) 
In experiment 1, an intravenous catheter was inserted and a fasting blood sample was taken. Subjects then completed an appetite and tolerance questionnaire. A shake (for composition see "dietary protocol") and $150 \mathrm{ml}$ water were consumed at time 0 . The shakes were served in randomized order and consumed within $5 \mathrm{~min}$. Subsequent blood samples were collected 30,60 , 90 and $120 \mathrm{~min}$ after time 0 . An appetite questionnaire was completed 30, 60, $90,120,180$ and $240 \mathrm{~min}$ after consumption of the shake, taking care that completing questionnaires was not affected by taking blood samples. At timepoint 240, subjects completed a tolerance questionnaire and left the university laboratory.

The results of the appetite questionnaire from experiment 1 were used to decide at which timepoint subjects were offered a lunch in experiment 2.

In experiment 2, subjects completed an appetite and tolerance questionnaire. A shake and $150 \mathrm{ml}$ water were consumed at time 0 . The shakes were served in randomized order and consumed within $5 \mathrm{~min}$. Subsequent appetite questionnaires were completed $30,60,90,120$ and 180 min after consumption of the shake. At timepoint 180 (as decided on the base of the results of experiment 1), subjects were offered an ad libitum lunch and $300 \mathrm{ml}$ water. Instructions were given to eat until comfortably satiated. Food was removed after $20 \mathrm{~min}$. Five and $60 \mathrm{~min}$ after lunch, subjects completed the appetite questionnaire. Sixty min after lunch, subjects completed a tolerance questionnaire, left the university laboratory and were instructed not to eat or drink at home, except water, till $240 \mathrm{~min}$ after lunch and to complete the appetite questionnaire at 120,180 and 240 min after lunch.

\section{Dietary protocol}

The peptides to be tested were provided as part of a $300 \mathrm{ml}$ shake $(1024 \mathrm{~kJ}$; $25 \%$ of total energy from protein, $33 \%$ from fat, and $42 \%$ from carbohydrate) which contained either $15 \mathrm{~g}$ whey protein (WP), $15 \mathrm{~g}$ pea protein hydrolysate (PPH, provided by DSM Food Specialties, Delft, The Netherlands), a combination of $7.5 \mathrm{~g}$ WP and $7.5 \mathrm{~g} \mathrm{PPH}$ (WP+PPH) or $15 \mathrm{~g}$ milk protein (MP, control). Detailed compositional data for the shakes is provided in table 2. Shakes were matched for energy, viscosity (shear rate: $0.3271 / \mathrm{sec}$ ) and macronutrient composition. Hedonic value of the shakes was sufficient $(>5.5$ on a 10-point scale), without any differences between the peptides.

The ad libitum lunch in experiment 2 consisted of Turkish bread, spread with egg salad (1137 kJ per $100 \mathrm{~g} ; 13 \%$ of total energy from protein, $46 \%$ from fat, and $41 \%$ from carbohydrate). Food was weighed prior to the meal and after the subjects left the laboratory. Food intake was assessed by difference. 
Table 2 Detailed compositional data for the shakes

\begin{tabular}{lcccc}
\hline & WP (\%) & PPH $(\%)$ & WP+PPH $(\%)$ & MP* $(\%)^{*}$ \\
\hline Water & 81.85 & 81.78 & 81.85 & 80.34 \\
Pectin & 0.70 & 0.70 & 0.70 & 0.50 \\
Starch & 2.00 & 2.00 & 2.00 & 1.50 \\
Skim milk powder & & & & 13.62 \\
Pea hydrolysate & & 6.83 & 3.41 & \\
Whey protein isolate & 5.42 & & 2.71 & \\
Sucrose & 6.67 & 5.65 & 6.16 & \\
Oil & 2.97 & 2.95 & 2.96 & 2.86 \\
Citric acid anhydrate & 0.31 & & 0.12 & 1.08 \\
Flavour & 0.085 & 0.085 & 0.085 & 0.085 \\
Sweetener & 0.005 & 0.005 & 0.005 & 0.007 \\
\hline TOTAL & 100 & 100 & 100 & 100 \\
\hline
\end{tabular}

$\mathrm{WP}=$ whey protein; $\mathrm{PPH}=$ pea protein hydrolysate; $\mathrm{WP}+\mathrm{PPH}=$ whey protein + pea protein hydrolysate; $\mathrm{MP}=$ milk protein (control)

${ }^{*}$ Milk protein consists of $80 \%$ casein and $20 \%$ whey protein

\section{Anthropometry}

Body weight was measured using a digital balance accurate to $0.02 \mathrm{~kg}$ (ChyoMW-150K, Chyo, Japan) with subjects in underwear after voiding their bladder. Height was measured to the nearest $0.1 \mathrm{~cm}$ using a wall-mounted stadiometer. The waist:hip ratio was calculated by dividing the waist circumference by the hip circumference. The waist circumference was measured at the site of the smallest circumference between the rib cage and the iliac crest, and the hip circumference was measured at the site of the largest circumference between the waist and the thighs. Both measurements were performed with subjects in standing position. Systolic blood pressure, diastolic blood pressure and heart rate were recorded using an automatic blood pressure monitor (OSZ 5 easy; Spreidel \& Keller GmBH and Co. KG, Jungingen, Germany). Body composition was measured using the ${ }^{2} \mathrm{H}_{2} \mathrm{O}$ dilution technique (22-24). The dilution of the ${ }^{2} \mathrm{H}$ isotope is a measure for total body water (23). In the evening, the subjects ingested a dose of ${ }^{2} \mathrm{H}$-enriched water $\left({ }^{2} \mathrm{H}_{2} \mathrm{O}\right)$ after collecting a background urine sample. After ingestion of the ${ }^{2} \mathrm{H}$ solution no further fluid or food consumption was permitted. The following morning, the second urine sample (second voiding) was collected. Deuterium concentration in the urine samples was measured using an isotope ratio mass spectrometer (Micromass Optima, Manchester, UK). Total body water was obtained by dividing the measured ${ }^{2} \mathrm{H}$ dilution space by 1.04 to correct for exchange of the ${ }^{2} \mathrm{H}$ label with nonaqueous 
hydrogen of body solids (22). Fat-free mass (FFM) was calculated by dividing the total body water by hydrating factor 0.73 . By subtracting FFM from body weight, fat mass (FM) was obtained. FM expressed as a percentage of body weight gives percentage of body fat.

\section{$\underline{\text { Questionnaires }}$}

The appetite questionnaire is a Visual Analogue Scale questionnaire (VAS, in $\mathrm{mm}$ ) with questions about feelings of hunger, fullness, satiety, thirst and desire to eat (25). Opposing extremes of each feeling were described at either end of a $100-\mathrm{mm}$ horizontal line, and subjects marked the line to indicate how they felt at that moment.

Tolerance was determined using a questionnaire on the occurrence of complaints (headache, nausea, stomachache, diarrhea,...) and scored (25). Frequency classification was: 0 , never; 1 , seldom; 2 , sometimes; 3 , relatively often; 4, often (5-point scale).

\section{Blood parameters}

Blood samples were collected for analysis of GLP-1, CCK, PYY, Ghr, insulin and glucose. The blood samples were mixed with EDTA to prevent clotting. Samples for GLP-1 (4 ml) and PYY analysis $(4 \mathrm{ml})$ were mixed with $40 \mu \mathrm{l}$ of a dipeptidyl peptidase IV (DPP-IV) inhibitor (Linco Research Inc., St Charles, Missouri, USA) to prevent degradation. Samples for CCK $(4 \mathrm{ml})$ and PYY analysis $(4 \mathrm{ml})$ were mixed with $2000 \mathrm{KIU}$ Trasylol (Bayer Diagnostics Europe Ltd, the Netherlands). Plasma was obtained by centrifugation $\left(4^{\circ} \mathrm{C}, 1500 \mathrm{x} \mathrm{g}, 10\right.$ $\min$ ), frozen in liquid nitrogen and stored at $-80^{\circ} \mathrm{C}$ until further analysis. Plasma Ghr samples were mixed with $\mathrm{HCl}$, methanol and phenylmethanesulfonyl fluoride (PMSF, Sigma-Aldrich, The Netherlands).

Glucose concentrations were determined using the hexokinase method (Glucose HK 125 kit, ABX diagnostics, Montpellier, France). Plasma concentrations of insulin, active Ghr and PYY3-36 were measured by RIA (Linco Research Inc., St Charles, Missouri, USA). Plasma active GLP-1 samples were analyzed using ELISA (EGLP-35K; Linco Research Inc., St Charles, Missouri, USA). CCK was determined using RIA (Euria-CCK, EuroDiagnostica AB, Malmö, Sweden).

\section{$\underline{\text { Statistical analysis }}$}

Data are presented as means \pm standard deviations, unless otherwise indicated. Data were analyzed using Statview SE + Graphics (Abacus Concepts, Berkeley, CA, USA, 1988) and using SPSS 14 (SPSS Inc. Chicago, Illinois, USA). A one-factor repeated measures ANOVA was used to determine 
possible differences between the conditions. For the appetite ratings of experiment 1, also an ANCOVA with the baseline values as covariate was used to determine possible differences between the conditions. Correction for multiple comparisons was applied. Post-hoc, a Scheffe F test was executed to locate the differences. Univariate linear regression was used to determine the relationship between selected variables. Area under the curve (AUC) was calculated as incremental area under the curve over time, using the trapezoidal method (26). The level for establishing significant differences was taken at $p<0.05$.

\section{RESULTS}

The baseline values of all measured variables were not significantly different between treatments.

Body weight $(\mathrm{kg})$ was not different between the first occasion of experiment 1 $(82.5 \pm 9.8)$ and experiment $2(82.3 \pm 9.8)$. In both experiment 1 and 2 , tolerance was not significantly different between the shakes (data not shown). The hunger scores (experiment 1) of the appetite questionnaire are shown in figures $1 \mathrm{a}$ and $1 \mathrm{~b}$.

(a)

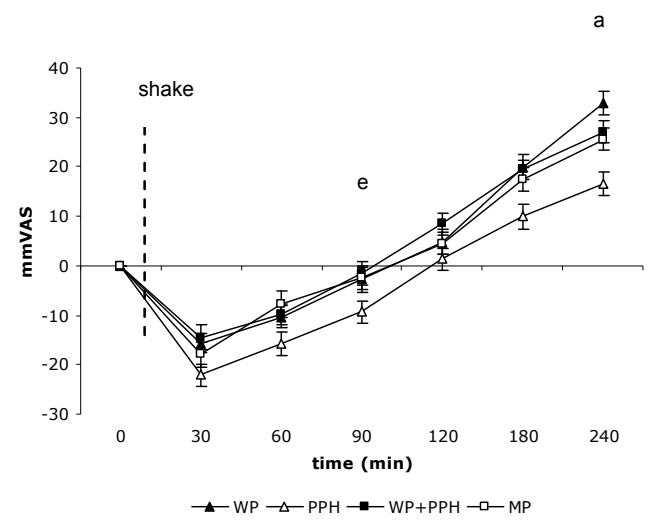

(b)

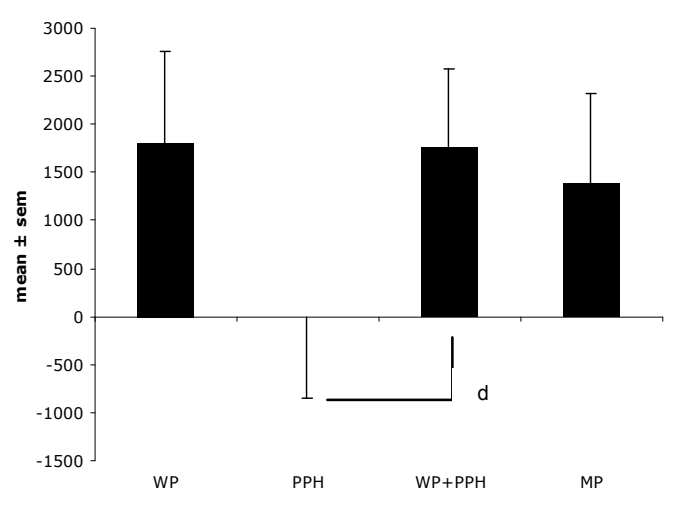

Figure 1 Hunger scores from experiment 1; (a) Hunger scores (changes from baseline, mmVAS); (b) AUC Hunger.

Values are means $\pm \mathrm{sem} ;{ }^{*} \mathrm{p}<0.05$ difference between 4 shakes (ANOVA repeated measures); ${ }^{a}$ $\mathrm{p}<0.05$ WP compared to PPH (ANOVA repeated measures); ${ }^{e} \mathrm{p}<0.05 \mathrm{PPH}$ compared to MP (ANOVA repeated measures); ${ }^{d} p<0.05 \mathrm{PPH}$ compared to WP+PPH (ANOVA repeated measures) $\mathrm{WP}=$ whey protein; $\mathrm{PPH}=$ pea protein hydrolysate; $\mathrm{WP}+\mathrm{PPH}=$ whey protein + pea protein hydrolysate; MP = milk protein (control). 
Post-hoc tests showed that ninety min after consumption of the shakes, significantly less hunger was reported after PPH, compared to MP $(p<0.05)$. Furthermore, an overall significant difference was found $240 \mathrm{~min}$ after consumption of the shakes with significantly less hunger after consumption of shake PPH compared to WP $(p<0.05)$. As presented in figure $1 b$, the Area Under the Curve (AUC) for hunger was significantly smaller for PPH compared to WP+PPH $(p<0.05)$. In addition, the intermeal interval $(\mathrm{min})$ was estimated. The intermeal interval is the time elapsed between consumption of the shake and the point at which hunger scores returned to baseline. As shown in table 3 , the hunger scores of the 4 groups returned to baseline between 90 and $120 \mathrm{~min}$ and the longest intermeal interval was observed for PPH. Due to the large variation between subjects, a statistical analysis of the intermeal interval was not useful.

Based on the overall significant difference in hunger ratings at $240 \mathrm{~min}$ and the intermeal interval between 90 and 120 min, we decided to provide the lunch in experiment 2180 min after consumption of the shakes.

Subjects were less thirsty $60 \mathrm{~min}$ after consumption of the shake containing $\mathrm{PPH}(-11.0 \pm 22.5)$ compared to the shake containing MP $(-3.8 \pm 24.4)(\mathrm{p}<0.05)$. No significant differences were seen for satiety, fullness and desire to eat (data not shown).

Using the ANCOVA (not shown in figures) with the baseline values as covariate, less hunger was reported 240 min after consumption of PPH compared to WP $(p<0.05)$. In addition, a greater satiety and fullness was observed 180 min after consumption of PPH compared to MP $(p<0.05)$.

Table 3 Estimated intermeal interval based on hunger scores

\begin{tabular}{lcc}
\hline & \multicolumn{2}{c}{ Estimated intermeal interval (min) } \\
\hline & Experiment 1 & Experiment 2 \\
\hline WP & 100 & 128 \\
PPH & 117 & 151 \\
WP+PPH & 95 & 131 \\
MP & 100 & 141 \\
\hline
\end{tabular}

Values are means.

$\mathrm{WP}=$ whey protein $; \mathrm{PPH}=$ pea protein hydrolysate $\mathrm{WP}+\mathrm{PPH}=$ whey protein + pea protein hydrolysate; $\mathrm{MP}=$ milk protein (control) 
The blood parameter results are presented in figures $2 a$ (glucose), $2 b$ (GLP-1), 2c (CCK), 2d (PYY), 2e (Ghr) and table 4 (AUC of these variables). No significant differences were seen for insulin (data not shown). Consumption of the WP, PPH or WP+PPH shakes caused, determined as AUC, a lower CCK and/or GLP-1 concentration compared to MP (table 4, p<0.05). At separate timepoints $(30,60,90$ or $120 \mathrm{~min})$ the WP, $\mathrm{PPH}$, or WP+PPH shakes caused higher plasma concentrations of glucose, and lower concentrations of GLP-1 and CCK (figure 2a, 2b, 2c, p<0.05). However, at $30 \mathrm{~min}$, PYY concentrations were higher after WP+PPH compared to MP and the other shakes (figure $2 \mathrm{~d}$, $p<0.05)$. At $120 \mathrm{~min}$, Ghr concentrations were lower after WP+PPH compared to MP (figure $2 \mathrm{e}, \mathrm{p}<0.05$ ).

Only in the WP condition, hunger and satiety were respectively negatively and positively correlated with PYY (time 60-0: $r^{2}=0.11$, resp $r^{2}=0.2, p<0.05$ ).

Furthermore, after WP consumption a significant positive relation between insulin and both GLP-1 (time 90-0: $p<0.05 r^{2}=0.18$; time 120-0: $p<0.05 r^{2}=0.52$ ) and CCK (time 90-0: $p<0.05 r^{2}=0.13$; time 120-0: $p<0.05 r^{2}=0.20$ ) was observed. In addition, after WP+PPH consumption a significant positive relation between insulin and CCK (time 90-0: $p<0.05 r^{2}=0.20$; time 120-0: $p<0.05$ $\left.r^{2}=0.11\right)$ emerged.

In experiment 2, 180 min after consumption of the shakes, no difference in food intake $(\mathrm{g})$ at lunch was seen between the 4 groups (WP $299.9 \pm 98.2 ; \mathrm{PPH}$ $304.2 \pm$ 106.6; WP+PPH $309.0 \pm 115.0$; MP $303.5 \pm 115.4$ ).

Table 4 Area Under Curve of blood parameters

\begin{tabular}{lcccc}
\hline & WP & PPH & WP+PPH & MP \\
\hline Glucose $(\mathrm{mmol} / \mathrm{l})$ & $-10.6 \pm 47.0$ & $-16.3 \pm 38.4$ & $-8.8 \pm 52.5$ & $-19.5 \pm 46.5$ \\
GLP-1 $(\mathrm{pmol} /)^{*}$ & $96.7 \pm 150.2$ & $65.5 \pm 99.1^{\mathrm{b}}$ & $89.5 \pm 155.8$ & $145.3 \pm 194.9$ \\
CCK $(\mathrm{pmol} /)^{\star}$ & $86.3 \pm 69.3^{\mathrm{a}}$ & $74.7 \pm 96.8^{\mathrm{b}}$ & $83.2 \pm 72.8^{\mathrm{c}}$ & $128.3 \pm 115.3$ \\
PYY $(\mathrm{pmol} / \mathrm{l})$ & $379.2 \pm 507.2$ & $376.0 \pm 494.7$ & $512.3 \pm 573.4$ & $440.9 \pm 628.8$ \\
Ghrelin $(\mathrm{pg} / \mathrm{ml})$ & $-222.9 \pm 2438.5$ & $-827.5 \pm 3807.9$ & $-878.6 \pm 2437.4$ & $-476.4 \pm 2205.1$ \\
\hline
\end{tabular}

Values are means $\pm s d$; $\mathrm{WP}=$ whey protein; $\mathrm{PPH}=$ pea protein hydrolysate; $\mathrm{WP}+\mathrm{PPH}=$ whey protein + pea protein hydrolysate; $\mathrm{MP}=$ milk protein (control).

${ }^{*} p<0.05$ difference between 4 shakes (ANOVA repeated measures); ${ }^{a} p<0.05$ WP compared to MP (ANOVA repeated measures); ${ }^{b} p<0.05 \mathrm{PPH}$ compared to MP (ANOVA repeated measures); ${ }^{c} p<0.05 \mathrm{WP}+\mathrm{PPH}$ compared to MP (ANOVA repeated measures). 
(a)

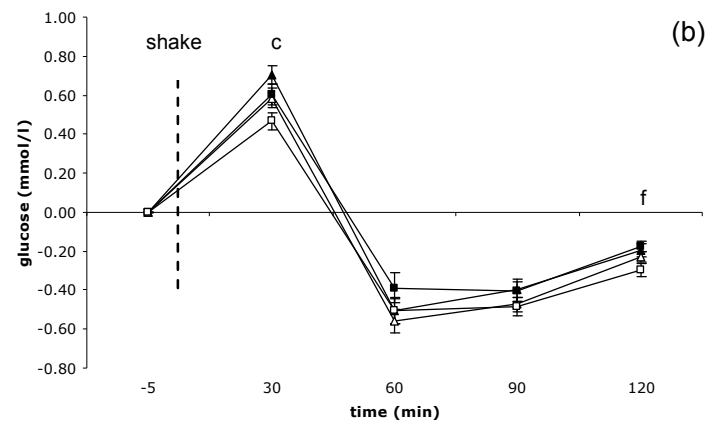

(c)

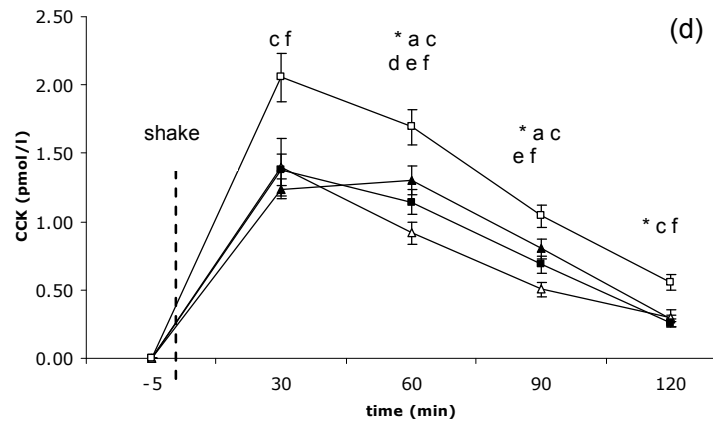

(e)

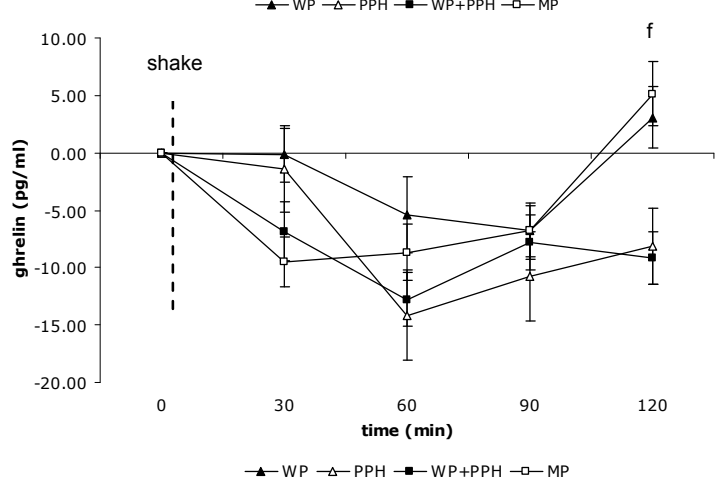

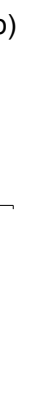

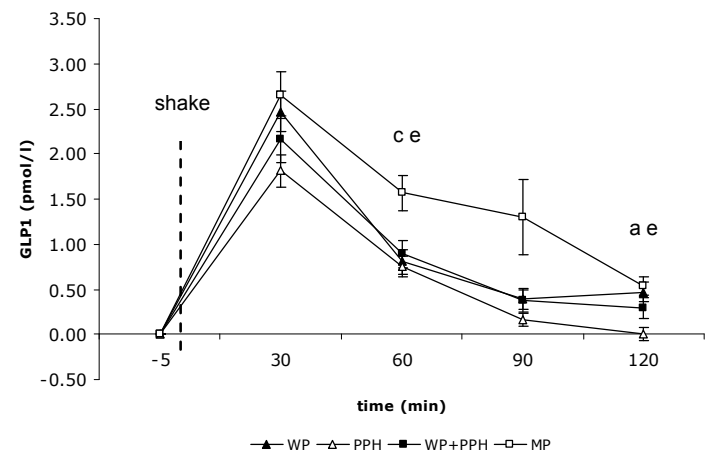

(d)

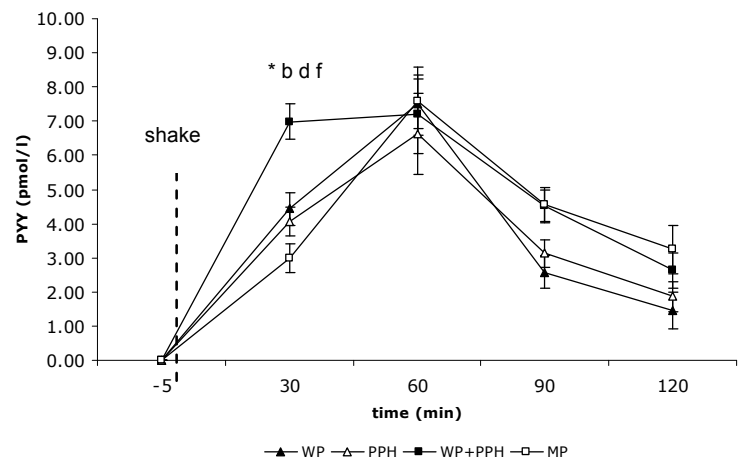

Figure 2 Blood parameters (changes from baseline); (a) Glucose; (b) GLP-1; (c) CCK; (d) PYY; (e) Ghr. Values are means \pm sem; * $p<0.05$ difference between 4 shakes (ANOVA repeated measures); ${ }^{a} p<0.05$ WP compared to PPH (ANOVA repeated measures); ${ }^{b} p<0.05$ WP compared to WP+PPH (ANOVA repeated measures); ${ }^{c} p<0.05$ WP compared to MP (ANOVA repeated measures); ${ }^{d} p<0.05$ $\mathrm{PPH}$ compared to WP+PPH (ANOVA repeated measures); ${ }^{\mathrm{e}} \mathrm{p}<0.05 \mathrm{PPH}$ compared to MP (ANOVA repeated measures); ${ }^{f} \mathrm{p}<0.05 \mathrm{WP}+\mathrm{PPH}$ compared to MP (ANOVA repeated measures).

$\mathrm{WP}=$ whey protein; $\mathrm{PPH}=$ pea protein hydrolysate; $\mathrm{WP}+\mathrm{PPH}=$ whey protein + pea protein hydrolysate; $\mathrm{MP}=$ milk protein (control). 
In experiment 2, no significant differences were seen for hunger (data not shown). Figures 3a (satiety), 3b (fullness), 3c (desire to eat) and 3d (thirst) show the appetite scores from experiment 2.
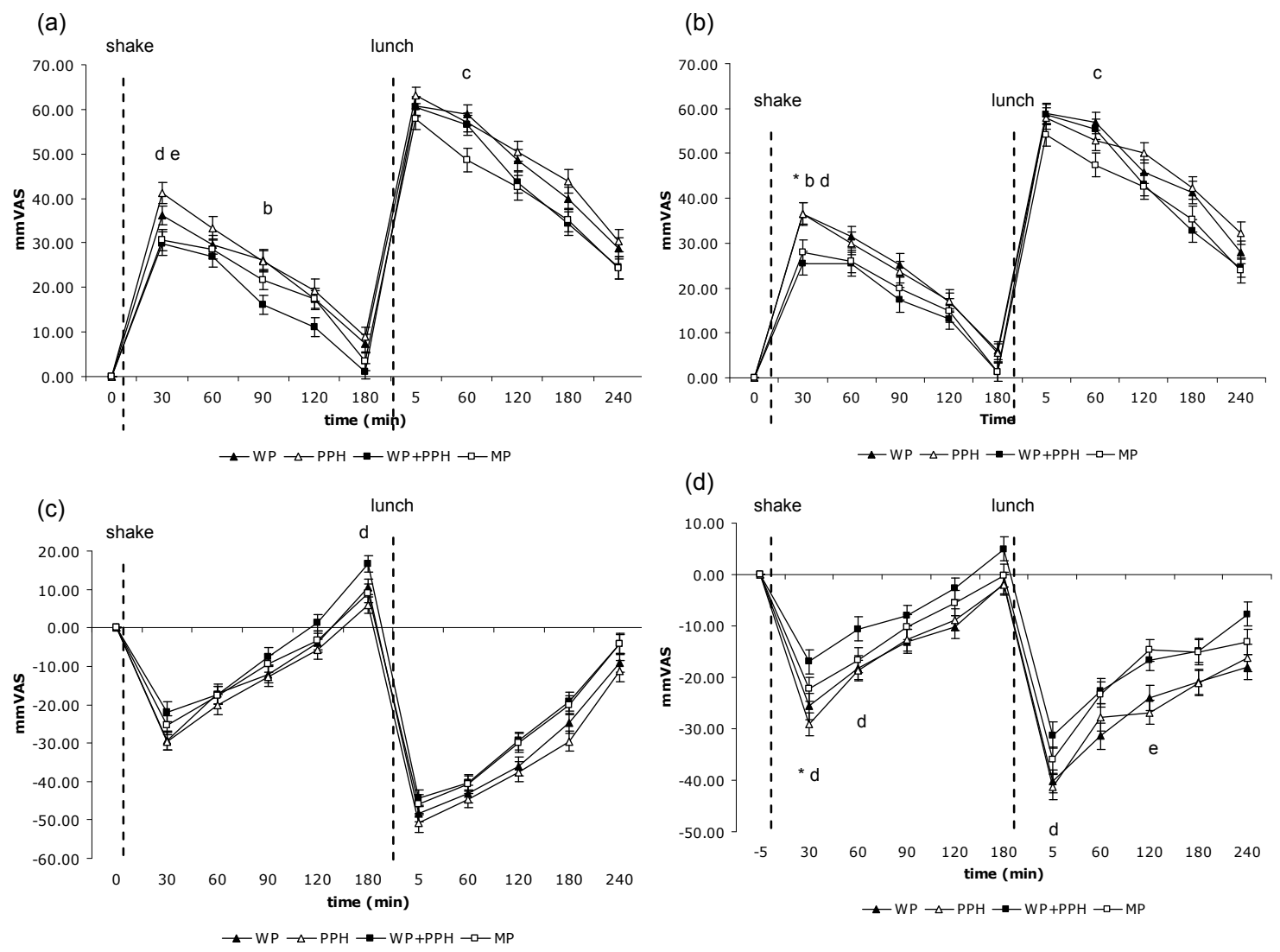

Figure 3 Appetite scores (changes from baseline, mmVAS) from experiment 2; (a) satiety; (b) fullness; (c) desire to eat; (d) thirst. Values are means \pm sem; * $p<0.05$ difference between 4 shakes (ANOVA repeated measures); ${ }^{b} p<0.05$ WP compared to WP+PPH (ANOVA repeated measures); ${ }^{c} p<0.05$ WP compared to MP (ANOVA repeated measures); ${ }^{d} p<0.05 \mathrm{PPH}$ compared to WP+PPH (ANOVA repeated measures); ${ }^{e} p<0.05 \mathrm{PPH}$ compared to MP (ANOVA repeated measures). $\mathrm{WP}=$ whey protein; $\mathrm{PPH}=$ pea protein hydrolysate; $\mathrm{WP}+\mathrm{PPH}=$ whey protein + pea protein hydrolysate; MP = milk protein (control). 
PPH consumption was followed by greater satiety, greater fullness, and a smaller desire to eat and thirst, at various timepoints $(30,60$ or $180 \mathrm{~min})$ compared to either MP or WP+PPH (figure $3, \mathrm{p}<0.05$ ). Here the smaller desire to eat is most remarkable. This coincides with the longer estimated intermeal interval after PPH consumption (table 3 ). WP consumption was followed by a greater satiety or fullness (at 30 or 90 min after shake, or 60 min after lunch) compared to MP or WP+PPH (figure $3 a$ and $3 b, p<0.05$ ). WP+PPH did not show remarkable effects compared to MP.

When a satiety index (AUC satiety after lunch/El in $\mathrm{kJ}$ ) was calculated for the different shakes (WP: $2.9 \pm 1.9$; PPH: $3.2 \pm 2.4$; WP+PPH: $2.5 \pm 2.1$; MP: $2.5 \pm$ $3.0)$, a trend $(p=0.09)$ was observed for a greater index for $\mathrm{PPH}$ compared to $\mathrm{WP}+\mathrm{PPH}$.

\section{DISCUSSION}

Based on appetite ratings, PPH and to a lesser extent WP are considered as most effective in suppressing hunger and stimulating satiety relative to whole milk protein. However, this finding is not supported by the observed changes in concentrations of the satiety hormones and Ghr. Both CCK and GLP-1 are more stimulated by MP than by the other shakes and PYY is stimulated in particular by WP+PPH, which also caused a less pronounced decrease in postprandial Ghr concentration.

This study shows that consumption of a $1 \mathrm{MJ}$ PPH shake caused less hunger (experiment 1), less desire to eat (experiment 2) and less thirst (experiment 1 and 2) prior to the next meal (pre-prandial effect). With respect to the postprandial effect of the $1 \mathrm{MJ}$ shakes on fullness and satiety, both PPH and WP caused greater satiety (experiment 2) and fullness (experiment 2) compared to $\mathrm{MP}$ and $\mathrm{WP}+\mathrm{PPH}$. Furthermore, a longer intermeal interval and greater satiety index appeared to occur after consumption of the PPH shake.

The effects of the shakes on the changes in plasma concentrations of the hormones do not support the findings from the appetite ratings. 120 min after consumption of WP+PPH, a lower concentration of the hunger hormone $\mathrm{Ghr}$ was seen compared to MP although both groups displayed similar hunger and satiety. In addition, $30 \mathrm{~min}$ after consumption of WP+PPH, a higher PYY concentration, but not greater satiety, was seen compared to the other shakes. No significant differences were seen on other time points. Presumably because the liquid meal (shake) was ingested within a short space of time, PYY concentration peaked already at $30 \mathrm{~min}$ after WP+PPH ingestion (27). In humans, PYY reduces Ghr so the decreased Ghr with WP+PPH may be a reflection of this (28). Both CCK and GLP-1 reached higher concentrations after MP consumption than after the other shakes. Milk protein consists of casein and whey protein (casein makes up about $80 \%$ of the protein in cow's milk, while the 
remaining $20 \%$ of protein in milk is whey). The digestion and absorption of whey and casein differ in that casein, unlike whey, coagulates in the stomach due to its precipitation by gastric acid $(4,29,30)$. As a result, overall gastric emptying time for casein is longer. The concept of "fast" and "slow" proteins was introduced by Boirie et al. to describe these differences in digestion and absorption of whey and casein (31). The "fast" whey may cause a fast peak and the "slow" casein brings about a prolonging effect. The unique combination of both whey and casein in milk protein may therefore explain the high CCK and GLP-1 concentrations observed after consumption of the MP shake.

For WP a positive correlation between insulin and both CCK and GLP-1 was seen. For $\mathrm{WP}+\mathrm{PPH}$, a positive correlation between insulin and CCK was observed. Previous studies reported differences in plasma insulin concentrations following different meal proteins $(5,32)$. Whey contains high concentrations of branched chain amino acids (leucine, isoleucine, and valine), and it has been suggested that these amino acids have a unique metabolic role, possibly enhancing satiety due to extra-hepatic metabolism and interactions with insulin signaling pathways $(33,34)$.

Despite the differences between shakes in appetite ratings and satiety hormones, no effect on El during the subsequent lunch was seen. Similarly, Lang et al. concluded that varying the protein source does not affect ingestive behavior in healthy humans $(5,6,9)$. In contrast, other research showed differences in $\mathrm{El}$ after consumption of different types of protein $(4,8)$. A general explanation for the postprandial effects instead of preprandial effects may be that the parameters characterizing the postprandial meal interval are correlated with the meal size and characteristics (35). People eat in an anticipating way, to bridge the following meal interval. Thus meal size is very unlikely to be affected by preprandial interventions, yet it affects postprandial parameters. Only when the preprandial triggers differ very substantially, meal size may be affected.

The appetite ratings of experiment 1 were analyzed with both ANOVA repeated measures (analysis of change score) and ANCOVA with the baseline values as covariate. There is continuing discussion regarding the conditions under which these different approaches are most appropriate (36). In this study, the use of ANCOVA with baseline values as covariates led to less apparent differences in treatments.

In conclusion, when ingested, different exogenous biopeptides cause differences in the release of endogenous peptide hormones that may have inconsistent relationships with satiety. When peptides such as whey trigger successively insulin, GLP-1 and CCK release, this does not guarantee a stronger satiety effect nor is it always correlated with a perceived satiety effect. There was modest evidence with respect to satiety enhancement for PPH consumption, in terms of hunger, satiety, desire to eat, and the suggested longer intermeal interval and the trend for a higher satiety index. Nevertheless, where greater satiety responses were seen with $\mathrm{PPH}$, they did not reflect strong 
correlations of self-reported satiety with proposed satiety hormones. Thus with respect to effects of exogenous and endogenous peptides, a supposed biomarker for satiety does not guarantee the highest satiety. It is very likely that the picture is still incomplete.

\section{ACKNOWLEDGEMENTS}

We gratefully thank Myrtha Arnold, Rachel Batterham, Patrick Egelmeers, Annemiek Joosen, Wolfgang Langhans, Manuela Lejeune, Natalie LuscombeMarsh, David Mela, Anthony Moses, Wendy Sluijsmans, Astrid Smeets, Jos Stegen and Loek Wouters for their contributions to the study and the manuscript.

The study was supported by Unilever Food and Health Research Institute, Unilever R\&D Vlaardingen, Vlaardingen, The Netherlands and DSM Food Specialties, Delft, The Netherlands.

\section{REFERENCES}

1. Poppitt SD, McCormack D, Buffenstein R. Short-term effects of macronutrient preloads on appetite and energy intake in lean women. Physiol Behav 1998;64:279-85.

2. Weigle DS, Breen PA, Matthys CC, et al. A high-protein diet induces sustained reductions in appetite, ad libitum caloric intake, and body weight despite compensatory changes in diurnal plasma leptin and ghrelin concentrations. Am J Clin Nutr 2005;82:41-8.

3. Anderson $\mathrm{GH}$, Moore SE. Dietary proteins in the regulation of food intake and body weight in humans. J Nutr 2004;134:974S-9S.

4. Hall WL, Millward DJ, Long SJ, Morgan LM. Casein and whey exert different effects on plasma amino acid profiles, gastrointestinal hormone secretion and appetite. $\mathrm{Br} \mathrm{J}$ Nutr 2003;89:239-48.

5. Lang V, Bellisle F, Alamowitch $\mathrm{C}$, et al. Varying the protein source in mixed meal modifies glucose, insulin and glucagon kinetics in healthy men, has weak effects on subjective satiety and fails to affect food intake. Eur J Clin Nutr 1999;53:959-65.

6. Lang V, Bellisle F, Oppert JM, et al. Satiating effect of proteins in healthy subjects: a comparison of egg albumin, casein, gelatin, soy protein, pea protein, and wheat gluten. Am J Clin Nutr 1998;67:1197-204.

7. Uhe AM, Collier GR, O'Dea K. A comparison of the effects of beef, chicken and fish protein on satiety and amino acid profiles in lean male subjects. J Nutr 1992;122:467-72.

8. Anderson GH, Tecimer SN, Shah D, Zafar TA. Protein source, quantity, and time of consumption determine the effect of proteins on short-term food intake in young men. $J$ Nutr 2004;134:3011-5.

9. Bowen J, Noakes M, Clifton PM. Appetite regulatory hormone responses to various dietary proteins differ by body mass index status despite similar reductions in ad libitum energy intake. J Clin Endocrinol Metab 2006;91:2913-9.

10. Cummings DE, Overduin J. Gastrointestinal regulation of food intake. J Clin Invest 2007;117:13-23.

11. Adam TC, Westerterp-Plantenga MS. Nutrient-stimulated GLP-1 release in normal-weight men and women. Horm Metab Res 2005;37:111-7. 
12. Bowen J, Noakes M, Trenerry C, Clifton PM. Energy intake, ghrelin, and cholecystokinin after different carbohydrate and protein preloads in overweight men. J Clin Endocrinol Metab 2006;91:1477-83.

13. Elliott RM, Morgan LM, Tredger JA, Deacon S, Wright J, Marks V. Glucagon-like peptide1 (7-36)amide and glucose-dependent insulinotropic polypeptide secretion in response to nutrient ingestion in man: acute post-prandial and $24-\mathrm{h}$ secretion patterns. $\mathrm{J}$ Endocrinol 1993;138:159-66.

14. Erdmann J, Lippl F, Schusdziarra V. Differential effect of protein and fat on plasma ghrelin levels in man. Regul Pept 2003;116:101-7.

15. Erdmann J, Topsch R, Lippl F, Gussmann P, Schusdziarra V. Postprandial response of plasma ghrelin levels to various test meals in relation to food intake, plasma insulin, and glucose. J Clin Endocrinol Metab 2004;89:3048-54.

16. Greenman Y, Golani N, Gilad S, Yaron M, Limor R, Stern N. Ghrelin secretion is modulated in a nutrient- and gender-specific manner. Clin Endocrinol (Oxf) 2004;60:3828.

17. Raben A, Agerholm-Larsen L, Flint A, Holst JJ, Astrup A. Meals with similar energy densities but rich in protein, fat, carbohydrate, or alcohol have different effects on energy expenditure and substrate metabolism but not on appetite and energy intake. Am J Clin Nutr 2003;77:91-100.

18. Ritzel U, Fromme A, Ottleben M, Leonhardt U, Ramadori G. Release of glucagon-like peptide-1 (GLP-1) by carbohydrates in the perfused rat ileum. Acta Diabetol 1997;34:1821.

19. Batterham RL, Heffron $\mathrm{H}$, Kapoor S, et al. Critical role for peptide $\mathrm{YY}$ in protein-mediated satiation and body-weight regulation. Cell Metab 2006;4:223-33.

20. Gerhardt CC, Tasker MC. Satiety inducing composition. In: Unilever, ed. The Netherlands, 2005.

21. Stunkard AJ, Messick S. The three-factor eating questionnaire to measure dietary restraint, disinhibition and hunger. J Psychosom Res 1985;29:71-83.

22. Schoeller DA, van Santen E, Peterson DW, Dietz W, Jaspan J, Klein PD. Total body water measurement in humans with $18 \mathrm{O}$ and $2 \mathrm{H}$ labeled water. Am J Clin Nutr 1980;33:2686-2693.

23. van Marken Lichtenbelt WD, Westerterp KR, Wouters L. Deuterium dilution as a method for determining total body water: effect of test protocol and sampling time. $\mathrm{Br} \mathrm{J} \mathrm{Nutr}$ 1994;72:491-497.

24. Westerterp KR, Wouters L, van Marken Lichtenbelt WD. The maastricht protocol for the measurement of body composition and energy expenditure with labeled water. Obes Res 1995;3 (suppl 1):49-57.

25. Kovacs EM, Lejeune MP, Westerterp-Plantenga MS. The effects of enterostatin intake on food intake and energy expenditure. Br J Nutr 2003;90:207-14.

26. Adam TC, Lejeune MP, Westerterp-Plantenga MS. Nutrient-stimulated glucagon-like peptide 1 release after body-weight loss and weight maintenance in human subjects. $\mathrm{Br} \mathrm{J}$ Nutr 2006;95:160-7.

27. Morinigo R, Moize V, Musri M, et al. Glucagon-like peptide-1, peptide YY, hunger, and satiety after gastric bypass surgery in morbidly obese subjects. J Clin Endocrinol Metab 2006;91:1735-40.

28. Batterham RL, Cohen MA, Ellis SM, et al. Inhibition of food intake in obese subjects by peptide YY3-36. N Engl J Med 2003;349:941-8.

29. Billeaud C, Guillet J, Sandler B. Gastric emptying in infants with or without gastrooesophageal reflux according to the type of milk. Eur J Clin Nutr 1990;44:577-83.

30. Miller MJ, Witherly SA, Clark DA. Casein: a milk protein with diverse biologic consequences. Proc Soc Exp Biol Med 1990;195:143-59. 
31. Boirie Y, Dangin M, Gachon P, Vasson MP, Maubois JL, Beaufrere B. Slow and fast dietary proteins differently modulate postprandial protein accretion. Proc Natl Acad Sci U S A 1997;94:14930-5.

32. Gannon MC, Nuttall FQ, Neil BJ, Westphal SA. The insulin and glucose responses to meals of glucose plus various proteins in type II diabetic subjects. Metabolism 1988;37:1081-8.

33. Layman DK, Baum Jl. Dietary protein impact on glycemic control during weight loss. J Nutr 2004;134:968S-73S.

34. van Loon LJ, Saris WH, Verhagen $\mathrm{H}$, Wagenmakers AJ. Plasma insulin responses after ingestion of different amino acid or protein mixtures with carbohydrate. Am $\mathrm{J}$ Clin Nutr 2000;72:96-105.

35. Schilstra AJ. Meal-interval correlations: what can they tell us? Physiol Behav 1981;27:299-304.

36. Senn S. Change from baseline and analysis of covariance revisited. Stat Med 2006;25:4334-44. 



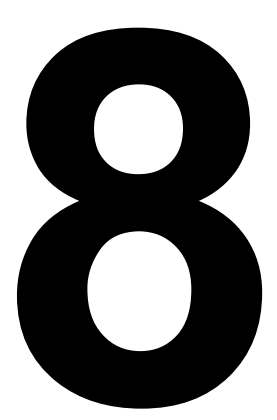

GENERAL DISCUSSION 
The major problem in the treatment of obesity is the failure to maintain longterm weight loss. The perception of the general public is that no one ever succeeds at long-term weight loss (1-3). However, research has shown that \pm $20 \%$ of overweight individuals are successful at long-term weight loss when defined as losing at least $10 \%$ of initial body weight and maintaining the loss for at least 1 year (3). These data underscore the fact that it is possible to achieve and maintain significant amounts of weight loss. To develop more effective weight maintenance interventions, it may be helpful to learn more about the variables that determine who fails and who succeeds at weight-loss maintenance.

\section{CONDITIONS FOR WEIGHT MAINTENANCE}

Body-weight regulation is the control of body weight through promoting a stable balance between energy intake (EI) and energy expenditure (EE). El must be balanced against energy requirement to ensure that storing energy as fat is avoided. The key body-weight management targets for metabolic intermediates include satiety, thermogenesis and body composition. These targets are in line with the concepts described in this thesis, that is, sustained satiety as well as sustained EE related to sparing fat-free mass (FFM), during a negative energy balance.

\section{Energy intake as a function of preprandial magnitude of hunger and satiety}

In controlled laboratory conditions, subject-specific appetite sensations have been shown to be associated with measured El (4). However, the changes in appetite scores from the Visual Analogue Scales must be sufficient to exert a significant effect on subsequent El. This is seldomly achieved. In our studies, it was shown that when the magnitudes of the changes in appetite scores were too small, no effect on subsequent El can be observed $(5,6)$. Even when a significant linear relation between hunger during the morning period and $\mathrm{EI}$ at lunch was observed, this relation was too weak to cause differences in El (6). This phenomenon was also reported in other studies $(7,8)$. Although a reduced El not always is observed after a greater satiety, other beneficial effects may occur. A sustained satiety during a weight-loss/-maintenance diet may facilitate compliance to this diet $(5,6,9-11)$.

Nevertheless, in situations where the differences in hunger or satiety ratings were of a considerable magnitude, a subsequent spontaneous reduction in $\mathrm{El}$ occurred $(12,13)$. However, such a relationship between preprandial hunger or satiety and El may be prevented by dietary restraint and disinhibition $(14,15)$. For example, it has been shown that restrainted eating behavior, which is higher in individuals seeking participation in weight-loss interventions (16), may over- 
ride normal appetite regulation and influence $\mathrm{EI}(17,18)$. Therefore, when El is measured in a study, restrained eating behavior must count as an exclusion criteria during initial screening of the subject. Furthermore, because mainly parameters characterizing the postprandial meal interval are correlated with the meal size and characteristics (19), meal size is less likely to be affected by preprandial interventions. For instance, the postprandial concentrations of glucagon-like peptide 1 (GLP-1), cholecystokinin (CCK) and peptide YY (PYY) are rather correlated to the recent meal size or characteristics, than indicative for the subsequent meal size (20-22). Such a larger postprandial satiety may prolong the intermeal interval $(5,6)$, defined as the time elapsed between consumption of food product and the point at which hunger scores returned to baseline. A longer intermeal interval was observed after consumption of Olibra ${ }^{\circledR}$ yoghurt during the short-term study in normal-weight women aged 18 to 30 years (6). It is still a hypothesis that this may be underscored by the so-called ileal brake mechanism (23-25). This ileal brake, for which fat is the most important trigger, initiates a feedback loop that inhibits upper gut motility (to slow gastric emptying and intestinal transit) in response to nutrients in the distal small intestine (26-28). The palm oil core of the relatively small emulsion particles is covered by hydrophilic galactolipids derived from the fractionated oat oil. Due to this particular combination of triglyceride oils, resulting in delayed digestion compared to the milk fat particles, (partly) undigested particles may penetrate more distal parts of the small intestine, where sensors may detect unabsorbed fat and send satiety signals to the brain. The ileal brake mechanism appeared to be related to the release of one or more satiety hormones from the distal intestine $(27,29,30)$. Therefore, in the long-term study, the effects of Olibra $^{\circledR}$ yoghurt were assessed on weight maintenance and blood hormones (9). Indeed, in the long-term, GLP-1 values at 180 minutes after test yoghurt consumption in week 25 were significantly increased compared to baseline levels. Thus our findings may provide some evidence for the ileal brake theory as an indirect explanation for the Olibra ${ }^{\circledR}$ effects on weight maintenance in the longer term (9). Yet more studies are needed to confirm that the ileal brake would be the mechanism indeed to explain subsequent effects of Olibra ${ }^{\circledR}$. Although a longer intermeal interval was also observed when comparing effects of different biopeptides, this finding was not supported by the observed changes in concentrations of the satiety hormones and Ghr (5). Based on appetite ratings, pea protein hydrolysate and to a lesser extent whey protein were considered as most effective in suppressing hunger and stimulating satiety relative to whole milk protein. Yet it was after consumption of milk protein that higher CCK and GLP-1 concentrations were observed (5). The timing of the unique combination of both "fast" whey and "slow" casein in milk protein may explain this increase in satiety hormones (31). Whey protein rapidly enters the jejunum mostly in the form of the intact protein, whereas casein is slow to appear and mainly in the form of degraded peptides $(31,32)$. This difference 
between the 2 proteins is largely attributed to the clotting and/or precipitation of the casein (unlike the soluble whey) in the acidic media of the stomach, giving it longer exposure to gastric peptide hydrolysis $(32,33)$. As a result, overall gastric emptying time for casein is longer. The "fast" whey may cause a fast peak and the "slow" casein brings about a prolonging effect. Thus time of consumption as well as protein source are factors determining the effect of protein on short-term satiety (34). For instance, whey protein triggers insulin, GLP-1 and CCK release (5). Whey contains high concentrations of branched chain amino acids (leucine, isoleucine and valine), and it has been suggested that these amino acids have a unique metabolic role, possibly enhancing satiety due to extra-hepatic metabolism and interactions with insulin signaling pathways $(35,36)$. The observed increases in hormones (insulin, GLP-1, CCK) after whey consumption did not guarantee a stronger satiety effect nor it was always correlated with a perceived satiety effect or a prolonged intermeal interval. Thus a supposed biomarker for satiety does not always guarantee the highest satiety. It is very likely that the picture is still incomplete. More work is needed to establish whether other potential biomarkers of satiety can be useful. When a biomarker is the reappearance of a specific substance present in food, ingestion of that particular food can be checked by taking a blood sample or urine sample that indicates qualitatively and quantitatively the presence of that particular substance above possible background concentrations. For example, biomarkers have been useful in checking ingestion of fruit and vegetables (37), ingestion of (-)-hydroxycitrate (38), ingestion of protein (39) and ingestion of caffeine (40). In addition, a biomarker can also be used for reported El, by measuring EE using doubly labeled water (41). With satiety, observations are less straightforward and less generally applicable. I suggest that there may be a postprandial synchronized concerted action of all factors that follow eating, for example, sensory experience (42), gastric distention (43-47), elevated concentrations of peptides involved in the digestion process (48), oxidative processes in the liver (49), diet-induced thermogenesis (50) which gives a cascade of satiety signals to the brain. Due to the many signals at the same time, possible relationships between elevated self-reported satiety and concentrations of relevant hormones are mainly peak-dependent (51) and therefore rarely statistically significantly different at any time point. A feeling of satiety and release of relevant hormones both occur after the meal at the same time, yet this does not mean that any increase in concentrations of hormones is an indicator of satiety or can be used like that. Since satiety is perceived centrally, it is the subject who decides upon the magnitude of the feeling of satiety. Research can use this for interpretation of results but the image of the concerted action is still too incomplete for prediction of results. Therefore, in every experiment, satiety as well as relevant hormones should be taken into account and possible relationships that may occur are still specific for that situation. 
Thus, one of the variables that determine success in weight-loss maintenance is sustained satiety, preferably leading to sustained reduced El. This sustained satiety is, depending on the amount and macronutrient composition of the food ingested, sometimes underscored by synchronized elevated concentrations of the hormones GLP-1 or PYY; or sometimes independent of the dynamics of these hormones. Therefore, the present view is that these hormones are, strictly speaking, not universal biomarkers. In cases that sustained satiety is present yet does not decrease El spontaneously, it at least contributes to compliance to the diet situation.

\section{Energy expenditure}

Weight maintenance appears to be antagonized by a reduction in basal metabolic rate (BMR) due to the preceding weight loss phase. As the largest component of daily EE, BMR comprises approximately $60-70 \%$. Fat-free mass (FFM) is the main factor that accounts for the magnitude of BMR (52-54). It is a well known fact that weight loss induced by energy restriction is accompanied by a decline in $\operatorname{BMR}(52,55)$. A decrease in FFM most certainly has considerable contribution to this effect (56). Concomitant neuroendocrine disturbances, such as alterations in leptin level (57), thyroid status (58), and sympathetic nervous system (SNS) activity (59) may further contribute to the decrease in BMR (60).

With respect to the possibility to offset the expected reduction in BMR, we applied consumption of green tea catechins during a low-energy diet (61). Studies in humans showed that green tea has thermogenic properties beyond that explained by its caffeine content per se $(62,63)$. Thus green tea, by containing both caffeine and tea catechins, may act at different steps of modulatory pathways, that is, via phosphodiesterase, and via catechol $\mathrm{O}$ methyl-transferase, and in this way exert a thermogenic and possibly an antiobesity effect $(62,64,65)$. In addition, studies in rats and mice showed an epigallocatechin gallate-induced reduction in food intake and/or an increase in EE (65-67). Human studies conducted over 3 months or more showed that the consumption of tea catechins can induce a notable reduction of body weight and body fat (68-72) and increases EE (73). Moreover, green tea has also successfully been applied as an agent to limit weight regain after weight loss $(74,75)$. In our study, we found indeed that BMR as a function of FFM and fat mass did not decrease significantly over time when green tea catechins were ingested together with a low-energy diet (61). However, no difference in body weight loss was seen between the treatment and placebo group. A possible explanation is the habitual caffeine intake of the subjects. Our subjects had a habitual caffeine intake of $300 \mathrm{mg} / \mathrm{d}$ before and during the study and the ingestion of the green tea capsules provided $237 \mathrm{mg}$ caffeine/d (61). This is in contrast to the subjects in the study of Dulloo et al, who were low-caffeine 
consumers (100-200 mg/d) and had to abstain from caffeine-containing foods and beverages the day before and during the experiment while the ingestion of the capsules provided daily $150 \mathrm{mg}$ caffeine (62). In this study, Dulloo et al showed that a green tea extract results in an increase in EE and fat oxidation in the short term (62). Thus it is possible that, in our study, prior habitual caffeine use led to tolerance to the anticipated effects of caffeine, rendering the green tea supplement ineffective. Another explanation is that decreased SNS activity during weight loss dominates possible mechanisms to such an extent that the offset for prevention of the decline in EE is too small to be able to account for weight maintenance. The observation that green tea was associated with greater weight maintenance in habitual low caffeine consumers, supported by relatively greater thermogenesis and fat oxidation (75) may have been associated with stimulated SNS activity during relative overfeeding which in fact takes place during the weight-maintenance or weight-regain period after weight loss. Especially in an affluent state, SNS activity may help to increase EE and fat oxidation in order to prevent fat storage. Landsberg and Young showed that SNS activation is a key element of the counterregulatory response to excessive food intake in heart and brown adipose tissue (76-78). Moreover, human studies have demonstrated that SNS activation is an important aspect of the response to overfeeding $(76,79-81)$. SNS activation increases thermogenesis and wastes excess energy as heat, and thereby compensates for the surplus El. The result theoretically should be the prevention of body weight gain. Also the discrepancies between the outcomes of the different studies still have to be solved. The differences between the outcomes of the Japanese studies (69-72) and our weight loss study is apparent. Apart from the possible effect from habitual caffeine intake as mentioned already, other explanations could be the differences in, for example, genetic background of the population, the difference in the catechins (epicatechin, epicatechin gallate, epigallocatechin, epigallocatechin gallate) in the green tea mixture, the dosage catechins that was consumed in the Japanese studies, or enzyme systems being more sensitive by being triggered by regular consumption of green tea mixtures while in our population enzyme systems are likely to be triggered by regular caffeine consumption (82).

Furthermore, the same mechanism, that is, a relative increase in BMR as a function of FFM was also observed after daily consumption of Olibra ${ }^{\circledR}$ yoghurt during approximately 4 months, which was sufficient to support moderate overweight subjects in maintaining their loss in body weight. As our data were analyzed with BMR corrected for FFM, the increase in BMR in the Olibra ${ }^{\circledR}$ group could not be explained by changes in FFM alone and therefore was attributed to the treatment (9). More research, however, is needed to elucidate the mechanism underlying the FFM sparing effect evoked by the Olibra ${ }^{\circledR}$ treatment. 
Thus a variable that contributes to weight maintenance is sustained $E E$ supported by sparing FFM. The FFM sparing effect, however, needs to be of a considerable magnitude to promote sustained EE indeed.

\section{Body composition}

In order to prevent the decline in BMR, sustaining FFM emerges as an important aim. Any diet or exercise interventions which are capable of maintaining FFM or at least attenuating its decline following weight loss could have significant effects on total energy balance. The generally used model to determine body composition is the two-compartment model, which assumes that the body consists of fat mass and FFM. A frequently used technique to measure this is the isotope dilution technique (83). When people lose weight, their weight loss usually consists of $25-30 \%$ FFM and $70-75 \%$ fat mass (84). This figure may vary with age, gender, ethnicity, initial fatness of the subject and severity of the weight reducing regimen (85-88). Previously, Dulloo et al. described a so-called FFM sparing effect in which the body composition of a given individual changes continuously towards a leaner body composition (the body loses mainly fat mass and consequently spares its FFM) during the course of starvation (89). This FFM sparing effect is associated with better weight maintenance (90). In our long-term Olibra ${ }^{\circledR}$ study, it was shown that fat mass was more decreased in the treatment group compared to the placebo group during the whole study period, which implies a higher percentage FFM in the treatment group that consequently contributed to better weight maintenance in this group (9). In addition, when a weight-loss period of 12 weeks was divided in different phases, we found that FFM was $21 \%$ of weight loss in phase 1 (4 weeks) vs. $7 \%$ in phase 2 (8 weeks) (91) and progressive FFM sparing occurred. Studies reveal that a protein intake sufficient to prevent negative nitrogen balance also is of great importance to lessen the decline in muscle mass during weight loss (92), as well as during weight maintenance thereafter $(10,11)$. Indeed, during weight maintenance after weight loss, Lejeune et al. observed that weight regain in the treatment group (18 en\% protein) consisted of only FFM, while the control group (15 en\% protein) gained fat mass as well (10). Although the FFM sparing effect seems promising, studies are still scarce and further examinations are needed. In particular, it is not known how this effect can be induced and what would trigger this effect specifically. Sometimes it is assumed that a greater fat oxidation would lead to a change in body composition that reduces the percentage of body fat and at the same time increases FFM, however, this has not yet been proven within one study $(53,93-$ 95).

Taken together, the FFM sparing effect is an important tool in the battle against obesity as it helps reducing BMI, but more importantly implies a specific 
reduction in body fat, which is the main characteristic of obesity in addition to BMI.

\section{REVERSAL EFFECT}

After having described the factors that are important and conditional for weight maintenance, some metabolic effects remain to be discussed, as these are assumed to be improved during weight loss and subsequent weight maintenance, but which is not always the case.

It is generally assumed that modest weight loss, $5-10 \%$ of the initial body weight, is sufficient to induce marked clinical improvements $(96,97)$. We observed in the first phase of a 12-week weight loss period that even smaller weight loss can induce beneficial metabolic changes. Surprisingly, this was not observed in phase 2 (91). It was intriguing and interesting that a certain number of metabolic benefits observed in phase 1 were reversed during the second phase of the treatment. In contrast to other studies that have shown a return to baseline concentrations after a weight-maintenance period (74), we observed the reversal during the weight-loss period (91). An explanation is that the weight loss was significantly higher in phase 1 compared to phase 2 , so phase 2 may be considered more like a weight-stabilization period. Sjöström et al. also showed a reversal effect. They demonstrated that, despite a maintained weight reduction of about $5 \%$, risk factor values were back at baseline after 2 years (98). This finding accords with 2-year observations in the Swedish Obesity Subjects study, showing that during steady-weight conditions, previous weight reductions of about $10 \%$ are required for long-lasting risk factor improvements to be detected (99). Thus beneficial metabolic changes appear to be induced by strong negative energy balance, and a moderate weight loss itself is not sufficient for longer-term metabolic benefits.

\section{CONCLUSION}

Relatively small increases in EE, combined with relatively small decreases in El, already can prevent weight gain, contribute to long-term weight loss and thus treatment of overweight and obesity. Based on results from thermogenic and satiating food ingredients described in this thesis and in the literature, it is concluded that these ingredients imply concepts that contribute to successful long-term weight loss, that is, sustained satiety as well as sustained EE related to sparing FFM during negative energy balance. Although these thermogenic and satiating food ingredients alone play a limited role in the treatment of overweight and obesity, they certainly are of great importance for persons who 
cannot achieve sufficient weight loss or obtain successful weight maintenance by lifestyle or behavioral modifications.

\section{FUTURE RESEARCH SUGGESTIONS}

There are still no ideal effective intervention strategies for the prevention of weight gain. This thesis was focused on food ingredients that may support concepts necessary for long-term weight loss, that is, sustained satiety as well as sustained EE during negative energy balance. The investigated food ingredients seem promising but there remain gaps in clinical evidence or knowledge of mechanisms which needs to be addressed. Although a green tea mixture has shown promising effects on $\operatorname{EE}(61,100)$, more data are needed on long-term weight control effects, SNS activation and the effect of a relatively high habitual caffeine intake. In addition, the different outcomes between the Japanese studies and our weight-loss study need to be explored concerning the genetic background of the subjects, different kind of catechins in the green tea mixture and the dosage catechins. It also may be of value to look at the effect of green tea given together with another thermogenic ingredient assessing a possible synergism, and adding a satiating agent. Furthermore, long-term Olibra $^{\circledR}$ consumption showed beneficial effects on body composition and weight maintenance (9). The mechanism of action of the novel fat emulsion is not precisely understood and our findings may support the ileal brake theory only indirectly as an explanation for the Olibra ${ }^{\circledR}$ effects in the longer term. Thus more research is needed to elucidate this mechanism. Also a FFM sparing effect was observed in this study as well as in the second phase of another study with 2 phases of weight loss $(9,91)$. The FFM sparing effect seems promising but studies are still scarce and further examinations are necessary. In particular, it would be interesting to know how this effect can be induced and what would trigger this effect specifically. The Olibra ${ }^{\circledR}$ emulsion also exerted a suppressive effect on appetite ratings in the short term (6). However, the magnitude of these effects as well as their relationship with subsequent food consumption did not affect El. Thus it might be important to know how large the changes in appetite ratings should be to exert a significant effect on subsequent $\mathrm{El}$ and also the timing of the lunch should be further explored. Also in the biopeptides study, no effect on El was seen despite significant changes in appetite scores. In this study was revealed that a supposed biomarker (satiety hormones and ghrelin) for satiety does not always guarantee the highest satiety (measured with VAS) (5). More work is needed to establish the concerted action of supposed potential biomarkers of satiety. Concerning the biopeptides, it is thought that certain amino acids are involved in their effects but it is not yet known which the key ones are. This requires further examination. 


\section{REFERENCES}

1. Kassirer JP, Angell M. Losing weight--an ill-fated New Year's resolution. N Engl J Med 1998;338:52-4.

2. Stunkard A, Mc L-HM. The results of treatment for obesity: a review of the literature and report of a series. AMA Arch Intern Med 1959;103:79-85.

3. Wing RR, Phelan S. Long-term weight loss maintenance. Am J Clin Nutr 2005;82:222S225S.

4. Parker BA, Sturm K, MacIntosh CG, Feinle C, Horowitz M, Chapman IM. Relation between food intake and visual analogue scale ratings of appetite and other sensations in healthy older and young subjects. Eur J Clin Nutr 2004;58:212-8.

5. Diepvens K, Häberer D, Westerterp-Plantenga MS. Effects of different proteins and biopeptides on satiety and 'satiety' or 'orexigenic' hormones. 2007; submitted for publication.

6. Diepvens K, Steijns J, Zuurendonk P, Westerterp-Plantenga MS. Short-term effects of a novel fat emulsion on appetite and food intake in different weight and age groups. 2007; submitted for publication.

7. Harper A, James A, Flint A, Astrup A. Increased satiety after intake of a chocolate milk drink compared with a carbonated beverage, but no difference in subsequent ad libitum lunch intake. Br J Nutr 2007;97:579-83.

8. Kovacs EM, Westerterp-Plantenga MS, Saris WH, et al. The effect of guar gum addition to a semisolid meal on appetite related to blood glucose, in dieting men. Eur $\mathrm{J}$ Clin Nutr 2002;56:771-8.

9. Diepvens K, Soenen S, Steijns J, Arnold M, Westerterp-Plantenga M. Long-term effects of consumption of a novel fat emulsion in relation to body-weight management. Int $\mathrm{J}$ Obes (Lond) 2007;31:942-9.

10. Lejeune MP, Kovacs EM, Westerterp-Plantenga MS. Additional protein intake limits weight regain after weight loss in humans. Br J Nutr 2005;93:281-9.

11. Westerterp-Plantenga MS, Lejeune MP, Nijs I, van Ooijen M, Kovacs EM. High protein intake sustains weight maintenance after body weight loss in humans. Int $\mathrm{J}$ Obes 2004;28:57-64.

12. Weigle DS, Breen PA, Matthys CC, et al. A high-protein diet induces sustained reductions in appetite, ad libitum caloric intake, and body weight despite compensatory changes in diurnal plasma leptin and ghrelin concentrations. Am J Clin Nutr 2005;82:41-8.

13. Westerterp-Plantenga MS, Smeets A, Lejeune MP. Sensory and gastrointestinal satiety effects of capsaicin on food intake. Int J Obes (Lond) 2005;29:682-8.

14. Stunkard AJ, Messick S. The three-factor eating questionnaire to measure dietary restraint, disinhibition and hunger. J Psychosom Res 1985;29:71-83.

15. Drapeau V, King N, Hetherington M, Doucet E, Blundell J, Tremblay A. Appetite sensations and satiety quotient: Predictors of energy intake and weight loss. Appetite 2007;48:159-66.

16. Boschi V, lorio D, Margiotta N, D'Orsi P, Falconi C. The three-factor eating questionnaire in the evaluation of eating behaviour in subjects seeking participation in a dietotherapy programme. Ann Nutr Metab 2001;45:72-7.

17. Provencher V, Drapeau V, Tremblay A, Despres JP, Lemieux S. Eating behaviors and indexes of body composition in men and women from the Quebec family study. Obes Res 2003;11:783-92.

18. Logan CM, McCaffrey TA, Wallace JM, et al. Investigation of the medium-term effects of Olibratrade mark fat emulsion on food intake in non-obese subjects. Eur J Clin Nutr 2006;60:1081-91.

19. Schilstra AJ. Meal-interval correlations: what can they tell us? Physiol Behav 1981;27:299-304. 
20. Adam TC, Westerterp-Plantenga MS. Nutrient-stimulated GLP-1 release in normal-weight men and women. Horm Metab Res 2005;37:111-7.

21. Batterham RL, Heffron H, Kapoor S, et al. Critical role for peptide $Y Y$ in protein-mediated satiation and body-weight regulation. Cell Metab 2006;4:223-33.

22. Nolan LJ, Guss JL, Liddle RA, Pi-Sunyer FX, Kissileff HR. Elevated plasma cholecystokinin and appetitive ratings after consumption of a liquid meal in humans. Nutrition 2003;19:553-7.

23. Burns AA, Livingstone MB, Welch RW, Dunne A, Reid CA, Rowland IR. The effects of yoghurt containing a novel fat emulsion on energy and macronutrient intakes in nonoverweight, overweight and obese subjects. Int $\mathrm{J}$ Obes Relat Metab Disord 2001;25:1487-96.

24. Burns AA, Livingstone MB, Welch RW, et al. Short-term effects of yoghurt containing a novel fat emulsion on energy and macronutrient intakes in non-obese subjects. Int $\mathrm{J}$ Obes Relat Metab Disord 2000;24:1419-25.

25. Burns AA, Livingstone MB, Welch RW, Dunne A, Rowland IR. Dose-response effects of a novel fat emulsion (Olibra) on energy and macronutrient intakes up to $36 \mathrm{~h}$ postconsumption. Eur J Clin Nutr 2002;56:368-77.

26. Spiller RC, Trotman IF, Higgins BE, et al. The ileal brake--inhibition of jejunal motility after ileal fat perfusion in man. Gut 1984;25:365-74.

27. Van Citters GW, Lin HC. The ileal brake: a fifteen-year progress report. Curr Gastroenterol Rep 1999;1:404-9.

28. Symerski T, Kee B, Haddeman E, Peters H, Masclee A. lleal brake effects on satiety and meal intake in humans after a meal replacer (abstract). Int J Obes 2004;28 suppl 1:S148.

29. Aponte GW, Fink AS, Meyer JH, Tatemoto K, Taylor IL. Regional distribution and release of peptide $Y Y$ with fatty acids of different chain length. Am J Physiol 1985;249:G745-50.

30. Jin $\mathrm{H}$, Cai $\mathrm{L}$, Lee $\mathrm{K}$, et al. A physiological role of peptide $Y Y$ on exocrine pancreatic secretion in rats. Gastroenterology 1993;105:208-15.

31. Boirie $\mathrm{Y}$, Dangin M, Gachon P, Vasson MP, Maubois JL, Beaufrere B. Slow and fast dietary proteins differently modulate postprandial protein accretion. Proc Natl Acad Sci U S A 1997;94:14930-5.

32. Anderson $\mathrm{GH}$, Moore SE. Dietary proteins in the regulation of food intake and body weight in humans. J Nutr 2004;134:974S-9S.

33. Mahe S, Roos N, Benamouzig R, et al. Gastrojejunal kinetics and the digestion of [15N]beta-lactoglobulin and casein in humans: the influence of the nature and quantity of the protein. Am J Clin Nutr 1996;63:546-52.

34. Anderson GH, Tecimer SN, Shah D, Zafar TA. Protein source, quantity, and time of consumption determine the effect of proteins on short-term food intake in young men. $J$ Nutr 2004;134:3011-5.

35. Layman DK, Baum Jl. Dietary protein impact on glycemic control during weight loss. J Nutr 2004;134:968S-73S.

36. van Loon LJ, Saris WH, Verhagen $\mathrm{H}$, Wagenmakers AJ. Plasma insulin responses after ingestion of different amino acid or protein mixtures with carbohydrate. Am J Clin Nutr 2000;72:96-105.

37. Bogers RP, Van Assema P, Kester AD, Westerterp KR, Dagnelie PC. Reproducibility, validity, and responsiveness to change of a short questionnaire for measuring fruit and vegetable intake. Am J Epidemiol 2004;159:900-9.

38. van Loon LJ, van Rooijen JJ, Niesen B, Verhagen $H$, Saris WH, Wagenmakers AJ. Effects of acute (-)-hydroxycitrate supplementation on substrate metabolism at rest and during exercise in humans. Am J Clin Nutr 2000;72:1445-50.

39. Bingham SA, Cummings $\mathrm{JH}$. Urine nitrogen as an independent validatory measure of dietary intake: a study of nitrogen balance in individuals consuming their normal diet. Am J Clin Nutr 1985;42:1276-89. 
40. Astrup A, Toubro S, Cannon S, Hein P, Breum L, Madsen J. Caffeine: a double-blind, placebo-controlled study of its thermogenic, metabolic, and cardiovascular effects in healthy volunteers. Am J Clin Nutr 1990;51:759-767.

41. Goris AH, Westerterp-Plantenga MS, Westerterp KR. Undereating and underrecording of habitual food intake in obese men: selective underreporting of fat intake. Am J Clin Nutr 2000;71:130-4.

42. Yeomans MR. Olfactory influences on appetite and satiety in humans. Physiol Behav 2006;89:10-4.

43. Cecil JE, Francis J, Read NW. Comparison of the effects of a high-fat and highcarbohydrate soup delivered orally and intragastrically on gastric emptying, appetite, and eating behaviour. Physiol Behav 1999;67:299-306.

44. Flint A, Raben A, Ersboll AK, Holst JJ, Astrup A. The effect of physiological levels of glucagon-like peptide-1 on appetite, gastric emptying, energy and substrate metabolism in obesity. Int J Obes Relat Metab Disord 2001;25:781-92.

45. Geliebter A. Gastric distension and gastric capacity in relation to food intake in humans. Physiol Behav 1988;44:665-8.

46. Geliebter A, Melton PM, McCray RS, Gallagher DR, Gage D, Hashim SA. Gastric capacity, gastric emptying, and test-meal intake in normal and bulimic women. Am J Clin Nutr 1992;56:656-61.

47. Melton PM, Kissileff HR, Pi-Sunyer FX. Cholecystokinin (CCK-8) affects gastric pressure and ratings of hunger and fullness in women. Am J Physiol 1992;263:R452-6.

48. Cummings DE, Overduin J. Gastrointestinal regulation of food intake. J Clin Invest 2007;117:13-23.

49. Langhans W. Role of the liver in the metabolic control of eating: what we know--and what we do not know. Neurosci Biobehav Rev 1996;20:145-53.

50. Westerterp KR. Diet induced thermogenesis. Nutr Metab (Lond) 2004;1:5.

51. Adam TC, Westerterp-Plantenga MS. Glucagon-like peptide-1 release and satiety after a nutrient challenge in normal-weight and obese subjects. Br J Nutr 2005;93:845-51.

52. Ravussin E, Lillioja S, Knowler WC, et al. Reduced rate of energy expenditure as a risk factor for body-weight gain. N Engl J Med 1988;318:467-72.

53. Seidell JC, Muller DC, Sorkin JD, Andres R. Fasting respiratory exchange ratio and resting metabolic rate as predictors of weight gain: the Baltimore Longitudinal Study on Aging. Int J Obes Relat Metab Disord 1992;16:667-74.

54. Tataranni PA, Harper IT, Snitker S, et al. Body weight gain in free-living Pima Indians: effect of energy intake vs expenditure. Int J Obes Relat Metab Disord 2003;27:1578-83.

55. Astrup A, Gotzsche PC, van de Werken K, et al. Meta-analysis of resting metabolic rate in formerly obese subjects. Am J Clin Nutr 1999;69:1117-1122.

56. Menozzi R, Bondi M, Baldini A, Venneri MG, Velardo A, Del Rio G. Resting metabolic rate, fat-free mass and catecholamine excretion during weight loss in female obese patients. Br J Nutr 2000;84:515-520.

57. Doucet E, St Pierre S, Almeras N, Mauriege P, Richard D, Tremblay A. Changes in energy expenditure and substrate oxidation resulting from weight loss in obese men and women: is there an important contribution of leptin? $\mathrm{J}$ Clin Endocrinol Metab 2000;85:1550-6.

58. Pelletier C, Doucet E, Imbeault P, Tremblay A. Associations between weight loss-induced changes in plasma organochlorine concentrations, serum T(3) concentration, and resting metabolic rate. Toxicol Sci 2002;67:46-51.

59. Rosenbaum M, Hirsch J, Murphy E, Leibel RL. Effects of changes in body weight on carbohydrate metabolism, catecholamine excretion, and thyroid function. Am J Clin Nutr 2000;71:1421-32.

60. Stiegler $\mathrm{P}$, Cunliffe $\mathrm{A}$. The role of diet and exercise for the maintenance of fat-free mass and resting metabolic rate during weight loss. Sports Med 2006;36:239-62. 
61. Diepvens K, Kovacs EM, Nijs IM, Vogels N, Westerterp-Plantenga MS. Effect of green tea on resting energy expenditure and substrate oxidation during weight loss in overweight females. Br J Nutr 2005;94:1026-34.

62. Dulloo AG, Duret C, Rohrer D, et al. Efficacy of a green tea extract rich in catechinpolyphenols and caffeine in increasing 24-h energy expenditure and fat oxidation in humans. Am J Clin Nutr 1999;70:1040-1045.

63. Berube-Parent S, Pelletier C, Dore J, Tremblay A. Effects of encapsulated green tea and Guarana extracts containing a mixture of epigallocatechin-3-gallate and caffeine on $24 \mathrm{~h}$ energy expenditure and fat oxidation in men. Br J Nutr 2005;94:432-6.

64. Dulloo AG, Seydoux J, Girardier L, Chantre P, Vandermander J. Green tea and thermogenesis: interactions between catechin-polyphenols, caffeine and sympathetic activity. Int J Obes 2000;24:252-258.

65. Kao Y-H, Hiipakka RA, Liao S. Modulation of endocrine systems and food intake by green tea epigallocatechin gallate. Endocrinology 2000;141:980-987.

66. Choo JJ. Green tea reduces body fat accretion caused by high-fat diet in rats through beta-adrenoceptor activation of thermogenesis in brown adipose tissue. J Nutr Biochem 2003;14:671-6.

67. Zheng G, Sayama K, Okubo T, Juneja LR, Oguni I. Anti-obesity effects of three major components of green tea, catechins, caffeine and theanine, in mice. In Vivo 2004;18:5562.

68. Chantre P, Lairon D. Recent findings of green tea extract AR25 (Exolise) and its activity for the treatment of obesity. Phytomedicine 2002;9:3-8.

69. Hase T, Komine Y, Meguro S, et al. Anti-obesity effects of tea catechins in humans. J Oleo Sci 2001;50:599-605.

70. Nagao T, Komine $\mathrm{Y}$, Soga S, et al. Ingestion of a tea rich in catechins leads to a reduction in body fat and malondialdehyde-modified LDL in men. Am J Clin Nutr 2005;81:122-9.

71. Nagao T, Meguro S, Soga S, et al. Tea catechins suppress accumulation of body fat in humans. J Oleo Sci 2001;50:717-728.

72. Tsuchida $\mathrm{T}$, Itakura $\mathrm{H}$, Nakamura $\mathrm{H}$. Reduction of body fat in humans by long-term ingestion of catechins. Prog Med 2002;22:2189-2203.

73. Harada U, Chikama A, Saito S, et al. Effects of the long-term ingestion of tea catechins on energy expenditure and dietary fat oxidation in healthy subjects. $J$ Health Sci 2005;51:248-252.

74. Kovacs EM, Lejeune MP, Nijs I, Westerterp-Plantenga MS. Effects of green tea on weight maintenance after body-weight loss. Br J Nutr 2004;91:431-7.

75. Westerterp-Plantenga MS, Lejeune MP, Kovacs EM. Body weight loss and weight maintenance in relation to habitual caffeine intake and green tea supplementation. Obes Res 2005;13:1195-204.

76. Landsberg L. The sympathoadrenal system, obesity and hypertension: an overview. J Neurosci Methods 1990;34:179-86.

77. Landsberg L, Young JB. Diet and the sympathetic nervous system: relationship to hypertension. Int J Obes 1981;5 suppl 1:79-91.

78. Landsberg L, Young JB. Sympathoadrenal activity and obesity: physiological rationale for the use of adrenergic thermogenic drugs. Int J Obes Relat Metab Disord 1993;17 Suppl 1:S29-34.

79. Bazelmans J, Nestel PJ, O'Dea K, Esler MD. Blunted norepinephrine responsiveness to changing energy states in obese subjects. Metabolism 1985;34:154-60.

80. Dulloo AG, Jacquet J. An adipose-specific control of thermogenesis in body weight regulation. Int J Obes Relat Metab Disord 2001;25 Suppl 5:S22-9.

81. McCargar LJ, Clandinin MT, Fawcett DM, Johnston JL. Short-term changes in energy intake and serum insulin, neutral amino acids, and urinary catecholamine excretion in women. Am J Clin Nutr 1988;47:932-41. 
82. Hodgson JM, Puddey IB, Burke V, Croft KD. Is reversal of endothelial dysfunction by tea related to flavonoid metabolism? Br J Nutr 2006;95:14-7.

83. Westerterp KR, Wouters L, van Marken Lichtenbelt WD. The maastricht protocol for the measurement of body composition and energy expenditure with labeled water. Obes Res 1995;3 (suppl 1):49-57.

84. Garrow JS, Summerbell CD. Meta-analysis: effect of exercise, with or without dieting, on the body composition of overweight subjects. Eur J Clin Nutr 1995;49:1-10.

85. Fernandez JR, Heo M, Heymsfield SB, et al. Is percentage body fat differentially related to body mass index in Hispanic Americans, African Americans, and European Americans? Am J Clin Nutr 2003;77:71-5.

86. Gallagher D, Heymsfield SB, Heo M, Jebb SA, Murgatroyd PR, Sakamoto Y. Healthy percentage body fat ranges: an approach for developing guidelines based on body mass index. Am J Clin Nutr 2000;72:694-701.

87. Forbes GB. Lean body mass-body fat interrelationships in humans. Nutr Rev 1987;45:225-31.

88. Prentice AM, Goldberg GR, Jebb SA, Black AE, Murgatroyd PR, Diaz EO. Physiological responses to slimming. Proc Nutr Soc 1991;50:441-58.

89. Dulloo AG, Jacquet J. The control of partitioning between protein and fat during human starvation: its internal determinants and biological significance. Br J Nutr 1999;82:339-56.

90. Vogels N, Westerterp-Plantenga MS. Categorical strategies based on subject characteristics of dietary restraint and physical activity, for weight maintenance. Int $\mathrm{J}$ Obes (Lond) 2005;29:849-57.

91. Diepvens K, Kovacs EM, Vogels N, Westerterp-Plantenga MS. Metabolic effects of green tea and of phases of weight loss. Physiol Behav 2006;87:185-91.

92. Ditschuneit $\mathrm{H}$. Ergebnisse ambulante adipositastherapie mit verschiedenen protëinereichen diaeten. In: Ditschuneit $H$, Wechsler JG, eds. Ergebnisse der adipositasfotschung.: perimed Fachbuch-Verlagsgesellschaft mbH: Erlangen, 1984:171178.

93. Pasman WJ, Saris WHM, Westerterp-Plantenga MS. Predictors of weight maintenance. Obes Res 1999;7:43-50.

94. Schutz Y. Abnormalities of fuel utilization as predisposing to the development of obesity in humans. Obes Res 1995;3 Suppl 2:173S-178S.

95. Zurlo F, Lillioja S, Esposito-Del Puente A, et al. Low ratio of fat to carbohydrate oxidation as predictor of weight gain: study of 24-h RQ. Am J Physiol 1990;259:E650-7.

96. Goldstein DJ. Beneficial health effects of modest weight loss. Int J Obes Relat Metab Disord 1992;16:397-415.

97. Van Gaal LF, Wauters MA, De Leeuw IH. The beneficial effects of modest weight loss on cardiovascular risk factors. Int J Obes Relat Metab Disord 1997;21 Suppl 1:S5-9.

98. Sjostrom L, Rissanen A, Andersen T, et al. Randomised placebo-controlled trial of orlistat for weight loss and prevention of weight regain in obese patients. European Multicentre Orlistat Study Group. Lancet 1998;352:167-72.

99. Sjostrom CD, Lissner L, Sjostrom L. Relationships between changes in body composition and changes in cardiovascular risk factors: the SOS Intervention Study. Swedish Obese Subjects. Obes Res 1997;5:519-30.

100. Diepvens K, Westerterp KR, Westerterp-Plantenga MS. Obesity and thermogenesis related to the consumption of caffeine, ephedrine, capsaicin, and green tea. Am J Physiol Regul Integr Comp Physiol 2007;292:R77-85. 
SUMMARY 
Treatment of overweight and obesity is beneficial in that weight loss reduces the risk for morbidity and mortality. Short-term weight loss is achievable and satisfactory in many overweight and obese subjects but within one year, the majority has regained most of the weight lost. Therefore, the major challenge of obesity treatment is to achieve long-term weight loss and maintenance of weight loss after weight reduction. Long-term weight loss and prevention of weight (re)gain can be achieved by reducing energy intake relative to energy expenditure. In practice, this is very difficult to realize. Therefore, concepts for food ingredients have been identified that may promote weight loss and weight maintenance by sustaining satiety and sustaining energy expenditure during, and despite a negative energy balance.

In order to offset the reduction in energy expenditure that occurs during weight loss, consumption of a mixture of caffeine and green tea catechins during a lowenergy diet was investigated. Indeed, resting energy expenditure as a function of fat-free mass and fat mass did not decrease significantly over time when the green tea mixture was ingested along with a low-energy diet. In contrast to other studies, this effect was not that large that an effect of the green tea mixture on body-weight loss was seen. A possible explanation for different outcomes in this respect is the relatively high background caffeine intake of the subjects. Furthermore, no effects of green tea on health-related blood parameters were observed during the whole weight-loss period. Initial improvements in several blood measures seen during the first phase of the weigh-loss period were reversed during the second phase, despite continued weight loss. Beneficial metabolic changes appeared to be induced by a strong negative energy balance, and moderate weight loss itself was not sufficient for long-term metabolic benefits. In contrast, modest weight loss did improve HDL cholesterol and systolic blood pressure. In addition to the green tea mixture, also effects of caffeine, ephedrine and capsaicin were described in this thesis. Although the use of these thermogenic agents in treatments seems effective, the consumption of ephedrine and capsaicin is contraindicated by adverse effects. Thus, the remaining combination of a mixture of caffeine and green tea catechins may be recommended as a concept for body-weight management.

Furthermore, the long-term effect of a novel fat emulsion $\left(\mathrm{Olibra}^{\circledR}\right)$, which has been shown before to increase satiety and decrease energy intake in the short term, was assessed. We found that consumption of Olibra ${ }^{\circledR}$ yoghurt improved weight maintenance, explained by the relatively higher resting energy expenditure as a function of fat-free mass, relatively larger decrease in fat mass, and the relatively lower increase in hunger. In addition, short-term previous experiments were repeated in different weight and age groups and the most expressed results on appetite ratings were found in normal-weight women aged 18-30 years. Also, the effect of different biopeptides on satiety and energy intake was investigated, especially regarding selected biopeptides such as whey protein and pea protein hydrolysate. There was modest evidence with 
respect to relatively increased satiety after pea protein hydrolysate consumption. Surprisingly, different exogenous biopeptides produced differences in release of endogenous peptides, while relationships with satiety were inconsistent.

Relatively small increases in energy expenditure, combined with relatively small decreases in energy intake already can prevent weight gain, contribute to longterm weight loss and thus treatment of overweight and obesity. Based on results from thermogenic and satiating food ingredients described in this thesis and in the literature, it is concluded that these ingredients imply concepts that contribute to successful long-term weight loss, that is, sustained satiety as well as sustained energy expenditure related to sparing fat-free mass during and despite negative energy balance. Although these thermogenic and satiating food ingredients alone play a limited role in the treatment of overweight and obesity, they certainly are of great importance for persons who cannot achieve sufficient weight loss or obtain successful weight maintenance by lifestyle or behavioral modifications. 

Gewichtsverlies bij personen met overgewicht of obesitas leidt tot een verminderd risico op morbiditeit en mortaliteit. Gewichtsverlies is op korte termijn haalbaar voor veel mensen met overgewicht. Het probleem is echter dat de meeste mensen na een jaar weer in gewicht toegenomen zijn. De grootste uitdaging in het behandelen van overgewicht en obesitas is daarom het bereiken van gewichtsverlies en gewichtsbehoud op lange termijn. Gewichtsverlies op lange termijn en het voorkomen van gewichtstoename kan bereikt worden door de energie inname, ten opzichte van het energiegebruik, te verlagen. In de praktijk is dit echter moeilijk te verwezenlijken. Daarom werden er concepten geformuleerd waar relevante voedingsingrediënten aan dienen te voldoen. Deze concepten zijn voorwaardelijk voor gewichtsverlies en daaropvolgend gewichtsbehoud en betreffen het handhaven van verzadiging en energiegebruik tijdens, en ondanks, een negatieve energiebalans.

Bij gewichtsverlies daalt normaal gesproken het energiegebruik. Ten behoeve van effectief gewichtsverlies moet dit worden voorkomen. Daartoe werd het effect van de inname van een mengsel van cafeïne en groene thee catechines tijdens een energiebeperkt dieet onderzocht. Bij consumptie van groene thee tijdens dit dieet bleek inderdaad het rust energiegebruik als een functie van de vetvrije massa en vetmassa niet verlaagd te zijn. In tegenstelling tot de bevindingen van andere studies was het effect van groene thee hier niet groot genoeg om een sterker verlies van lichaamsgewicht te veroorzaken. Een mogelijke verklaring hiervoor is de relatief hoge gebruikelijke cafeïne inname van de proefpersonen. Verder werden er gedurende de studie geen effecten van groene thee op bloed parameters, gerelateerd aan gezondheid, gezien. Alhoewel er tijdens de hele studie steeds gewichtsverlies plaatsvond, werd alleen initiële verbetering in bloedwaarden in de eerste fase van de studie waargenomen; deze werden teniet gedaan in de tweede fase. Gunstige metabole veranderingen werden dus blijkbaar geïnduceerd door een sterke negatieve energiebalans en niet zozeer door matig gewichtsverlies zelf. Matig gewichtsverlies had echter wel een gunstig effect op HDL cholesterol en systolische bloeddruk. Behalve de thermogene effecten van groene thee, werden ook de effecten van cafeïne, ephedrine en capsaicine in dit proefschrift beschreven. Alhoewel de inname van deze thermogene produkten effectief lijkt te zijn voor de behandeling van overgewicht en obesitas, kunnen neveneffecten optreden bij het gebruik van ephedrine en capsaicine. Daarom is enkel de combinatie van cafeïne en groene thee catechines aan te bevelen als een concept voor lichaamsgewichtregulatie.

Verder werd in het kader van handhaving van verzadiging en energiegebruik het effect van een nieuwe vetemulsie $\left(\mathrm{Olibra}^{\circledR}\right)$ onderzocht. Uit eerder onderzoek was gebleken dat deze emulsie op korte termijn de verzadiging kan verhogen en de energie inname verlagen. Wij vonden dat consumptie van Olibra $^{\circledR}$ yoghurt bijdroeg aan gewichtsbehoud wat verklaard kon worden door het relatief hogere rust energiegebruik als een functie van vetvrije massa, door 
de relatief grotere afname in vetmassa en de relatief mindere stijging van het hongergevoel, ten opzichte van placebo. Vervolgens werden de eerder uitgevoerde korte termijn experimenten herhaald in groepen die verschilden in leeftijd en lichaamsgewicht. Afname van de eetlust ten gevolge van consumptie

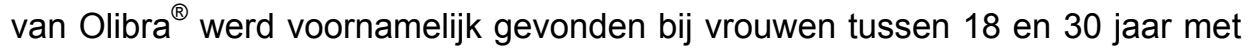
een normaal gewicht.

Tenslotte werd het effect van biopeptiden, met name wei-eiwit en erwt-eiwithydrolysaat op verzadiging en energie inname onderzocht. Het verzadigingsgevoel was relatief verhoogd na inname van erwt-eiwit-hydrolysaat. Een verrassend resultaat was dat verschillende exogene biopeptiden verschillen in het vrijmaken van endogene biopeptiden met zich meebrengen, die evenwel vaak tegenstrijdige relaties met verzadiging lieten zien.

Relatief kleine verhogingen van het energiegebruik, gecombineerd met relatief kleine verminderingen in energie inname, kunnen al gewichtstoename vermijden, en op die manier bijdragen aan gewichtsverlies op lange termijn en dus aan de behandeling van overgewicht en obesitas. Op basis van de resultaten van de thermogene en verzadigende voedingsingrediënten die in dit proefschrift en in de literatuur beschreven zijn, kan er geconcludeerd worden dat ze concepten impliceren die bijdragen aan succesvol gewichtsverlies op lange termijn. Deze concepten zijn een handhaving van verzadiging en energiegebruik, gerelateerd aan het sparen van vetvrije massa, tijdens en ondanks een negatieve energiebalans. Hoewel deze thermogene en verzadigende voedingsingrediënten wellicht een beperkte rol spelen in de behandeling van overgewicht en obesitas, zijn ze zeker erg belangrijk voor personen die moeite hebben om voldoende gewichtsverlies of succesvol gewichtsbehoud met levensstijl- of gedragsveranderingen te bereiken. 

DANKWOORD 
Graag wil ik iedereen bedanken die rechtstreeks of onrechtstreeks bijgedragen heeft aan het tot stand komen van dit proefschrift. Ik ga beginnen met 'BEDANKT ALLEMAAL' zodat ik zeker niemand vergeet.

Beste Margriet, tijdens mijn stage kreeg ik de mogelijkheid aan een groene thee project te werken waardoor ik de smaak voor 'het onderzoek' te pakken kreeg. Toen er een aioplaats vrijkwam op een project rond enkele voedingsingrediënten, heb ik dan ook niet lang getwijfeld om te solliciteren. Ik wil je dan ook bedanken dat je me de kans gegeven hebt om verder van het wetenschappelijk onderzoek te proeven. Verder wil ik je bedanken voor je goede en efficiënte begeleiding die er zeker aan bijgedragen heeft dat dit proefschrift op tijd klaar is.

De beoordelingscommissie, bestaande uit Prof. dr. ir. R. Mensink, Prof. dr. R-J. Brummer, Dr. C. Gerhardt, Prof. dr. A. Masclee en Prof. dr. ir. G. Schaafsma, wil ik bedanken voor het kritisch evalueren van dit proefschrift.

Ook wil ik ook al mijn mede-auteurs bedanken voor de goede samenwerking: Eva, Ilse, Neeltje, Margriet, Klaas, Stijn, Jan, Peter, Myrtha en Doreen, bedankt voor jullie bijdrage! A special word of thanks I would like to address to the group from Switzerland, that is, Prof. Dr. Wolfgang Langhans, Doreen Häberer and Myrtha Arnold for the nice collaboration. Verder wil ik ook nog de mensen van Campina Innovation, Unilever Food and Health Research Institute en DSM Food Specialties bedanken voor de goede en productieve samenwerking.

En dan natuurlijk mijn paranimfen: Neeltje en Manuela. Ik vind het fijn dat jullie bij de verdediging van mijn proefschrift achter me willen staan. Ik wil jullie graag voor heel veel dingen bedanken, voor onder andere de gezellige pauzes, alle babbels, de vriendschap, de vertrouwelijke gesprekken, alle hulp en overlevingstechnieken $;$. Bedankt! Neeltje, toen ik als aio begon, kwam ik bij jou op de kamer terecht en ik had me echt geen beter kamergenootje kunnen voorstellen. Jij nam me onmiddellijk mee naar feestjes en zo waardoor ik op erg korte tijd de collegas van de vakgroep leerde kennen. Manuela, in mijn laatste driekwart jaar kwam jij bij mij op de kamer te zitten. Super! Daarvoor hadden we natuurlijk ook al veel contact, maar samen op de kamer, dat was natuurlijk extra leuk. Manuela en Neeltje, ik vond het ook altijd erg fijn om samen met jullie naar een congres te gaan. Ik denk bijvoorbeeld terug aan het SSIB congres in Pittsburgh waar we met z'n drieën een kamer deelden. Vooral die laatste ochtend hebben we toen veel lol gehad (zeker achteraf $(\dot{)})$.

Lydia, Mirjam en Guy ook jullie wil ik bedanken voor de vele gesprekken en leuke pauzes. Lydia, veel succes met alles. Al woon je nu in Zweden, ik hoop dat we contact kunnen houden. En Mirjam, succes bij Mars en volg gewoon je gevoel als je over iets twijfelt. Guy, ik heb je altijd erg gewaardeerd, niet alleen omdat je Belg bent $:$ en ik wil jou dan ook bedanken voor de vele babbels en natuurlijk alle onzin en totale nonsens. 
Astrid (bedankt voor alle hulp), Stijn, Marcel, Margriet V, Ananda, Jurriaan, Femke, Sofie, Anneke, Andrea S, Mirjam B, Freeha, Hanneke, Andrea K, Steven, Henrike, Freddy, Isolde, oftewel zowat de derde verdieping, bedankt voor de fijne pauzes! Ook de rest van de vakgroep wil ik bedanken voor de leuke feestjes, borrels, pauzes of bamboe-lunches: Chantal, Jos, Ralph, Elke, Kirsten, Julian, Johan, Joris, Gijs, Janneke, Maartje, Jonathan, Arie, Gabby, Herman, Wouter, Marleen, Ellen, Stan, Chantalle, Loek, Wendy, Ruth, Freek, Antoine, Larisa, Claudia, Stefan, Marjolijn, Julia, Ariënne, Pascal, Martine, Joan, René, Esther, ... iedereen opnoemen wordt moeilijk dus gewoon: bedankt HB!

Wendy, Jos en Joan, bedankt voor de vele en vele analyses. Loek, bedankt voor de deuterium analyses en samen met Paul, voor het oplossen van alle computer-gerelateerde en ventilated hood problemen. Larisa, Claudia, Ilona, Kerstin, als secretaresses zijn jullie eigelijk de spil van de vakgroep, bedankt voor alle hulp.

Ook enkele oud-collegas wil ik nog noemen: Kaatje, Natalie, Marieke, Tanja, Joost, 'buurman' Kristof, Petra, Maartje S en Mandy. Ilse, ik vond het heel erg leuk dat ik tijdens mijn stage jou mocht helpen. Ik vond het dan ook echt spijtig dat je naar Rotterdam ging. Bedankt voor alles. Miek, bedankt voor je hulp bij mijn laatste studie en je collegialiteit. Roy, heel erg bedankt voor alle hulp en ik wil ook Stijn hierbij betrekken. We hebben lange dagen gemaakt en heel veel yoghurt versleept. Bedankt! Ilse, Miek, Roy, Stijn, Patrick, en stagair(e)s Eléonore, Sanne, Esther en Andy, zonder jullie was de uitvoer van de studies niet mogelijk geweest.

Ook wil ik graag alle proefpersonen bedanken. Zonder jullie inzet was dit proefschrift nooit tot stand gekomen!

Bart, bedankt voor het maken van mijn omslag en kaartjes. Al word je dit jaar 'os' (-), geef vooral de moed niet op. Bart, Wouter, Katleen, Stein, Dries, Ben, Kenny, Pieter, Hanne, Fré, Nielske,... het is altijd plezant om in het weekend samen iets te drinken.

Chantal en Bas, Sandra, John en Jesse, fijn dat het ons lukt regelmatig af te spreken en hopelijk kunnen we dit nog lang blijven doen.

Dieter, Bert, Kim en Caroline, we hebben samen een toffe tijd gehad in Diepenbeek en we moeten maar weer snel eens afspreken...

Mama en papa, Hilde en Dennis, Nele en Jan, Valère en Marleen, Goele en Ronald, bedankt voor jullie interesse en steun. Rob, jij bent mijn steun en toeverlaat. Bedankt dat je er voor me was en dat je er altijd voor me wilt zijn! 



\section{FULL PAPERS}

- Diepvens K, Kovacs EM, Nijs IM, Vogels N, Westerterp-Plantenga MS. Effect of green tea on resting energy expenditure and substrate oxidation during weight loss in overweight females. $\mathrm{Br} J$ Nutr 2005;94:1026-34.

- Vogels N, Mariman EC, Bouwman FG, Kester AD, Diepvens K, Westerterp-Plantenga MS. Relation of weight maintenance and dietary restraint to peroxisome proliferator-activated receptor gamma2, glucocorticoid receptor, and ciliary neurotrophic factor polymorphisms. Am J Clin Nutr 2005;82(4):740-6.

- Vogels N, Diepvens K, Westerterp-Plantenga MS. Predictors of longterm weight maintenance. Obes Res 2005;13(12):2162-8.

- Diepvens K, Kovacs EM, Vogels N, Westerterp-Plantenga MS. Metabolic effects of green tea and of phases of weight loss. Physiol Behav 2006;87:185-91.

- Westerterp-Plantenga M, Diepvens K, Joosen AM, Berube-Parent S, Tremblay A. Metabolic effects of spices, teas, and caffeine. Physiol Behav 2006;89(1):85-91.

- Westerterp-Plantenga MS, Luscombe-Marsh N, Lejeune MPGM, Diepvens K, Nieuwenhuizen A, Engelen MPKJ, Deutz NEP, AzzoutMarniche D, Tome D, Westerterp KR. Dietary protein, metabolism, and body-weight regulation: dose/response effects. Int J Obes 2006;30:S1623.

- Diepvens K, Westerterp KR, Westerterp-Plantenga MS. Obesity and thermogenesis related to the consumption of caffeine, ephedrine, capsaicin, and green tea. Am J Physiol Regul Integr Comp Physiol 2007;292:R77-85.

- Diepvens K, Soenen S, Steijns J, Arnold M, Westerterp-Plantenga M. Long-term effects of consumption of a novel fat emulsion in relation to body-weight management. Int J Obes (Lond) 2007;31:942-9.

- Diepvens K, Steijns J, Zuurendonk P, Westerterp-Plantenga MS. Shortterm effects of a novel fat emulsion on appetite and food intake in different weight and age groups. 2007; submitted for publication. 
- Diepvens K, Häberer D, Westerterp-Plantenga MS. Effects of different proteins and biopeptides on satiety and 'satiety' or 'orexigenic' hormones. 2007; submitted for publication.

\section{PUBLISHED ABSTRACTS}

- Diepvens K, Kovacs EMR, Westerterp-Plantenga MS. Reversal of dietinduced metabolic improvement in relation to phases of body weight loss. Int J Obes 2004;28(1):S176.

- Diepvens K, Kovacs EMR, Westerterp-Plantenga MS. Reversal of dietinduced metabolic improvement in relation to phases of body weight loss. Appetite 2004;42(3):355.

- Diepvens K, Kovacs EMR, Westerterp-Plantenga MS. Effect of green tea on resting energy expenditure and substrate oxidation during weight loss in overweight females. Obes Rev 2005;6(suppl1):143.

- Diepvens K, Kovacs EMR, Westerterp-Plantenga MS. Effect of green tea on resting energy expenditure and substrate oxidation during weight loss in overweight females. Appetite 2005;44(3):347.

- Diepvens K, Soenen S, Steijns J, Arnold M, Westerterp-Plantenga M. Long-term effects of consumption of a novel fat emulsion in relation to body-weight management. Appetite 2006;46(3):350.

- Westerterp-Plantenga MS, Diepvens K, Soenen S, Steijns J, Arnold M. Long-term effects of $\mathrm{Olibra}^{\circledR}$ consumption in relation to body-weight management. Obes Rev 2006;7(suppl2):345.

- Diepvens K, Steijns J, Zuurendonk P, Westerterp-Plantenga MS. Shortterm effects of a novel fat emulsion on appetite and food intake in different weight and age groups. Appetite 2007;49(1):287.

- Diepvens K, Häberer D, Arnold M, Westerterp-Plantenga MS. Different relationships with respect to satiety between exogenous and endogenous peptides. Appetite 2007;49(1):286.

- Häberer D, Diepvens K, Geary N, Langhans W. Intragastric infusion of pea protein hydrolysate reduces food intake more than pea protein. Appetite 2007;49(1):295. 

CURRICULUM VITAE 
Kristel Diepvens was born on August 7th 1981 in Diest, Belgium. She completed secondary school at the 'Heilig-Hart College' in Heusden-Zolder in 1999. In the same year, she started her study Biomedical Sciences with specialization Biological Health Sciences at the Transnational University Limburg (Diepenbeek, Belgium and Maastricht, The Netherlands), where she graduated in 2003. She did her master thesis entitled 'The effect of 4-week ingestion of green tea on thermogenesis and substrate oxidation in overweight females' at the department of Human Biology, Maastricht University. She started her Ph.D. research 'The battle against obesity - A role for thermogenic and satiating food ingredients' at the same department in 2003. The research performed during this period is described in this thesis. 

